\title{
Contesting Collective Representations of the Past: The Politics of Memory in South Korea
}

\author{
By
}

Thomas Vink

Thesis submitted in partial fulfillment of the requirements for the degree of Masters of Development Studies

School of Geography, Environment and Earth Sciences

Victoria University of Wellington Aotearoa New Zealand

March 2010 


\section{Acknowledgements}

I am indebted to all those that I met during my time in Korea. Your hospitality always amazed me. A big thank you to Sung-soo and Young-nan, for getting me started in Korea, and for helping me whenever I was in need along the way. To my two host families, I am particularly grateful. Thank you for accepting me so easily in to your lives and sharing your homes, food and culture with me. A special thanks to all those who had the patience to listen to my (often badly worded) questions and, especially, for giving me so much in reply. You are this thesis and I hope that I have done your words justice. Above all, I would like to thank Suyeong, Hyeong-Bok, Jin-Hwan and Beomhwi, not only for being great friends, but also for your translation skills. I don't know what I would have done without you.

To Stephen, you are all I could have asked for in a supervisor and more. I thoroughly enjoyed working with and learning from you. Thanks for your always-swift replies, your scrupulous editing and, most of all, for always being there. Throughout the whole process you were like a massive trampoline underneath me as I blindly stumbled along the thesis tightrope. You gave me the confidence to keep going and even take a few leaps every now and then. To your wife, Mi-Young, my amazing Korean teacher, thank you for welcoming me into your home and putting up with me all those weeks!

I am grateful to all the office staff, lecturers and fellow students within the school. You made university a very supportive environment to work in. I'd particularly like to thank Sara Kindon. The courses I took with you inspired this research and my plans for the future. At times you have even been a second supervisor to me, a privilege that I know most students do not receive.

For financial support, I am very thankful to Victoria University and Education New Zealand. 
Finally, I would like to thank all my friends and family. You know who you are (if you have the patience to read this, you are most likely one of them!). M y brothers, flatmates, office buddies, friends around the globe; all those who've written me emails, given me phone calls, shared your stories - your lives - with me; those who have laughed with me, encouraged me, criticised me; every one of you is in here somewhere, it may not resemble you very much, but you're there nonetheless! A special thanks to Mum and Dad. You may be on the other side of the world, but you've never felt far away to me. Thanks for always being there to talk things over, for reading through all the bits and pieces I sent to you over the months, and most importantly for your unconditional support, not only during my masters, but throughout my whole life at university. 


\section{Abstract}

Because monuments, memorials and other 'sites of memory' privilege particular collective interpretations of the past over others, they represent inherently contentious and political spaces. Contention over representing the past is particularly resonant in Korea, where sites of memory are imbued with strong, often polarised meanings. By focusing on two such sites in Korea, this thesis seeks to discuss the wider implications of the ongoing conflict over what representations of the past should be privileged.

In Gwangju, the area surrounding the former provincial hall (docheong) is being redeveloped, part of the city's attempts to become 'reborn' as a capital city of human rights and democracy in Asia. However, to many citizens in Gwangju, this new image ignores the meaning that the city's dissident past holds for local communal understandings of identity. Conflict arose as citizens protested to keep the symbolism of the docheong intact, thus, helping to maintain local narratives of the past. In Seoul, M yeongdong Cathedral, a key symbol of protest and democracy in the 1970s and 1980s, is now having its meaning re-interpreted, as the Catholic Church de-couples religion from socio-political concerns. The conflicting meanings of Myeongdong Cathedral are representative of a wider divergence in Korean society, as apathy towards Korea's past grows among society at large while other segments appropriate the past to protest contemporary socio-political concerns.

Ultimately, these Korean case studies emphasise that the meanings sites of memory convey are not fixed, and that groups are often able to appropriate sites to affirm their own narratives of the past and to emphasise their own collective voice. Therefore, sites that represent particular understandings of the past, while contentious, also provide a space for debate and, thus, help to understand ongoing concerns within wider society. 


\section{Table of Contents}

Acknowledgements...............................................................................................ii

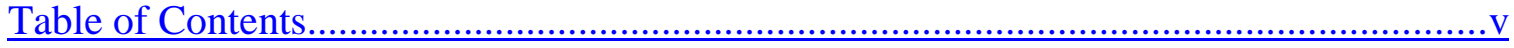

List of Figures.................................................................................................................vii

Glossary: Acronyms, Abbreviations and Frequently Used Korean Terms.......................viii

Chapter One - Introduction: Contextual, Theoretical and Personal Background................1

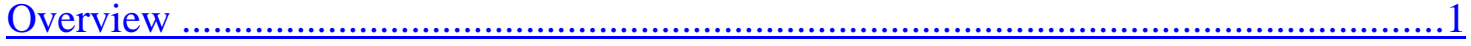

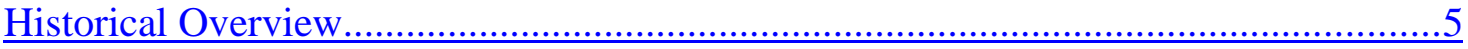

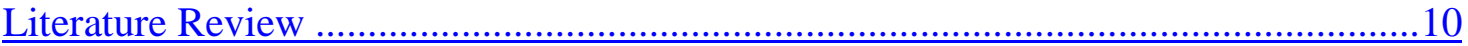

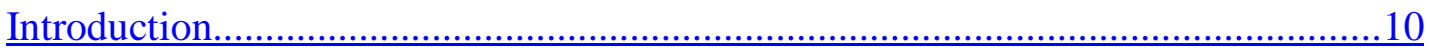

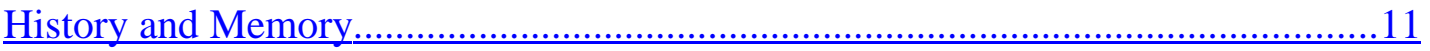

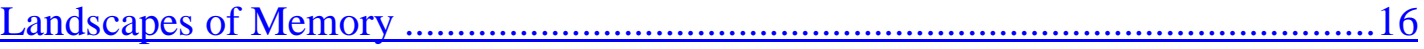

Invisible Monuments and the Sanitisation of History..................................................19

Contesting the Past in the Present: Global Concerns with Memory.........................21

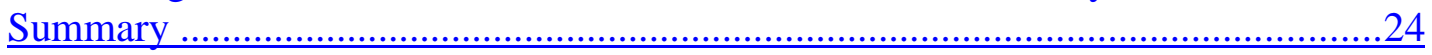

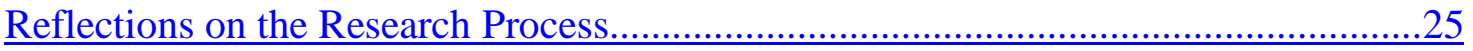

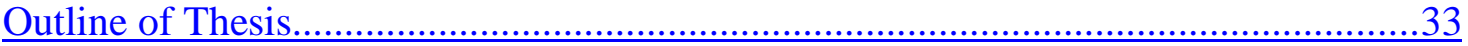

Chapter Two - Case Study One: The Provincial Hall (docheong) of Jeolla, in Gwangju 34 Memory in Gwangju: City of Darkness versus City of Light.........................................36

Gwangju Economy................................................................................................

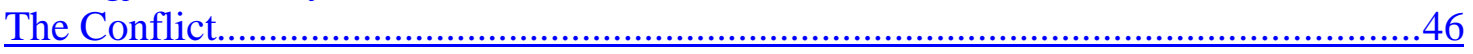

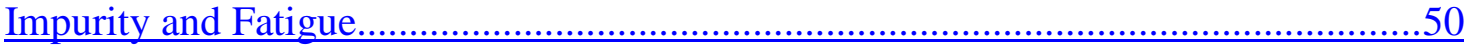

Symbolism: What's In a Name? ..........................................................................55

Contradictions and Misunderstandings: The Bigger Picture...........................................56

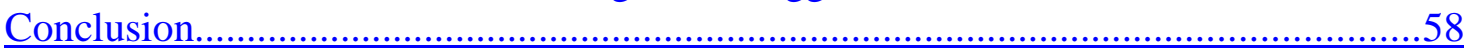

Chapter Three - Case Study Two: Myeongdong Cathedral in Seoul................................60

Changing Identities: Painting a Picture of Myeongdong Cathedral..............................62

Following Democracy: Changes Afoot......................................................................67

"The Best Time We've Ever Had" ..............................................................................69

"The Deterioration of Democracy" .............................................................................71

The Conflicting Role of the Catholic Church in Social and Political Movements in

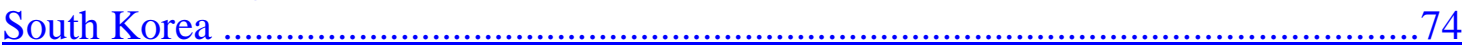

Kim Sou-Hwan: The "Conscience of Korea" ..................................................................77

Impurity and Corruption ................................................................................................79

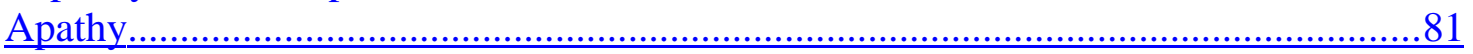

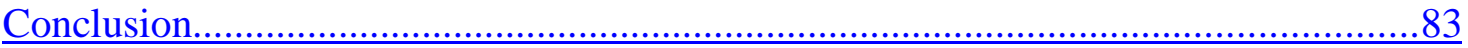

Chapter Four - The docheong and Myeongdong Cathedral: Comparison..........................85

Generational and Regional Discrepancies ..........................................................8

Shifting Representations ...........................................................................................90

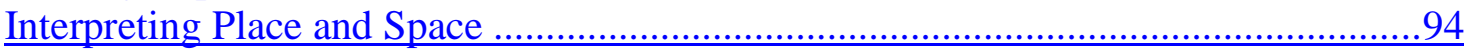

Conclusion: "The past is never dead; it's not even past" ...............................................99

Chapter Five - Epilogue: Back to the Future .............................................................103

Appendices..............................................................................................................112

Appendix One: VUW Ethics Committee Approval Memorandum.............................113 
Appendix Two: Participant Information Sheet and Consent Form for 'Organisational Representatives'.............................................................................................. 114 Appendix Three: Participant Information Sheet and Consent Form for 'Site Visitors'

A

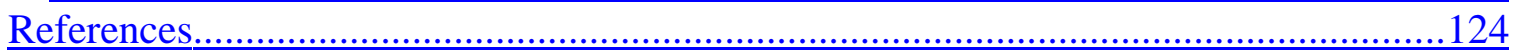

Literature and Websites..................................................................................................124

Personal Communication..........................................................................................138 


\section{List of Figures}

Figure 1: Map of South Korea (Seoul Maps and Orientation - World Guide to Seoul 2000-2010).

Figure 2: 5.18 National Cemetery during 5.18 anniversary commemorations, Gwangju (Photo: Thomas Vink, 18/05/09).

Figure 3: 5.18 Memorial Park and Culture Center. Gwangju (Photo: Thomas Vink, 18/04/09).

Figure 4: The docheong (left) and the byeolgwan (right, covered in protest banners). In the foreground is 5.18 Democratic Plaza. Gwangju (Photo: Thomas Vink, 17/04/09)....48 Figure 5: Model of the completed Asian Cultural Center, with the byeolgwan removed. HCAC Information Centre. Gwangju (Photo: Thomas Vink, 19/05/09).....

Figure 6: Myeongdong Cathedral, Seoul (Photo: Thomas Vink, 07/05/09)

Figure 7: Tour bus outside Myeongdong Cathedral, Seoul (Photo: Thomas Vink, 07/05/09)

Figure 8: A man holds up a sign asking for the resignation of President Lee Myung Bak and for the police to dismantle. City Hall plaza, Seoul (Photo: Thomas Vink, 02/05/09).

Figure 9: Portrait of Cardinal Kim Sou-Hwan. Myeongdong Cathedral, Seoul (Photo:

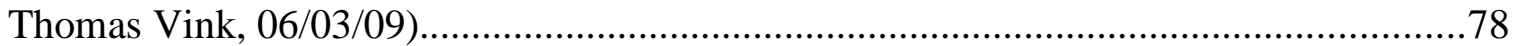

Figure 10: ACC construction site (view from the byeolgwan). Gwangju (Photo: Thomas

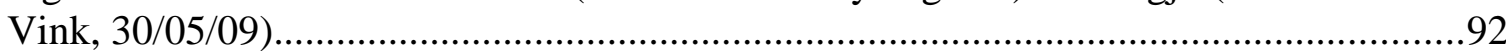

Figure 11: Inside the byeolgwan. Gwangju (Photo: Thomas Vink, 30/05/09).................92

Figure 12: Looking across the road from Myeongdong Cathedral, Seoul (Photo: Thomas

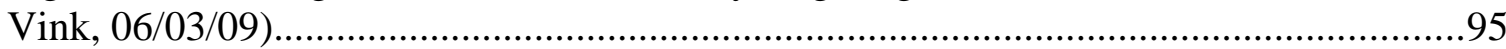

Figure 13 (left): One of the 'stations of the cross' inside Myeongdong Cathedral. Seoul

(Photo: Thomas Vink, 07/05/09)................................................................................97

Figure 14 (right): Memorial service and prayer meeting held for Park Jong-Cheol.

Myeongdong Cathedral. 02/07/1987 (Catholic Priests' Association for Justice website, 2009).

Figure 15: The so-called 'candlelight demonstrations.' Seoul. 10/06/08 (S.H. Yoo. In R. Hauben, 2009).

Figure 16: People gathered in front of City Hall for Roh Moo-Hyun's funeral. Seoul.

Photo: Thomas Vink, 29/05/09..... 


\section{Glossary: Acronyms, Abbreviations and Frequently Used Korean Terms}

5.18: $\quad$ Refers to the military crackdown that occurred between the $18^{\text {th }}$ and $27^{\text {th }}$ of May 1980 in Gwangju, South Jeolla province. Otherwise known as the 'Gwangju Uprising' or 'May 18 Democratic Movement,' among other names.

6.10: $\quad$ Refers to demonstrations on the $10^{\text {th }}$ of June 1987 when approximately one million people gathered in Seoul to protest against the government; the demonstrations ultimately led to Korea's first democratic elections later in the same year.

ACC: $\quad$ Asia Cultural Center. Asia Munhwa Jeondang.

BFA: $\quad 5.18$ Bereaved Family Association. Minju Yugongja Yujoghoe.

byeolgwan: Annex. In this thesis the term refers to the annex building to the former provincial hall (docheong) of Jeolla, in Gwangju.

CPAJ: $\quad$ Catholic Priest's Association for Justice. Jeongeui Guhyeon Sajedan.

docheong: Provincial Hall. In this thesis the term refers to the former provincial hall of Jeolla, in Gwangju.

DTA: $\quad 5.18$ Detainees Association. Yugongja Dongjehoe.

HCAC: $\quad$ Hub City of Asian Culture, Gwangju. Asia M unhwa Jungsim Dosi Gwangju.

i-ikjibdan: A group seeking to make their own profits or gains.

KCTU: $\quad$ Korean Confederation of Trade Unions. Jeon-guk Minju Nodong Johap Cheonyeonmaeng.

KTO: $\quad$ Korean Tourism Organisation. Hanguk Gwan-gwang Gongsa.

minjuhwa

undong: Literally democratisation.

minjung: Literally 'the people' or 'the masses.' A movement that gained momentum in the 1980s in Korea and sought to privilege a new sense of history that was separate from past state-dominated interpretations. 
WPA: $\quad 5.18$ Wounded Persons Association. M injuhwa Undong Busangjahoe. 


\section{Chapter One - Introduction: Contextual, Theoretical and Personal Background}

\section{Overview}

South Korea's ${ }^{1}$ rapid rise from poverty to prominence as an economic and technological powerhouse in a matter of decades is remarkable. Thus, to many around the world today, South Korea is a role model of development and modernisation. However, Korea's economic success also masks a turbulent history of vast human rights abuses. The growing strength of democracy in Korea throughout the 1990s and the state's move from autocracy to a more populist agenda opened the way for investigations into Korea's unsettled past. Recent decades in South Korea, then, have seen a proliferation of memorials, monuments and commemorative activities related to events and atrocities that occurred during the Korean War and Korea's democratisation movement (minjuhwa undong).

In Korea, the privileging of particular memories has very quickly been put to the service of not merely nation-building, but the building of collective identities, with social and political groups appropriating sites with historical resonance to meet their own needs. As a result, the sites in which the past is memorialised have often become hugely contested spaces. The overarching aspiration of this thesis is to investigate why so many historical sites in Korea - so many sites of memory - become contested spaces, sites of contention.

The forging of a collective identity requires the portrayal of a given reading of the past; the past is re-interpreted to meet the needs of the present. However, immediately questions arise: whose needs are being met? Whose narrative of the past is privileged to build this collective identity? What voices are excluded? Therefore, the contestation at sites of memory is not so much over what happened in the past, but

${ }^{1}$ Henceforth referred to as Korea, except when contrasted with North Korea. 
rather who is entitled to speak for the past in the present. The chapters that follow reveal that the conflict at sites of memory helps in understanding ongoing social and political concerns within Korean society.

I spent March to June 2009 in Korea, carrying out research on two case study sites that have great symbolic importance for Korea's minjuhwa undong. However, as interpretations and representations of the past are always changing and conflicting they have also become sites of great contention.

One case study is the former Provincial Hall (docheong) of South Jeolla, in Gwangju, a city in the south-west of Korea (see Figure 1 on page 3). The docheong was a major rallying point for citizens during the 'Gwangju Uprising' in M ay 1980, and remains an important symbol in remembering this event. The Jeolla region has a history of association with resistance and was largely excluded from government investment as other parts of the country rapidly industrialised. Gwangju, too, has long been a marginalised place and many citizens there now have an increasing desire to remold the city's image. Currently there are conflicts surrounding the construction of a new Asian Cultural Center (ACC) as part of Gwangju's attempts to become reborn as a capital of culture, human rights and democracy in Asia. A number of associations that were formed to uphold the memory of the Gwangju Uprising are concerned because the ACC plans require the destruction of the docheong annex building (byeolgwan), and worry that the ACC will not represent the Gwangju Uprising appropriately.

My other case study is M yeongdong Cathedral in Seoul. The cathedral developed a reputation as a safehaven for protesters during the 1970s and 1980s and became a key symbol of democracy. More recently, however, Myeongdong Cathedral has been trying to promote a new image, distancing itself from its past reputation and emphasising both its religious and cultural heritage. The situation at Myeongdong Cathedral is also representative of a desire on the part of Catholic Church officials to decouple religion and socio-political concerns. 


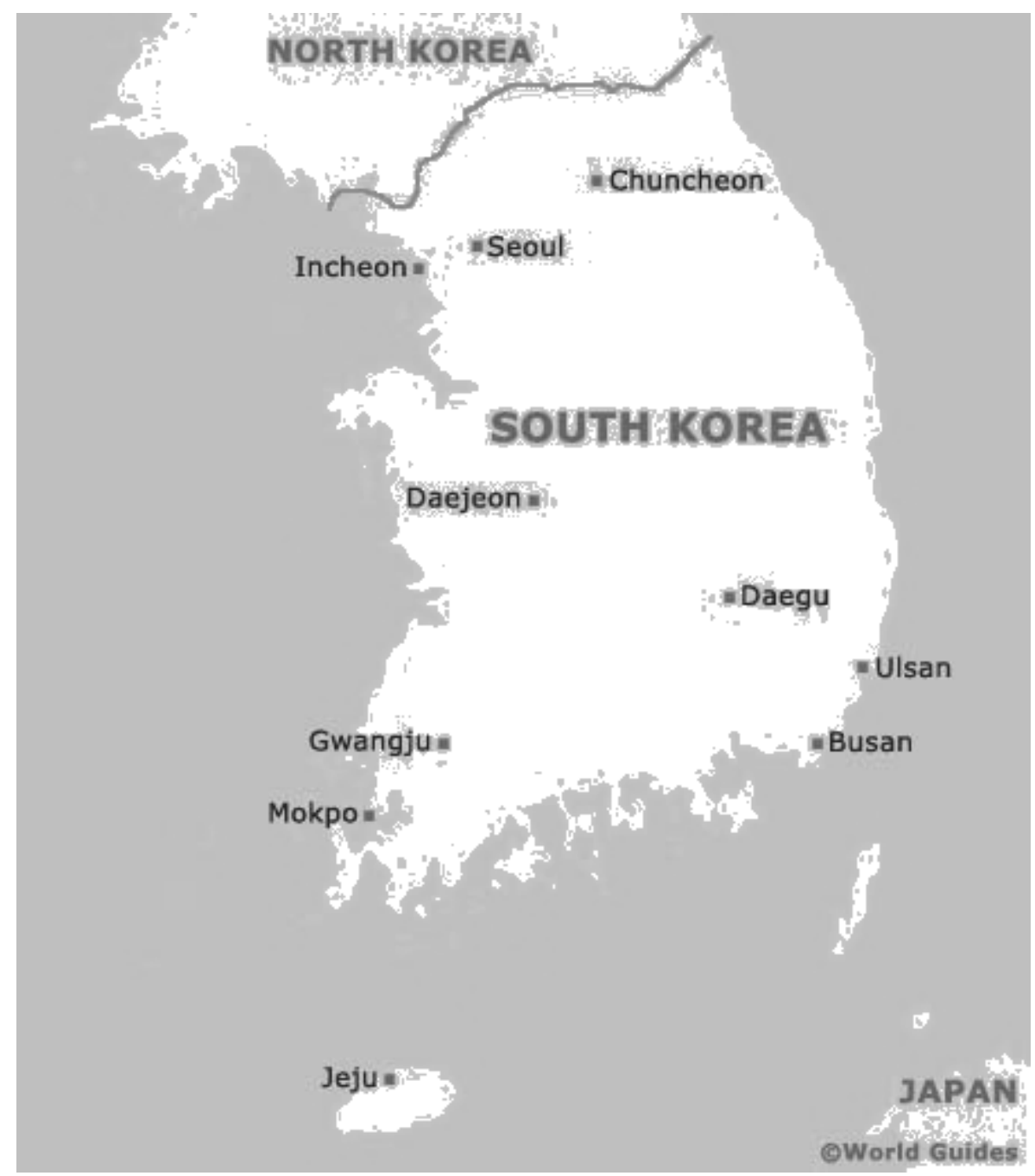

Figure 1: Map of South Korea (Seoul Maps and Orientation - World Guide to Seoul 2000-2010).

This introductory chapter sets out the contextual, theoretical and personal background of my thesis. First, I give a brief overview of contemporary Korean history, focusing on events that led to the present situation, in which contests over the privileging of collective memories have become so prominent. The historical overview will illustrate that contestation over the representation of the past has become so prominent because only in recent years have Koreans had the chance to examine closely and critically the rapid changes of the last several decades. A review of the literature related to history and memory studies, as it pertains to Korea, follows. After these 
contextual and theoretical discussions I address the personal aspects of the thesis by giving my own reflections on the research process. Finally, I offer a summary of the chapters to come. 


\section{Historical Overview}

"'To understand history,' Chacko said, 'we have to go inside and listen to what they are saying. And look at the books and the pictures on the wall. And smell the smells'...

'But we can't go in,' Chacko explained, 'because we've been locked out. And when we look in through the windows, all we see are shadows. And when we try and listen, all we hear is a whispering. And we cannot understand the whispering, because our minds have been invaded by a war. A war that we have won and lost. The very worst sort of war. A war that captures dreams and re-dreams them.'"

Arundhati Roy The God of Small Things (1997: 52-53).

The $20^{\text {th }}$ century in Korea was characterised by contrast and change as the peninsula experienced foreign occupation, division, war, protest, poverty and rapid economic and industrial growth. From 1910 to 1945, the Korean peninsula was occupied by the Japanese, who initiated reforms of assimilation designed to erase Korean nationality and conscripted Korean citizens as soldiers and comfort women. Following liberation, the United States and the Soviet Union divided the Korean peninsula and established governments in each half that conformed to their own antagonistic Cold War ideologies. In 1950, war broke out between the two, resulting in the deaths of millions of people before an armistice was signed in 1953.

South Korea, in the 1950s, was characterised by stark poverty and post-war development was almost entirely reliant on aid from the United States. In 1961, General Park Chung-Hee took over the presidency in a military coup and went on to lead the country for almost two decades. Under his leadership Korea went through a period of rapid, export-led economic growth and industrialisation. However, Korea's economic

growth came on the back of harsh authoritarianism and ideological suppression; leftist sentiment was seen as pro-North Korean and thus harshly condemned. Park also revised the constitution in order to maintain his hold on power, all the while suppressing organised political opposition, controlling the media, and banning civil organisations not 
sponsored by the state (Yea, 2002). Labour conditions in Korea at the time were among the worst in the world, and from the 1970s on widespread demonstrations occurred. Korea's movement for democracy began its first tentative steps forward as some members of the Catholic Church and liberal politicians like Kim Dae-Jung began to stand up for social and political concerns. Following Park Chung-Hee's assassination in 1979 came a brief period of quiet, but only two months later, General Chun Doo-Hwan seized power in another military coup.

A crackdown by the government in M ay 1980 following demonstrations in Seoul against the instigation of martial law resulted in the closure of universities and the banning of political activities nationwide. In Gwangju, students clashed with paratroopers in front of the gates of Jeonnam University on the $18^{\text {th }}$ of May to demonstrate against its closing. The protests moved downtown and as more soldiers arrived in the city the clash turned into a violent suppression. By the $21^{\text {st }}$ of May gunfights had broken out and many citizens killed. The uprising ended on the $27^{\text {th }}$ of May when an estimated 20,000 new troops were sent to the city. Due to a number of factors, such as the historical marginalisation of Gwangju, regional tensions, and the fact that Kim Dae-Jung, ${ }^{2}$ a key dissident at the time, was from Jeolla, the military crackdown in Gwangju was much harsher than anywhere else in the country. The Gwangju Uprising was brushed off by the government at the time, with their official stance at a polar opposite to local perceptions of the event. However, as international media coverage of the uprising spread, and word gradually reached other parts of the country throughout the 1980s, the government was widely condemned, never able to attain legitimacy due to turning so brutally on its own people. The uprising also represented a turn towards nationalist sentiments in Korea; the apparent complicity of the United States in Chun's rise to power, and in the uprising itself, resulted in a surge of anti-Americanism. The Gwangju Uprising is now officially recognised by the government as the "May 18 Democratic Movement," a key event in Korea's minjuhwa undong, and had a major

${ }^{2}$ Kim was convicted of instigating the "rebellion" and sentenced to death, though this sentence was later reduced due to international outcries. 
influence on the demonstrations for democracy that followed. The event is also known (sometimes revered) locally as 5.18 (o-il-pal), the date the uprising began. I generally refer to the event as 5.18 throughout the thesis.

The period that followed 5.18 was one "of political inquietude when millions of people marched in the streets protesting the military rule...[but] economic prosperity enabled millions to found their middle class identities" (Kim Kyung-Hun, 2004:18). In June 1987 alone, there were almost 3500 demonstrations held throughout the country (Chung, 1997: 91-92) and, throughout the year, over 670,000 canisters of tear gas were discharged by riot police in an attempt to contain the demonstrations (Chung, 1997: 84). On the $10^{\text {th }}$ of June 1987 (otherwise known as 6.10) approximately one million people gathered in Seoul to demonstrate against the Chun Doo-Hwan government. Hundreds of protesters sought protection from riot police at Myeongdong Cathedral; Catholic priests, led by Cardinal Kim Sou-Hwan, were also an integral element of the 1987 demonstrations. The sheer size and scale of citizen unrest and discontent compelled Chun to stand down. Later that year Korea held its first direct democratic elections.

In Nov 1997, former dissident Kim Dae-Jung was elected, the first Korean president from Jeolla Province, ending an almost 40-year run of presidents from Gyeongsang Province in the south-east of Korea. ${ }^{3}$ Regionalism has long had a major influence on Korean political processes and been seen as a barrier to the establishment of democracy (Yea, 2003: 117). Therefore, the election of Kim signalled the potential decline of the regional influence on politics and, for the citizens of Jeolla, an end to decades of neglect from the central government. Kim Dae-Jung's presidency also represented a turn away from conservatism towards more liberal policies, and he

\footnotetext{
${ }^{3}$ Park Chung-Hee (president from 1961 to 1979), Chun Doo-Hwan (1980-1987), Roh Tae-Woo (1987-1992) and Kim Young-Sam (1993-1998) were all born in Gyeongsang Province.
} 
remains well-known for initiating the "Sunshine Policy" ${ }^{4}$ towards North Korea, and his historic meeting in 2000 in Pyeongyang with Kim Jong-II.

The FIFA World Cup in 2002, co-hosted by Korea and Japan, signalled an emphasis in Korea away from gathering as a form of dissent, as millions of Koreans came together to celebrate their collective identity as Koreans rather than for political reasons. ${ }^{5}$ Under President Roh M oo-Hyun (2003-2008) the progressive policies initiated by Kim Dae-Jung continued. In 2005, under a new act set up to foster national unity by investigating the truth of past events, the Korea Truth and Reconciliation Commission was formed and scholarship related to revealing various non-hegemonic interpretations of the past grew in scale.

The election of Lee Myung-Bak of the conservative Grand National Party in 2008 saw the end of a ten-year period of progressive governance. Many citizens in Korea are concerned that Lee has brought back aspects of the military-dominated past through a greater use of riot police and by issuing laws that lessen the voice of civil society. These concerns were highlighted most clearly during candlelight demonstrations in 2008 that saw more than one million people gather in central Seoul to protest against the government.

The sprawling urban metropolis of Seoul that represents most visitors' first impressions of Korea highlights the country's transformation over a matter of decades from poverty to a modern, technologically advanced global economy. However, as I have highlighted in this historical overview, just below the surface lies a turbulent past that many in Korea are still coming to terms with. As in the imagery of Arundhati Roy above, until recent decades Korea's history was a 'locked door,' the 'windows' hazed

\footnotetext{
${ }^{4}$ The sunshine policy emphasised peaceful cooperation between the two nations as a prelude to eventual reunification.

${ }^{5}$ As Cho Han Hae-Joang states (2004: 21), "Koreans, for the first time in their history of nation-building, experienced the euphoria of being together, a collectivity for itself, not for defense or antagonism."
} 
over by the constraints that came from decades of occupation and authoritarianism. As aspects of Korea's history became more acknowledged in the 1990s - as the 'lights' turned on and the 'shadows' regressed - the contestation over whose readings of the past were given importance also increased. Accordingly, research related to the conflict over the privileging of particular understandings of the past also grew substantially. A thorough reading of debates in the literature over the meaning of Korea's past, and how these debates are informed by wider studies of memory and history, helps to understand the underlying meaning behind these contestations in Korea. 


\section{Literature Review}

\section{Introduction}

Within academia, the emergence of 'sites of memory' as a key area of study has opened the way for a geographical exploration of memory and history scholarship. Many academics are now interested in the link between contention over the use of space and place, and the representation of specific narratives of the past. Memory as described in this thesis is cultural memory and, thus, a collective remembering as well as an individual remembering. Collective memory is based on a perceived shared experience and understanding of the past. Sites of memory embody particular collective memories of the past and are, thus, inherently contentious and political places. To understand this contestation over the use of place to represent particular memories requires an analysis of the social constructions and ideologies that affirm some readings of the past over others. By investigating whose understandings of the past are emphasised at two sites in Korea, I reveal underlying reasons behind the resonance of contested memory in Korea, and the relationship of such contested memories to wider concerns in Korean society.

Throughout this review I relate the literature on Korea with wider scholarship to give a sense of why debates over space, place and identity take on such importance in Korea. I begin by acknowledging how the research on contested memory in Korea fits with more general studies of history and memory. I then examine how specific narratives of the past are privileged to create a sense of collective identity, not only in Korea, but throughout the world. Collective identities have long been constructed through memorials, monuments and museums that set given understandings of history in 'stone,' although this process can have negative effects, which are also discussed. Finally, I describe how the contest over the privileging of particular narratives of the past in Korea is an example of a wider global concern with attempts to reconcile the past with the present. 


\section{History and Memory}

Sites of memory are particularly contentious spaces in Korea because of the country's tumultuous history and the speed with which it changed over the second half of the $20^{\text {th }}$ Century. Michael Robinson (2007) points out that only since the 1990s, and Korea's democratisation, have Koreans begun to question the 'obligation to forget' ${ }^{6}$ and to ask what was really lost in the drive to modernise. The study of contested understandings of nation and identity in Korea fits within a worldwide turn towards memory studies, and mounting debates over the meanings of 'history' and 'memory.' Many studies of memory share a belief that the distinction between history and memory is changing because, in recent decades, history has essentially been "speeding up." "This "acceleration of history" refers to the link between globalisation and memory and is an idea used prominently by Pierre Nora in his research $(1989,2002)$ on the "upsurge of memory." ${ }^{8}$ Nora argues (2002) that "the most continuous or permanent feature of the modern world is no longer continuity or permanence but change." Moreover, because we are forced to consume information more rapidly we must also forget at a rapid pace (Todorov, 2001). For instance, in Korea, new political pressure on remembering war and protest movements has also opened up spaces for the past not only to be remembered but to be forgotten as well. As Sheila Jager \& Rana Mitter explain (2007: 14), "as long 'forgotten' war crimes are being brought out into the open for public inspection, other crimes are being reburied in the name of re-establishing the bonds of community torn apart by the cold war." Thus, some scholars, such as Jager and

\footnotetext{
${ }^{6}$ The 'obligation to forget' in Korea is representative of the way in which authoritarianism and human rights abuses were justified by the 'greater' push to develop and industrialise, and to deal with the threat of North Korea.

${ }^{7}$ Huyssen, 2000; Klein, 2000; Kundera, 1979, 1984; Nora, 1989, 2002; Todorov, 2001.

${ }^{8}$ Nora's research focused on France as the first country to embark on an age of "memorialism." In the 1970s, with the end of revolutionary ideas in France, came a growing awareness of the historical traditions that had been pushed aside since the 'French Revolution' of the late 18th Century (Nora, 2002). Nora (1989) argues that there was a turn towards lieux de memoire - sites of memory - in order to protect these traditions and once more promote the idea of a national memory and thus a collective identity. Following France there came a worldwide turn towards "memorialism" and an emergence of initiatives related to "settling scores" with the past (Nora, 2002).
} 
Ji-Yul Kim, argue (2007: 251) that the new focus on commemorating the past is really a different form of forgetting, "a new national strategy of memory-through-forgetting."

Because interest over how collective understandings of the past are represented has increased worldwide, Nora argues (2002) that the rhetoric of 'memory' has become so broad and encompassing that it is now often used simply as a substitute for history. The traditional view that history is objective and scientific and memory is subjective and personal is now outdated; the distinction between memory and history is much more complicated. The South Korean Presidential Truth Commission conducted research to reveal the truth behind "suspicious deaths" that occurred during the Korean War and the following years of authoritarianism in Korea and argue (2004: 527) that "history is not simply something that happened in the past." To ignore history ${ }^{9}$ increases the risk that future groups will face the same issues (South Korean Presidential Truth Commission, 2004). Bringing the past into the present, therefore, is about more than just memory, because all interpretations of history are acts of remembering. Instead, interpretations of the past need reflection and an active attempt to create understanding. As Alessandro Portelli states (1991: 52), "memory is not a passive depository of facts, but an active process of creation of meanings." Because memory can create meaning, emphasising particular memories over others has become a major way of building on a collective sense of identity; by creating meaning from the past, individuals are able to form connections between each other, ties that bind them together.

Memory holds crucial importance to the individual. Nora argues (2002) that only vestiges of the past remain, however, these snippets of the past "hold the key to our "identity," to who we are." Because information is consumed so rapidly in today's global society only some of this information can hold individual meaning. Thus, collective memories of historical events - or rather representations of collective memories - are

${ }^{9}$ In the case of South Korea, an ideological suppression of human rights, and mass murder and imprisonment. 
accentuated as a way to build on, or create, a given social group's sense of identity; a way of keeping a sense of place, nation or community in an increasingly globalised and changing world. However, privileging given collective readings of the past immediately raises the question of which events are given importance: what is considered important to remember, what is 'forgotten,' and who has the power to decide? Different sets of people remember different things, so whose memories determine collective memory?

The clash over what memories are emphasised - what is 'remembered' and what is 'forgotten' - in a social group's history is widely discussed in the literature. ${ }^{10}$ For example, Darien Rozentals studies (2008) how urban monuments act as spaces for forgetting by exploring case studies in Lithuania, Japan and England. Rozentals speaks (2008: 2) of "the binary of memory and amnesia," arguing that there cannot be one without the other, and seeks to find new forms of representation that can 'reclaim' memory back from where it has been 'forgotten.' Remembering or privileging some events necessarily requires that other events be given less importance or that they even be forgotten. For Huyssen (2000: 38) the remembering/forgetting binary is necessary because human memory is short, social, "always transitory, notoriously unreliable, and haunted by forgetting." Put simply, "memory without forgetting is impossible" (Zehfuss, 2006: 226).

As with any binary, conflict exists over which half is more significant. In the case of memory, the debate is between the merits of remembering or forgetting: is it more important to 'remember' or 'forget' when building collective identity? Friedrich Nietzsche argues (1969: 57-58) that forgetfulness is like a doorkeeper that keeps out the pain and grief of the past. Overcoming pain requires forgetting because "only that which never ceases to hurt stays in the memory" (Nietzsche, 1969: 61). Paul Ricoeur is less cynical about memory, claiming that there is a tendency in history to celebrate the victors, but often more can be learnt from those who have suffered: "the duty to remember is a duty to teach" (Ricoeur, 1999: 10-11). Acclaimed movie director, Luis Bunuel, asserts (1983: 5) that there is in fact no life without memory: "our memory is

${ }^{10}$ Hodgkin and Radstone, 2003; Huyssen, 1995, 1996, 2000; Klein, 2000; Passerini, 2003; Ricoeur, 1999; Rozentals, 2008; Todorov, 2001; Zehfuss, 2006. 
our coherence, our reason, our feeling, even our action. Without it, we are nothing." Anna Funder, who explores memory issues in Germany following the fall of the Berlin Wall, asks an important set of questions (2003: 52), what is healthier, "to remember or forget...to demolish it or fence it off? To dig it up, or leave it lie in the ground?" This question above all - of memory or forgetting - is widely explored in memory scholarship. However, the debate over what to 'remember' or 'forget' when building collective identities is unresolved. Remembering and forgetting both have merits and consequences so perhaps more scholarship should look at the different ways of remembering and forgetting rather than dichotomising the two notions.

Whatever the arguments for and against forgetting, commentators generally agree that forgetting (or the erasure of certain memories) plays an important role in the creation of identity generally, and more specifically in relation to a collective identity. ${ }^{11}$ In his seminal work, Imagined Communities, Benedict Anderson argues (1991: 201) that national identity is built through "reminders" of "already forgotten tragedies." Following the same link - between nation and memory - Katherine Hodgkin and Susannah Radstone (2003a) claim that memory dispersed in a public sphere is inseparable from discourses of national identity and Pierre Nora states (1989: 15) that every social group must redefine identity through the "revitalisation" of its own history.

In Korea, the late 1990s saw a surge of work on 5.18 and the minjuhwa undong, and associated issues of memory. Much of this work is related to so-called minjung nationalism and attempts by Korean citizens to create new narratives of the past. ${ }^{12}$ The minjung are variously defined as the masses, the people, or the grassroots, and comprise those "who are made peripheral to, or alienated from, the political process" (Shin, 1998: 161). Thus, minjung culture revolved around attempts to re-articulate the voices of 'the people' to depict past protesters as victims, or 'sufferers' (Ward, 1995).

\footnotetext{
${ }^{11}$ Anderson, 1991; Bhaba, 1990; Huyssen, 1995; Klein, 2000; Morris-Suzuki, 2005; Nora, 1989, 2002; Ricoeur, 1999; White, 1997.

${ }^{12}$ Byun, 2000; Chung \& Rhyu et al, 2003; Choi, 1999; Jager, 2003; Jung Keun-Sik, 2000, 2003; South Korea Presidential Truth Commission, 2004; Shin, 1998, 2006; Shin \& Kyung 2003; Wells, 1995; Yea, 1999, 2000, 2002, 2003.
} 
Around this victim construct a collective sense of history and identity could be built, separated from past state-dominated perceptions of identity. In other words, the minjung movement was a way to "revitalise" (cf. Nora, 1989: 15) Korean history to give previously marginalised identities more prominence.

To construct national identity by redefining or appropriating history implies that identity is constructed via the sanctioning of some memories over others. Homi Bhabha (1990) argues that all ideas of nationhood are shaped by 'narratives.' His research builds on the idea of amnesia with a discussion of how identity, principally national identity, is intersected by the "obligation to forget," or "forgetting to remember" (Bhabha, 1990: 310). Bruce Cumings applies Bhabha's notion of amnesia to an appraisal of how Korean War memory is privileged or 'forgotten,' claiming (2007a: 270) that "you remember one verdict and forget the other. Each verdict implies a corresponding amnesia." Thus, identity is built on narratives that are created by eliminating some events and accepting others. Through the creation of these narratives the past is related to, and made meaningful in, the present. By communally remembering a given aspect of the past, individuals create a sense of collective belonging (M orris-Suzuki, 2005: 23). Discussions regarding the intersection of memory, the Korea War and nationalism, for example, analyse how memory is appropriated for the creation of separate national identities in North and South Korea. ${ }^{13}$ Gi-Wook Shin, whose research $(1998,2006)$ explores the creation of Korean identity, argues that both North and South Korea have relied on nationalist politics to legitimise their own regimes and de-legitimise the other's. Sheila Jager is similarly interested in the factors that have led to the creation of a Korean 'national' identity, and argues (2003: 118) that the meanings of the past in South Korea have always been constituted and appropriated in the context of the promotion of state legitimacy. In her reading, the struggle over how to deal with the North Korean nuclear crisis and efforts to end the Korean War, for example, are caught up in the politics of memory and the need for the South to accommodate the North in its national past and future (Jager and Kim 2007: 265).

${ }^{13}$ Cumings, 1997, 2003, 2007a; Jager, 2003; Jager and Kim, 2007; Jager and M itter, 2007; Shin, 1998, 2006. 
If memory and collective/national identity are so intimately connected in Korea, then it is worthwhile, even necessary, to interrogate the narratives of the past that are currently privileged, to question the narratives of the past around which Korean collective and national identity is formed. In Korea and throughout the world, then, a growing literature studies sites of memory in order to question whose readings of the past are given importance in the present.

\section{Landscapes of Memory}

"He thought each memory recalled must do some violence to its origins. As in a party game. Say the word and pass it on. So be sparing. What you alter in the remembering has yet a reality, known or not."

Cormac M cCarthy The Road (2006: 131).

As the 'acceleration' of history has coincided with a rise in 'forgetting,' then, throughout the world collective memories of given social groups have become increasingly displayed through memorials and monuments that set the past in 'stone' and prevent it from being forgotten. In Korea, too, since the late 1990s more effort has been made to commemorate events like 5.18 and the Korean War through memorials and other sites of memory. However, the sites of these physical representations of the past, or what Hodgkin and Radstone (2003) term public statements about what the past has been, have become hugely contested space, in Korea and worldwide. This contestation is not so much over what happened in the past, but rather who or what is entitled to speak for the past in the present (Hodgkin \& Radstone, 2003). The crux of the arguments made in the literature is that sites of memory have an inherent capacity for transformation and "come to act not only as spaces for representation and reinscription of political events...but also as sites of contention in and of themselves" (Yea, 2002: 1571). By appropriating the meaning that sites of memory hold, social and political groups are able to re-conceive and 'invent' various sites as places and spaces to meet 
their own needs: "though statues might be, their meaning is not written in stone" (Agnew, 1997: 322).

Memory scholarship shows that sites of memory rarely hold the same meaning to individuals as to the state and this discrepancy inevitably leads to conflict. ${ }^{14}$ In the context of her research into the impact that the commemoration of 5.18 has on understandings of the event, Sallie Yea discusses (2002: 1570) the "ongoing connection between history, memory and resistance/dissent." Yea describes how the national cemetery built in Gwangju to memorialise 5.18, has altered images of the event and the city by inscribing national importance to the event. However, the "official memorialisation of the uprising unleashed a profound paradox in which the very act of official recognition failed to accommodate these populist claims which were at the very core of the uprising itself" (Yea, 2002: 1561-1562). The case study explored by Yea exemplifies how sites of memory are increasingly politicised as state forces realise the potential of appropriating these sites to align themselves with a populist historical agenda. Besides Yea's work, there is little in English about other sites of memory in Gwangju. Linda Lewis (2000, 2002, and with Byun Ju-Na, 2003) has written of the changing image of Gwangju, as a city, looking specifically at how the competing interpretations held by individuals and the state have created an "identity crisis" within the 5.18 movement. Yea (2002) named the former sangmudae (a prison that held captive citizens during 5.18) and the area around the docheong, as the two other key sites in what many Gwangju residents have termed Gwangju's "memorial industry" (ginyeom sa-eop) (cf. Yea, 2002: 1559), ${ }^{15}$ but very little has been written about whose collective understandings of the past are represented (and whose are marginalised) by these sites.

\footnotetext{
${ }^{14}$ See also Brenda Yeoh's and Tan Bon Hui's (1995) discussion regarding the nature of Chinese burial grounds in Singapore. They posit that space is a social and public product that holds interest to multiple individuals and groups. Thus, burial grounds and other sites of memory are construed with a plurality of diverse, often antithetical, meanings. In his discussion of commemorating the holocaust in Germany, Andrew Charlesworth (1994: 579) explains that the "very act of memorialisation, of capturing memory so that we do not forget, can by its exclusivity push aside the claims of others for their own collective rights and identities."

${ }^{15}$ The other key site is 5.18 National Cemetery.
} 
Many scholars also discuss the ways in which landscapes of memory are socially produced (Kong \& Law, 2002; Yea, 2002; Zelinsky, 1994). The key point to take from the research into landscapes is that exploring the discourse around social constructions of place and memory asks a question of something that is too often blindly accepted. Sites of memory convey political messages - even subconscious and unintended messages that, until recent years, have been rarely studied (Yea, 2002). Lily Kong and Lisa Law (2002) also examine the issue of socially constructed landscapes and state:

"To understand the contestations of landscapes involves unsettling extant social constructions and exposing dominant ideologies that underlie such constructions, the institutions that aid those constructions, the groups that are privileged by them and the urban landscapes that naturalise them" (Kong and Law, 2002: 1504).

The study of landscapes, and the contestations within them, then, can act as a way of uncovering socially produced meaning by, what Wilbur Zelinsky (1994: 29) terms, "peeling back" the central layers of our value systems and inviting all manner of social and geographical questions. Accordingly, sites of memory act as spaces to debate the relevance and meaning of the past for the present and the future. However, sometimes imparting emphasis on particular aspects of the past can, conversely, distance the past from the present, as the following section discusses. 


\section{Invisible Monuments and the Sanitisation of History}

"Anybody can stand quietly by the side of the road and allow glances to be bestowed on him; these days we can demand more of monuments."

Robert Musil Selected Writings (1986: 322).

Robert Musil once stated (1986: 320) that "there is nothing in the world as invisible as monuments." Now, some scholars claim that representing memory through monuments and landscapes is unhelpful and that sites of memory actually induce forgetting. ${ }^{16}$ The argument that monuments are figures for forgetting relates to a point made by Nora (1989: 7) that "there are lieux de memoire, sites of memory, because there are no longer milieux de memoire, real environments of memory." Real memory gestures, habits, skills passed down through generations, unspoken traditions - is replaced by modern memory, which is "self-conscious, historical, individual, and archival...[and] necessitate[s] collective forgetting or amnesia" (Johnson, 1995: 54). In Andreas Huyssen's study of the German obsession with monuments he argues (1996: 199) that monuments are figures for forgetting because as they become more pervasive, the past becomes more invisible; because monuments act as symbols of the past, they can often take the place of our memory. ${ }^{17}$ Sheila Jager and Ji-Yul Kim assert (2007) that by placing the Korean War in a broader expanse of national history, what they term "a larger story of the heroic overcoming of adversity" (p.30), the Korean War Museum in Seoul marginalises the actual brutality of the war. Tessa Morris-Suzuki (2009) claims that the museum, for the most part, evokes "silence." With a desire to leave open a path to reconciliation with North Korea, the museum contains only small references to massacres, by both North and South Korean troops, of prisoners of war and civilians, thus, sanitising the atrocities of the war (M orris-Suzuki, 2009).

\footnotetext{
${ }^{16}$ Bell, 2003; Gillis, 1994; Huyssen, 1996; Johnson, 1995; Klein, 2002; Nora, 1989.

${ }^{17}$ Huyssen believes that the goal of Germany's monumental obsession is redemption through memory. So the events of the holocaust for example, can be redeemed by memorialising the victims. However, he also claims (1996: 184) that this mass memorialisation actually obscures the events of the holocaust, thus, equating to "entsorgung, the public disposal of radio-active historical waste."
} 
The turn towards memorialisation has increased a tendency towards what Kerwin Klein describes (2000: 133) as "ironic historical representations of postmodernity." Monuments and museums sanitise history by promoting certain memories over others or marginalising the actual historical events they are dealing with in favour of images that are easier for people to understand or relate to, but may, nevertheless, have less meaning. Anna Funder (2003, 2009) and Linda Richter (1999) both claim that many sites of memory have become 'disneyfied' because they privilege benign narratives of historical events. For example, Funder (2003: 276) writes that monuments to the Berlin wall are "sanitised Disney version[s]... [they represent] history, airbrushed for effect." ${ }^{18}$ Linda Lewis (2002a), too, notes a touristic emphasis in Gwangju, where 5.18 now has its own mascot and souvenir items related to the event are available at various gift shops. Lewis $(2000,2002,2003)$ and Yea (2002) both discuss, in depth, the potential sanitisation of 5.18 that has occurred by memorialising the event.

Milan Kundera claims (1984: 278) that, ironically, "before we are forgotten, we will be turned into kitsch." ${ }^{19}$ Kitsch refers to the creation of 'sanitised' views of the world in order to exclude the things that people find difficult to come to terms with. If we take this line of thought then sites of memory are sanitised representations of the past, 'dumbed down' and lacking in meaning. Memorialising an event in a museum, for example, implies that interpretations of the event are over, that the event is history. This causes problems, in the case of commemoration, when the events being "put behind glass" (Funder, 2003: 276) are not yet over, when readings of the event (such as the collapse of the German Democratic Republic, the Korean War or 5.18) are still being constructed. Therefore, monuments, and commemoration in general, can be used for exclusionary ends, as catalysts to forgetting or accepting an event, of which the meaning

\footnotetext{
${ }_{18}$ Likewise the new museum to the 'German Democratic Republic' (GDR) deals in tourism and memorabilia and yet, Funder (2009) argues, even now twenty years later, there are still people for whom the GDR exists, at least as a representation of their identity. Interpretations of the GDR are ongoing, but the sanitised views of the GDR painted by memorials and museums are becoming, amongst younger generations, the reality and marginalising the actual events that occurred (Funder, 2009).

${ }^{19}$ Kitsch is the unoriginal mass production of cultural icons, but Kundera relates it to totalitarianism, particularly in relation to his country of birth, the Czech Republic.
} 
is still being contested. In other words, rather than memorials ensuring that nothing is lost, they ensure that only certain things are not (Hodgkin \& Radstone, 2003).

Critics of monumentalism and memorialism have been termed part of an 'antimonument movement.' They argue, along the same lines as Bell (2003: 73), that "buildings, archives, poems and all the other artefacts, symbols and rituals that cultures imbue with meaning, do not remember. And neither are they necessarily spurs to us remembering." According to Gillis (1994), then, this movement calls for the return to memory as an everyday part of life, going back to Nora's aforementioned milieux de memoire, real environments of memory, and rejecting memory sites, rejecting sanitised memory, rejecting kitsch. In this way, Gillis argues, the gap between the past and the present - between memory and history - can be closed.

\section{Contesting the Past in the Present: Global Concerns with Memory}

"The struggle of man against power is the struggle of memory against forgetting."

Milan Kundera The Book of Laughter and Forgetting (1979: 4).

The global spread of memorialisation that we are currently witnessing (Bell 2003, 2006; Huyssen 2000; Nora 1989, 2002), has called forth increasing examples of attempts to 'decenter' history. The globalisation of specific responses to memory is seen most prominently in the pervasiveness of Truth and Reconciliation Commissions (Bell, 2006), and a 'world-wide memorialism' involving attempts to reconcile the past with the present (Nora, 2002). Korea's Truth and Reconciliation Commission was established in 2005 as the relatively progressive Roh Moo-Hyun government emphasised a need among Koreans to uncover more of the truth about past events. Attempts to 'recover memory' have spread worldwide: in Eastern Europe following the fall of the Berlin Wall and the collapse of the Soviet Union, in Latin America following the fall of military dictatorships, in South Africa following the end of Apartheid. This global memory 
recovery still exists today, with truth and reconciliation commissions now established in countries as diverse as South Africa, Chile, Peru, Fiji, Sierra Leone, and even Canada and the United States.

The past continues to haunt the present, as the responses to the wars of the 1990s, such as the Gulf War, civil wars in Rwanda and Sierra Leone, and the Kosovo War, highlight (Bell, 2006). In Chile, this haunting, in the form of reverberations from years of right-wing military dictatorships, has enabled political action, with social reconciliation acting as a tool to collectively resolve the wrongs of the past (Frazier, 1999: 110). In post-Apartheid South Africa the desire to re-interpret colonial history has led to the creation of a more superficially appealing narrative of past atrocities, but one that also fails to really address the "spectre" of the past (M eskall, 2006: 16).

National unity and memory also go hand in hand in many countries without truth commissions. ${ }^{20}$ However, the implications that conflicts over representing the past have on wider development issues are less widely explored, particularly in Asia, where many countries are going through transitional periods of governance and identity in which memory has proven to be a key issue (Bell 2006). Because perceptions of the past can deligitimise previous regimes and support new claims of legitimacy, there is a "dearth of research on landscape contests" (Lily and Law 2002: 1508). Erishna Naidu, in her work on community-centred approaches to memorialisation in the Vaal region of South Africa, contends (2004: 1) that processes related to memory and memorialisation play a significant role in reconciliation because of their ability to mediate between the past and the present. There is potential to look beyond nationalist agendas to the impact that

\footnotetext{
${ }^{20}$ For example, Matthew McDonald (2009) and Paula Hamilton (2003) argue that in Australia, commemoration of Australia's role in World War One, particularly in relation to Gallipoli, is celebrated as a 'baptism of fire,' marking the emergence of the Australian nation (Hamilton, 2003). Japan continues to struggle in its quest for a particular cultural identity, in the context of globalisation, the loss of 'old Japan' and as a way of coming to terms with the horrors of war memory (Saaler and Schwentker, 2008). In Indonesia (Adams, 1997) and Malaysia (Kalb, 1997) also, memory is playing an increasing role in reconciling state and local conceptions of identity. These few examples are representative of a much wider scholarly emphasis on more inclusive and redemption-driven attempts to (re)build national memory and identity.
} 
sites of memory, and the contests within them, have on a country's interaction with its neighbouring countries and the rest of the world.

By 1996 Nancy Abelmann (1996: 226) could write that, in South Korea, the 1980s had become distant and receded into "history." Furthermore, the state has now appropriated many minjung concerns for its own populist claims and, therefore, some argue that minjung ideology, too, has lost relevance (Lewis, 2002; Yea, 2002). ${ }^{21}$ An expanding literature now focuses on Korea's growing multiculturalism and global identity. ${ }^{22}$ With an increasing number of migrant workers and marriage immigrants now living in Korea, ${ }^{23}$ more individuals are questioning the make-up of the Korean nation, which historically has been built on the idea of Korea as homogenous and unified. While the concept of the minjung, which posits populist forces as the crucial agents of historical progress and change, was important for Korea as it went through the process of democratisation, its dichotomising tendencies contradict the growing acknowledgement of Korea as a multicultural, multiethnic society (Shin, 2006). Likewise, sites of memory in Korea no longer represent the same links to resistance (and to the minjung movement) as in the past. Instead, many of these sites (such as 5.18 National Cemetery, or the Korea War M useum) were constructed by the state for the purposes of national unity and attempts to move on from the past. In Gwangju, throughout the 1990s, many citizens were able to reclaim their identities by promoting their own narratives of the past. Now, however, these identities have also been appropriated, conveyed in terms of national and Asia-wide discussions of democracy and human rights, and disconnected from the social issues of the 1980s (Lewis, 2002). Nonetheless, conflicts and discussions over whose narratives of Korea's past are given emphasis remain. For Linda Lewis (2002), many individuals in Gwangju still offer a 'counterhistory' to the increasingly nationalistic portrayal of 5.18 , a point that will be highlighted

\footnotetext{
${ }^{21}$ Note that this is already dated; minjung has become even less relevant with the passage of another decade.

${ }^{22}$ Hwang \& Jang, 2009; Jeong, 2008; Kim Andrew Eungi, 2009; Kim Youngok, 2007; Lim, 2009; Shin, 2006.

${ }^{23}$ The number of foreign residents rose from 380,000 in 1997 to over one million in 2007 (Jeong, 2008).
} 
in the discussions that come in the following chapters. Likewise, the recent establishment of official organisations that seek to be more open about the past, such as the Korea Truth and Reconciliation Commission, indicate that history still holds contemporary relevance in Korea.

In recent years more groups have been given the chance to voice and commemorate their interpretations of the past, not only in Korea, but worldwide. Linda Richter argues (1999) that while the number of heritage sites commemorating the marginalised has 'exploded' globally, this explosion has also increased contestation by involving more interested parties. Unlike history, "memory has acquired all the new privileges and prestige of a popular protest movement" (Nora, 2002). South Korea is an example of this 'explosion,' and the city of Gwangju presents the most contested site and is symbolic of the subaltern. The ongoing contestation over memory in South Korea, and especially in the city of Gwangju, thus, offers an example of the increasing global concern with memory and attempts to reconcile the past with the present

\section{Summary}

This literature review has discussed various contests over the representation of the past in Korea and how these contests relate to wider studies of history and memory. In Korea, and throughout the world, conflict over the meaning of place and space has increased in recent decades, and is related to the emergence of sites of memory within the more general discourses of history and memory. By representing given understandings of memory through place - sites of memory - individuals and groups privilege narratives around which collective understandings of identity can be built. However, emphasising a particular interpretation of the past can also exclude other voices and, thus, sites of memory become contentious and political spaces. 


\section{Reflections on the Research Process}

Before I conclude this chapter, I offer a personal and reflective discussion of the research process: the motives, desires and fears I had when developing plans for my research; the fun, the sadness, the dilemmas faced and the lessons learned in the field; and the long, frustrating task of turning my research into a thesis.

In the early stages of building a thesis topic I was interested in how meaning and power/identity relations are constructed in, and represented through, place and space. $\mathrm{My}$ interest was brought on by a graduate class, which examined the geographies of power, place and identity, and was informed by discourses surrounding power relations, such as (post)feminism, post-structuralism and post-colonialism. This class opened my mind to the innumerable conflicts that come up in relation to interpretations of place and space. Elizabeth Teather states (2000), for instance, that landscapes of memory are the contexts of, and hold the potential for, confrontations between profoundly different discourses. This idea of discourse - as "a material condition (or set of conditions) which enables and constrains the socially productive 'imagination'" (M cHoul and Grace, 1993: $5)$ - is hugely important to the study of sites of memory. The conflict of discourses within sites of memory fascinated me because memory is such a subjective and socially constructed notion. Principally, I am influenced by the post-structuralist viewpoint that power is exercised through the production of knowledge and truth, and that all 'knowledges' and 'truths' are subjective and contested. Therefore, memory can be conceived of as praxis rather than text, as an ongoing process of uncovering meaning.

The choice of Korea as a site to focus these initial theoretical ideas came later. I am new to the field of Korean Studies. Only in 2008 did I learn what kimchi (spicy pickled vegetable - the national dish) is and annyeong (hello) meant. I knew of key figures like Kim Dae-Jung and Kim Jong-II, that North Korea was isolated and involved in nuclear proliferation, that there had been a war between the North and South in the mid $20^{\text {th }}$ 
Century, and that South Korea had co-hosted the 2002 Football World Cup. I was hardly alone in having such basic knowledge of Korea. In fact this widespread lack of knowledge about Korea interested me; the desire to look at something most New Zealanders do not study served as a reason why Korea became my research site. The theoretical ideas that initially formed my plans for a thesis, like my background, also had little direct connection to Korea. Ultimately, the choice of Korea as a research site was an amalgamation of small things coming together, it's as simple as that. Before I knew it I was leaving the New Zealand summer and touching down in near freezing temperatures at Incheon airport.

Of course, I needed to know more about Korea before beginning my fieldwork. Scholarly literature has provided valuable context and understanding. My reading initially focused on Korean history, primarily since the Korean War. Meanwhile, I began to study the language and to delve into Korean film. I continued to read sporadically during my time in Korea. Much of this research gained specificity as I realised the niches I wanted to explore. Obviously, my limited language skills have restricted the breadth of my reading, an aspect of my research that I will always question. M ore specific research since I returned to New Zealand has consisted of filling in gaps. Much of this reading is dense and philosophical but, as shown in my literature review, it has been important for me to go through these works and build my own understanding of the implications that representing particular aspects of the past have, particularly in the context of Korea.

I look at my in-field research as split into two periods. The first, I now recognise, was a time to find my feet and direction. The second mainly consisted of specific interviews and travel between case study sites. Leaving Seoul for the first time after six weeks completely changed my field experience, giving me a much broader conception of Korea. Part of this was helped by finally choosing my case studies.

I left for Korea, and spent the first weeks of my time there, having not yet decided on the specifics of my research. What I learnt in this period contributed greatly 
to my overall understanding of Korean culture and society but, without case-studies, never really felt like 'research,' it was background. The sense of direction I felt after finally choosing my case-studies changed the whole nature of my field experience, providing me with direction and confidence.

I decided that two case studies provided more advantages than one, and would make my research more interesting, not only to read, but for me to carry out. Looking at the docheong in Gwangju and Myeongdong Cathedral meant focussing on two slightly different key moments of history and memory, 1980 and 1987 respectively, and two very different cities, but the two key cities in terms of Korean democracy protests: Seoul, the capital, and Gwangju, the neglected 'outsider' of Korea's 'imagined geography' (Yea, 1999: 230). Thus, part of having two case studies meant the ability to compare attitudes and meanings held by people in Seoul with those in Gwangju.

When going through ethical approval processes (see Appendix One on page 113 for a copy of my Ethics Approval) I developed the idea that I would be carrying out interviews with two categories of people about my research - 'organisational representatives' and 'site visitors' - and that I would use a different structure, semistructured and informal respectively, to interview each of these types (See Appendix Two and Appendix Three, on page 114 and 120 respectively, for copies of the Participant Information Sheets and Consent Forms that were used). In reality, the distinction between the two categories, and in how I carried out my interviews, proved almost nonexistent. Being flexible and hearing a wide range of opinions became more important than the number and structure of interviews.

The informal nature of many of my interviews allowed for flexibility in whom I spoke to and the information I gathered. However, it also meant that I rarely had any background on the person I was talking to and, therefore, did not know the questions that would best bring out their unique knowledge. By nature, I am a relatively quiet person and approaching random people was not easy for me to do, especially given language and cultural differences. Many times I frustrated myself by turning away or 
making an excuse. While this led to missed opportunities, overall the nature of my research was character and confidence building, and ultimately, a great base to overcome some of my shyness and hear what 'real' Koreans had to say.

While the information I learned from interviews forms the specific and legitimising base of my research, I would also like to acknowledge the importance of more general conversations and experiences that I had throughout my stay. Whether with friends, my host-family or just someone I met briefly at a gathering or backpackers, the knowledge gained from these conversations - when people invited me into their spaces - has really come to form the backbone of my current understanding of Korean culture and of my research.

The little things made my experience real and brought me closer to Korea and its people. It changed things for me to hear a friend recall her childhood in the late 1980s when tanks and tear gas filled the streets, or talk of the cousin living in a mental institute as a result of brain damage inflicted by a police beating; or how as a child she asked her mother - "what is it?" - on seeing a Caucasian person at the 1988 Seoul Olympics; to hear another informant speak of dressing up in priest's robes to escape police, and jokingly explaining his arrest in the 1980s for being involved in an 'anti-state organisation' on the basis of owning a copy of The Russian Revolution, before completely changing expression and soberly recalling that he was "beaten like hell" because of this book. It moved me to see protesters get dragged away by police right in front of me and to stand among hundreds of thousands of mourning Koreans at former President Roh Moo-Hyun's funeral. These conversations and experiences, rather than the more academically substantive interviews I carried out, were what truly opened my eyes and made my research feel real and important.

Friends and colleagues not only contributed to more personal understandings of Korea, but were also involved in many of the interviews I carried out. Their involvement brought up a range of benefits and complications. 
I first imagined that I could carry out interviews without using Korean, but in hindsight this was ignorant. The interviews I was able to carry out in Korean, with the help of friends translating, provided knowledge that has become essential to my research. The hardest thing for me about using translators was that doing so took power away from me. What I mean by power here is the ability to control the direction of an interview: what questions are asked, what follow up is made to responses, what kind of background is given. Initially I was relieved to have someone there to take the pressure off me. But, very quickly, translation became a frustrating process. Because my friends were not trained translators they felt uncomfortable in the traditional translation format (ask a question, translate the question, receive answer, translate answer, ask new question, translate question...). Rather, translated interviews tended to be conducted almost entirely in Korean with my friend taking notes, and they would translate afterwards. Therefore, I had to discuss questions beforehand, which felt like I was training friends to do my research for me. This structure meant being included and excluded from conversations at the same time and interviews became disempowering and mentally draining.

I have to always remind myself of the positives. Having any kind of translation at all immediately gave me more access to knowledge. The fact that almost half of the most specific interviews I had were in Korean with a translator meant that this extra knowledge was crucial. While it may have been less frustrating for me to use professional translators, I still feel that my friends were a better option. They knew me, and my intentions and motives. They trusted me and I trusted them, which allowed for much more personable, and therefore meaningful, conversations and interviews. During the discussions that we had about the conversations they were a part of, my friends also offered insights that I may have missed on my own. It was a great feeling to watch my friends talking passionately about the topic I was researching - Korean people do care about their history! 
Also important to my research was keeping a regularly updated diary. Writing about interviews brought on new interpretations that I did not think about at the time. More importantly, writing about my experiences helped me remember them. Most of the reflections within this work and the narratives from my point of view are based on, or appropriated from, diary entries and the memories brought on by these entries. Through a diary I was also able to reflect upon the complications of living in Korean society, and how these complications informed my work.

With my height, pale skin, freckles, blue eyes and red hair I definitely stand out as a 'foreigner' within Korea, which M ichael Breen (2004: $\mathrm{x}$ ) describes as probably the most homogenous place on earth. Being from another country and culture had both advantages and disadvantages. As a foreigner I believe more leniencies were granted to me in terms of following hierarchical and cultural protocols. Often my friends were shocked that I could approach organisations simply by phoning up and working my way through the sections of power. Apart from the obvious disadvantages, such as language and cultural misunderstandings, the main problem with being a foreigner was mental, as I asked myself what right I had to research a topic that really has very little to do with me.

Coming to terms with the 'dressing up' that was required of me in Korea also took some time. An opinion of me could be based upon my business card and whether I was wearing a suit (of course this is the case in some contexts everywhere, but was much more extensive in Korea than I was used to). While not directly related to being from a different country, religious differences also became important issues to consider. I went to church more times in my three months in Korea than in my whole lifetime in New Zealand. As I am not religious, this presented some difficulties, and further requirements to 'dress up.' I do not mean in terms of attending church - I have no problem attending church service generally - but rather, how I interacted with people at church, or when talking about M yeongdong Cathedral. I believe that one of my friends, when helping translate interviews, got into the habit of answering questions about my 
religion with the reply that my grandparents are Catholic (which is true, but ignored the fact that I am not). I think it is safe to assume that many of the Christian Koreans I talked to would have altered their replies based on assumptions about my religious beliefs.

After three months my research was over and I came back to New Zealand. One of the hardest things about coming back was the sense that I, almost immediately, lost the same level of personal association with my research. Thus, one of the concerns I have always tried to pay attention to is attempting to keep a 'foot' in Korea. Writing a thesis is a constant battle to make sure that it does not become a piece of work disassociated from a sense of personal attachment; a fight to, as Ruth Behar (1996: 9) asserts, "bring the ethnographic moment back...to communicate the distance, which too quickly starts to feel like an abyss, between what we saw and heard and our inability, finally to do justice to it in our representations." While it has been hard at times, I feel like I have managed to keep the 'Korean' part of myself intact, and in some ways even built on it. Building on the Korean part of my identity by reading Korean news and blogs, emailing friends and former host-families, and continuing to study the language has also brought a new level of interpretation to my research.

The process of coding my research and interview notes was a frustrating one. Looking beyond the tediousness of the work, the most frustrating aspect was the way that coding de-personalises individual voices. By taking sections of conversations from their context and appropriating them to fit other categories, one loses the narrative that makes these voices so meaningful in the first place. Therefore, keeping a sense of the original context was important. Likewise, where possible I have referenced people by name in order to keep the personal and contextual meaning intact. Of course, I have adhered to ethical guidelines and only used names where the individual gave me permission to do so. Everyone else is given a pseudonym or referenced more generally, in order to keep their confidentiality. I have only quoted people who spoke to me personally in English, given that the interviews carried out in Korean were interpreted 
through a translator. The process of coding was not all negative. Stepping back and reorganising my research notes, ultimately, gave me a fresh perspective and a further chance to reflect on my research and how the various aspects connected together.

My thesis is not a story, but I have tried to weave myself - stories of my own experiences in Korea - into the text throughout. While all of the sections within that are told from my point of view are summaries, amalgamations and expansions of journal notes, they are also interpretations of these notes made months after they were written. Therefore, they are built from my memory, of the events and of the meaning behind the words themselves. Every time I look at my writing I remember it in a different way - the version of events shifts and mutates - and my understanding changes, so these 'stories' are representative of numerous times and states (and spaces) of mind. As in the research I am exploring, any event can have multiple, complex and often conflicting meanings. Therefore, it is crucial to acknowledge that what is written in this thesis is my understanding of the events that unfolded in my three months in Korea, my interpretation of what others told me during that time, and my appropriation of those words in order to create my own interpretation. Tying in my own experiences and stories with those of the people I spoke to has been my way of attempting to break holes in the "fenced boundary between emotion and intellect" inherent within academia (Ruth Behar, 1996: 86). 


\section{Outline of Thesis}

The structure of my thesis took shape relatively quickly after I returned from Korea in June 2009. The core of my writing and of my research in general - and what separates it from other pieces of research - are the two case studies, Myeongdong Cathedral and the docheong, around which my thesis revolves. Chapters Two and Three are descriptions of the situations I encountered during my fieldwork and analysis based on the interviews and conversations I had in the country, as well as scholarship consulted back in New Zealand. I discuss the contestations and conflicts that have arisen at each site, and the groups and individuals that have become involved, due to the privileging of new readings of the past. The comparative chapter that follows consists of my own reflections and judgments regarding the conflicts I witnessed at the docheong and Myeongdong Cathedral, and my attempt to relate this fieldwork to theory and existing literature. Chapter Five acts as an epilogue and has grown out of extra reflections and narratives regarding the contestation over representing particular aspects of the past. This chapter moves beyond my two case study sites, and sets my research within the larger Korean context. I reflect on my experiences as a whole and discuss why the contestation of memory is so resonant in Korea and why I think collective memories of the past will continue to be contested in Korea for a long time to come. 


\section{Chapter Two - Case Study One: The Provincial Hall (docheong) of Jeolla, in Gwangju}

This place is being demolished...all citizens help us protect it, can't you remember the screams and the colour of blood in our province in May 1980?

Leaves fall on Gumnamno like...blood, blood, blood. Protect the 518 Provincial Hall to the end. ${ }^{24}$

The clatter and murmurs from the office space and dining area disappear below, as we walk through the hollow remains of this building that once housed citizens as they prepared for their final stand against a military crackdown during the Gwangju Uprising of May 1980. Floorboards are ripped up, windows are cracked or smashed in, light sockets hang limply from the ceilings, post-it notes are scattered around the walls demanding preservation of the building and, by extension, the memory of the uprising. I have just finished talking to a couple of enthusiastic people from the Gwangju Uprising Bereaved Family (BFA) and Wounded Persons Associations (WPA) and, with the help of two friends who have come along to translate, have asked whether I could take a look around this Gwangju landmark.

The bottom floor of the byeolgwan to the former docheong of South Jeolla has been converted into temporary offices, where volunteers in the 5.18 associations have meetings, make calls, answer emails and update their websites. Tubs of drinking water line the walls, instant coffee packs and plastic cups crowd the desks, and chairs are bunched sporadically throughout this muddled but seemingly ordered space. On the second floor, a presentation has just finished - a group of 300 university students from Gyeonggi Province (in the north-west) have come to Gwangju to learn about 5.18 as part of a 'Gwangju Pilgrimage' (Gwangju seongji sullye) - and people have gathered in the sparse kitchen and eating area. Some of the individuals I run into essentially live

\footnotetext{
${ }^{24} \mathrm{My}$ translation of two pieces of writing hung from the walls of the byeolgwan by protesters from the 5.18 associations (16/04/09). Original Korean:

- Phrase one = Igoteul Cheolgeohandamnida...1980 Nyeon 5 Wol, Gu Pibit Cheolgyureul Ge-eok Hasimnika? I-Je Siminyeorobungeseo Jekyeo Jusipsi-o.

- Phrase Two = Kkot Ipcheorom Geumnamro-e...pi, pi, pi.
} 
here; whether working, eating or sleeping, this building has become the focus of their lives.

As we make our way up the flights of stairs, the reality of the situation becomes clearer. One overly literal English rendering for byeolgwan in Korean dictionaries is 'outhouse, ${ }^{25}$ and in some ways the unintended connotations are almost fitting. The building was left out of plans to construct a new ACC in the area, overshadowed by the more pervasive symbolism of the former docheong building beside it. Now it's a shell, filled with echoing empty space and set for destruction. The main reason the byeolgwan remains standing is the people camped out below. Up on the roof a flag of Korea hangs limply in the still air. Looking down on May 18 Democracy Plaza and towards Geumnamno brings to my mind the dozens of images I have seen commemorating the gatherings, the battles, and the deaths that occurred here. In the other direction there is nothing but dirt and machinery, the remains of this neighbourhood.

The docheong in Gwangju is located at the crossroads of a key intersection on Geumnamno, one of the main arteries in downtown Gwangju. With most of the surrounding buildings demolished the docheong stands out even more than in past images of the area. The building, though, is most well-known as a key site of resistance during the Gwangju Uprising (5.18) and now represents an important symbol in remembering this event. In 2008, construction was begun on an Asian Cultural Center (ACC) in and around the docheong as government officials progressed with plans to promote Gwangju as a hub city of Asian culture.

This chapter draws on the conflict that arose when this construction began to discuss the contestation over the ongoing re-interpretation of 5.18, and its meaning, in Gwangju and Korea. The history of Gwangju, which is associated with marginalisation and protest, has contributed to the creation of a resistant and dissident image of the city. Therefore, I begin the discussion by documenting the historical background of Gwangju, making particular note of the uprising that the city is famous for and the

25 “별관 (別館) [Byeolgwan]): an annex $\square$ to a building $\mathrm{B}$; an extension; an outhouse; an outbuilding” (Naver Korean-English Dictionary, 2009). 
buildings that now symbolise this uprising. I then give an overview of the 'Hub City of Asian Culture' (HCAC) (Asia Munhwa Jungsim Dosi Gwangju) project before describing the conflict that arose over the construction of the ACC, including the groups involved and the concerns they raised. The discussion then turns to the underlying reasons behind the docheong conflict. The contested meaning of the site is illustrative of a larger issue over how to negotiate competing understandings of 5.18 in Gwangju. Rather than the construction of the ACC, the key issue at stake is the impact that re-interpretations of 5.18 have for the city of Gwangju and its citizens.

\section{Memory in Gwangju: City of Darkness versus City of Light}

The Chinese characters that give Gwangju its name literally mean 'city of light.' However, the city has a dark past in which, as a result of consistent neglect by the government, it became the site of many large protests and a resistance movement, and developed a reputation as home to a radical, 'rough-edged' population. Gwangju is most well-known for the uprising there from the $18^{\text {th }}$ to $27^{\text {th }}$ of May 1980. The uprising, 5.18, has become one of the most re-interpreted, contested and debated events in Korean history and is widely cited as an important, if not the most important, moment in South Korea's minjuhwa undong. ${ }^{26}$

The docheong was constructed in 1930 during the Japanese occupation of Korea and is best known as the key rallying point for citizens to organise resistance during 5.18. On the $21^{\text {st }}$ of May 1980, the first mass shooting of Gwangju citizens by paratroopers took place in front of the docheong. Five days later, on the night of the $26^{\text {th }}$, approximately 150 people gathered at the docheong to protect the building from as many as 20,000 new military troops sent in to 're-capture' the city. These 150 people

\footnotetext{
${ }^{26}$ For example, former President Kim Young-Sam (in Choi Jungwoon, 1999: 36) has stated that "blood in Gwangju was fertiliser for this country's democracy" and Mr. Seo, a university professor in Gwangju who asked for confidentiality, has called it the key weapon in the mobilisation for democracy (Pers. Comm. 17/04/09).
} 
made their final stand in the byeolgwan in the early hours of the morning on the $27^{\text {th }}$ of M ay 1980 (Chung Sangyong, Rhyu Simin, et al, 2003: 360 and 366). Official government statements following the event denounced the uprising as a rebellion and, in the following years, Gwangju came to be viewed as a center of resistance, "a city of outlaws - evok[ing] the historical treachery of the periphery against the state" (Linda Lewis 1988b in 2002b: 90). ${ }^{27}$

The image of Gwangju as a city of resistance relates to a history in which the Jeolla provinces are chronicled by annals of dissent (Yea 1999). In the "imagined map" (Yea, 1999: 230) of South Korea's political geography, Jeolla is figured as a deviant, resistant and marginalised space, an image that goes back at least as far as the Donghak (Eastern learning) Peasant Rebellion of 1894-1895, which started in Jeolla. Jeolla's dissident history is closely wedded to its agrarian landscape, or rather that the province remained agrarian while other parts of the country industrialised. Gwangju, and Jeolla in general, largely missed out on the investment and rapid development in other parts of the country during South Korea's economic boom, which occurred from the 1960s on. While cities like Busan, Masan and Pohang, in President Park Chung-Hee's home province of Gyeongsang, in the southwest of Korea, underwent rapid industrial development, Jeolla was largely disregarded. Thus, north and south Jeolla, "were left alone to feed rice to Japan in the colonial period, and they were left alone again as the [Park Chung-Hee] regime poured all kinds of new investment into the southeast [North and South Gyeongsang provinces]" (Cumings, 1999: 21). Therefore, the discursive construction of Jeolla as a resistant space is strongly related to long-held frustration amongst its citizens following decades of marginalisation. Images of Jeolla and Gwangju have changed since Korea democratised after 1987, most notably after 5.18 gained official recognition as a nationally important event in Korea's minjuhwa undong.

\footnotetext{
${ }^{27}$ Accurately counting the number of fatalities attributed to 5.18 is impossible, but estimates have been made. According to Gwangju Metropolitan City data obtained in 1999, 163 died during the turmoil of 5.18 (Na Kahn-Chae, 2008: 712). The HCAC information centre states that 3872 people had harm inflicted on them, which includes not only 166 deaths, but 64 missing and 3642 arrested. Others argue that closer to 2000 people were killed during 5.18 (Katsiaficas, 2003: 263).
} 
However, many of the old stereotypes remain and Gwangju continues to be associated with dissent.

Increasingly, the connotations of dissent have become unacceptable to many residents in the Jeolla region. Therefore, attempts to change the regions image are being made. This is particularly the case in Gwangju, which was the capital of South Jeolla province until 2006, when the provincial headquarters were re-located to Muan, 28 leaving Gwangju's docheong without a use. In the lead up to this relocation, and as early as 1995, plans over how to use the building were discussed. In 2002, as part of his presidential campaign, Roh Moo-Hyun made an assurance that, if elected, he would initiate plans to see Gwangju become a cultural capital. Jeolla citizens were a major source of support for Roh's successful presidential bid, and his assurance materialised in the form of a 'gift' back to the province, not only for their support but also to make up for the ill-treatment and marginalisation that the Jeolla provinces, and Gwangju especially, had experienced in the past.

The HCAC project was initially presented in November 2003, but not until December 2005, after a contest, was the final design for the ACC was chosen. Approval for the final plan was given by the Chairman of the Presidential Committee ${ }^{29}$ in September 2007, and a public announcement regarding the 'Hub City' project was made in October 2007 (HCAC Information Centre, 2009). The HCAC project consists of four phases, begun in 2004 with completion set for 2023 (HCAC DVD, 2008).

The ACC is scheduled to open in May 2012 and is part of a much wider development programme for Gwangju. By the time the final phase is completed in 2023,

\footnotetext{
${ }^{28}$ This lies on the coast to the south-west of Gwangju.

${ }^{29}$ The committee is officially known as the Executive Agency for Culture Cities under the Ministry of Culture and Tourism (M unhwa Gwangwangbu Asia Munhwa Jungsim Dosi Chujindan), but I refer to it as the presidential committee throughout the thesis. The committee was established in March 2004 (HCAC website). Song Gi-So, the first chairman of the committee, supervised the whole process, choosing the design and taking it through the relevant approval processes (Mr. Ryu, a representative of the HCAC project who asked for confidentiality, Pers. Comm. 24/04/09).
} 
Gwangju, as the 'Asia Hub City of Culture,' will be comprised of seven cultural zones. ${ }^{30}$ The ACC is part of the core zone, referred to as the "epicenter" or "cultural power plant" of 'Hub City' (HCAC Information Centre, 2009). 'HCAC - Gwangju' is the single largest cultural project in Korean history and its missions have a cultural focus: establishing the ACC as a production center for cultural contents, developing a culture-based urban environment, promoting the arts and culture/tourism industries and heightening Gwangju's status as a cultural exchange centre (HCAC Information Centre, 2009). More specifically, the ACC is expected to raise individual quality of life, provide economic growth for the Jeolla region, raise national prestige and build relationships throughout Asia and worldwide (HCAC Information Centre, 2009). The goals of HCAC and the ACC are related to the national turn towards 'culture industries,' and more specifically, promoting Gwangju and the Jeolla region as a culture and green economy hub. Further in to this chapter I discuss why the goals of the ACC, and the HCAC project more generally, with their promotion of cultural and tourism industries, conflict with some local understandings of the site and the city. I highlight the turn towards cultural industries by first discussing recent changes in the Gwangju economy.

\section{Gwangju Economy}

Many officials and citizens in Gwangju hope to break away from the image of Jeolla as a peripheral, marginal and radical place. Thus, a primary consideration behind plans for the ACC is the economic boost of improving Gwangju's status as an Asian capital of culture, human rights and democracy. During my fieldwork I attended the annual Gwangju International Peace Forum, ${ }^{31}$ in which a number of academics and organisational representatives from throughout Asia gathered to discuss human rights and democracy in the region. Gwangju itself is recognised as a symbolic model for

\footnotetext{
${ }^{30}$ The overall cost of the 'Hub City' project is estimated at 5.3 trillion won (approximately NZ $\$ 6.6$ billion in 2010). Of this 53 percent will come from national government expenditure, 15 percent from local (Gwangju) government expenditure, and the final 32 percent from "private capital" (HCAC DVD, 2008).

${ }^{31}$ From M ay 15 to May 182009 . Hosted by the M ay 18 M emorial Foundation.
} 
democratisation movements in Asia, and there is also a major human rights award named after the city. ${ }^{32}$ As Jung Keun-Sik states (2000: history-49), 5.18 "showed that democracy was possible in the third world. Especially, its influence is ever increasing among south-eastern Asian democratisation movement groups in Thailand, the Philippines, Myanmar, and Indonesia." Gwangju activists are now also working in solidarity with the likes of the Asian Human Rights Commission in Hong Kong, the Democratic Movement Organisation for Burma, and Human rights groups in Cambodia (Katsiaficas and Na Kahn-Chae, 2003: 157). ${ }^{33}$

In addition to a new focus on international solidarity, Gwangju is emphasising many other aspects of the economy, almost as if the city is rapidly trying to catch-up on decades of neglect. The city is strengthening its status as a center for industrial production and export, with a focus on three leading industries: LED, autos, and electronics, as part of a future-oriented economic outlook, and large corporations like Samsung Electronics and KIA Motors have now set up factories in the city (Gwangju M etropolitan City website). Many of the city's universities, such as J eonnam University, Joseon University and Gwangju University, have developed strong national reputations and attract students from around the country. More importantly, in terms of the reputation of the city nationally and globally, the economic expansion of Gwangju in recent years has been dominated by two streams of development, one made up of large-scale cultural events and the infrastructure that holds these events, and the other, constructions and events related to conveying particular memories of 5.18.

Examples of cultural events and infrastructure include the Gwangju Biennale, Gwangju Kimchi Cultural Festival (Gwangju kimchi munhwa chukje), the Jeongyulseong

\footnotetext{
${ }^{32}$ The 'Gwangju Prize for Human Rights.' It has a reputation as almost being like an Asian Nobel Peace Prize.

${ }^{33}$ Every year Gwangju also hosts an Asian Human Rights Folk School. According to the 5.18 Memorial Foundation, in 2009 there were representatives of 21 different organisations in attendance. These ranging from Tuul Sleng Suicide Museum in Cambodia, to the Pirbhat Women's Development Society Sindh in Pakistan, Taiwan Truth and Reconciliation Association, National Protection and Durable Solutions for Internally Displaced Persons Project within the Human Rights Commission of Sri Lanka, United Nations Assistance M ission in Afghanistan (UNAM A), and the Youth Initiative in Nepal.
} 
Music Festival (Gwangju Jeongyulseong Gukje Eumakje), and the Kim Dae-Jung Convention Center. Currently a nationwide campaign is trying to promote unique aspects of Korean culture: hangeul (the Korean alphabet), hansik (traditional food), hanbok (traditional clothing), hanok (traditional housing) and hanji (traditional paper) (Korean Tourism Organisation (KTO) website, 2009). The national campaign has a regional bent, and associates different regions and cities with given aspects of the national culture in order to build distinctive local identities. The cultural events in Gwangju are part of the rise of this 'culture industry' in Korea and Jeolla's new status as the culture and green economy hub of Korea.

The first major construction built to memorialise 5.18 was the 5.18 National Cemetery in Mangwol-dong, which opened in May 1997..$^{34}$ The cemetery was created to recover the honour of the people affected by 5.18 , as explicitly desired by a number of associations set up to protect the memory of $5.18 .{ }^{35}$ Approximately 550 people are currently buried in the cemetery (see Figure 2 on page 42), which is now considered "a democratic sacred ground for human rights activists" (HCAC information centre). More recent developments related to memorialising 5.18 include the 5.18 Liberty Park $^{36}$ and the 5.18 Memorial Park and Culture Center (see Figure 3 on page 42). A 'pilgrimage' of all 26 'important' 5.18 sites, from Jeonnam University to the 'old' 5.18 Cemetery at Mangwol-dong, is also possible and these sites can all be visited on a 5.18 bus.

\footnotetext{
${ }^{34}$ And was officially recognised by the government as a national cemetery in 2002.

${ }^{35}$ See page 46 for a description of these associations.

${ }^{36}$ At the site of Sangmudae, a former court and prison, in which those arrested during 5.18 were held.
} 


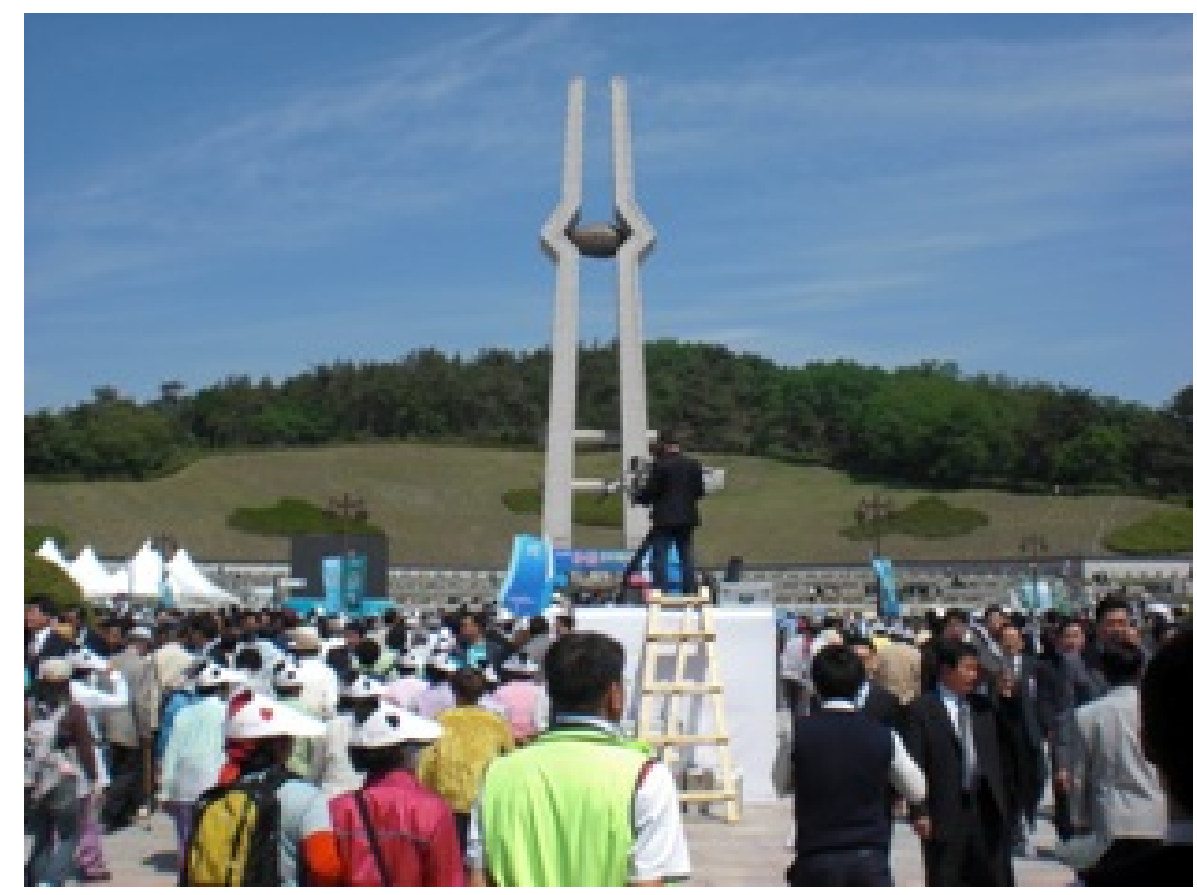

Figure 2: 5.18 National Cemetery during 5.18 anniversary commemorations, Gwangju (Photo: Thomas Vink, 18/ 05/09).

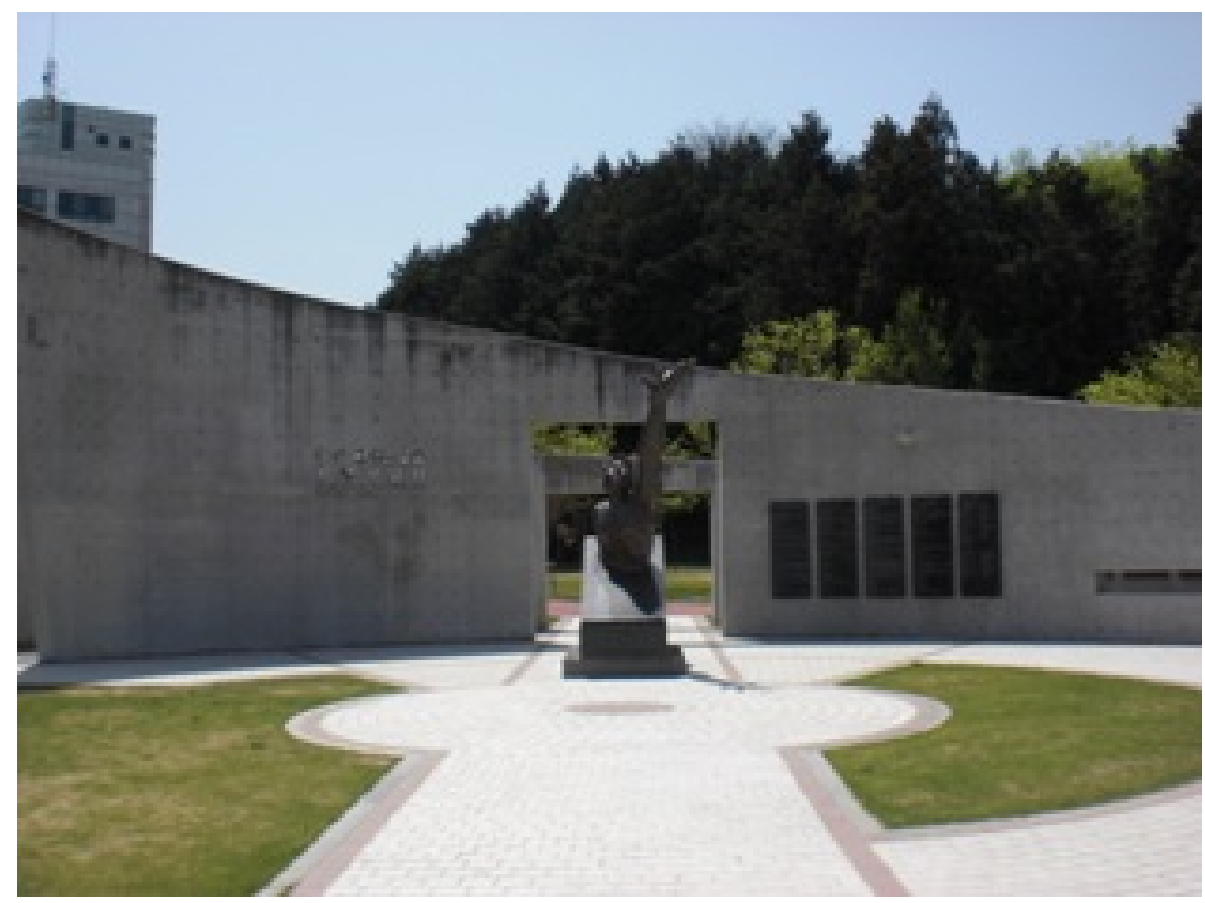

Figure 3: 5.18 Memorial Park and Culture Center. Gwangju (Photo: Thomas Vink, 18/04/09). 
The Korean term for Gwangju pilgrimage - Gwangju seongji sunrye ${ }^{37}$ - is interesting to explore, especially when contrasted with the material that promotes the pilgrimage itself. One of the implications of the term seongji is sacred place, ${ }^{38}$ which indicates that Gwangju is, in some sense at least, considered a sacred space because of its importance to the achievement of democracy in Korea. The 5.18 pilgrimage is widely promoted in various tourist materials published by Gwangju Metropolitan City and the M ay $18 \mathrm{M}$ emorial Foundation. The 5.18 sites are represented by either the 5.18 mascot, Nuxee, in the Gwangju City materials, or cartoon images of burning buses, bandanawearing demonstrators and faceless riot police in the Memorial Foundation materials. The connotations of Gwangju as a sacred space appear to contrast with the images portrayed by the promotion material, which is a combination of comic relief and tourist information.

Likewise, the sites constructed in relation to the memory of 5.18 also offer "sanitised" readings of the event (cf. Funder, 2003: 276. See also Klein, 2000; Kundera, 1984; Yea, 2002). As a collection of monumental constructions, wide concrete walkways, emotion-charged photo exhibits and video displays, the 5.18 National Cemetery resembles an open-air museum dedicated to 5.18 more than a cemetery. In its original conception, $5.18 \mathrm{M}$ emorial Park and Cultural Center was even presented as a theme park: "May 18 Memorial Park and Theme Park" (Yea, 2002: 1559). Linda Lewis also notes a touristic emphasis, or "disneyfication," (cf. Yea, 2002; Richter, 1999) of 5.18, when she states (2002a: 165-166) that "the twentieth anniversary [of 5.18] saw the introduction of a cute cartoon 5.18 mascot, Nuxee, whose visage graces T-shirts, post-cards, ballpoint pens and other souvenir items available for sale in the May 18 Cemetery gift shop."

Many Gwangju citizens have termed the recent proliferation of memorials and

\footnotetext{
${ }^{37}$ A phrase that I first heard when Gang Gu-Yeong of the 5.18 Wounded Persons Association used it, but which is also seen in official material released by Gwangju Metropolitan City and the May 18 Memorial Foundation.

${ }^{38}$ 성지 (聖地) [seongji] shrine, sacred place, the Holy Land (Naver Korean-English Dictionary, 2009).
} 
parks dedicated to 5.18 a "memorial industry" (ginyeom sa-eop) (Yea, 2002: 1559). However, the collective understandings of 5.18 in the city are increasingly influenced by the promotion of Gwangju as a cultural capital. The desire to promote new images of Gwangju over the memory of its tragic history is part of an increasingly widespread view that, "Gwangju cannot sustain itself on memorialising 5.18" (Mr. Seo, Pers. Comm. 17/04/09). Individuals, like Mr. Seo, a university professor in Gwangju who asked for confidentiality, see a need to break away from the 5.18 image in order to create a new sense of place within the city. Catharine Hodgkin and Susannah Radstone claim (2003: 7) that "to emphasise memory over history, perversely enough, can mean to remain past rather than future-oriented." That the memorialisation of 5.18 in Gwangju has been termed an industry in itself indicates the influence that the event continues to hold on the city. Nevertheless, the association of Gwangju with 5.18 is a key reason behind the continuing image of Jeolla as a peripheral and marginal place. Therefore, the promotion of new images of the city could act as a way of moving on from the past.

The Gwangju Biennale is an example of the conflict over emphasising new images in the city. The Biennale is a cultural event first organised in 1995, 50 years after independence from Japan, "to uplift the cultural value of the Gwangju spirit" (HCAC Information Centre, 2009). Park Hae-Gwang, a professor of Cultural Sociology at Jeonnam University, claims that most people in Gwangju and Korea do not care about the Biennale because it does not relate to 5.18 and, thus, according to Park, the Biennale has failed to build a new image of Gwangju. However, to many others, the Biennale is considered a major success, and the event attracts large numbers of people. According to Matthew Kelley (2008), the organisers of the Biennale say that Gwangju's "tragic past" is an inspiration for their work today ${ }^{39}$ and Anna Schneider claims (2009) that the Biennale is actually a more democratic space than a museum because it offers a way to engage in the production of cultural value. The Biennale is recognised in Asia and

\footnotetext{
${ }^{39}$ The Biennale also "linked its founding myth to the...May 18 uprising" (Schneider, 2009) and "was founded to commemorate and honor the uprisings that led to the democratisation of South Korea" (Gioni, 2009).
} 
worldwide as a leading global art exhibition and as the largest art event in Korea (Hoffmann, 2000; HCAC Website, 2008). Thus, the success of cultural events like the Biennale is subjective to an individual sense of what the memory of 5.18 means. The use of seongji in discussions of Gwangju suggests that there are many individuals within the city who think of 5.18 , and the buildings and landscapes that now represent its memory, as sacred. Therefore, a major conflict exists in Gwangju over breaking away from the image of the city as a resistant and marginalised space through cultural events like the Biennale, and maintaining the connection to 5.18 that, to so many citizens in Gwangju, represents a key aspect of their identities.

The National 5.18 Cemetery, which sought to create a national narrative of 5.18, is another example of the conflict over which collective understandings of 5.18 are given prominence. The old cemetery for the 5.18 victims was a space that enabled the ongoing connection between history, memory and resistance to be realised by Gwangju citizens (Yea, 2002: 1570). M any local groups expressed concern that the new cemetery would relegate the memory of 5.18 victims to history and marginalise the individual meaning taken from the event in the name of national commemoration. With the HCAC project now emphasising international connotations, the implications the docheong holds as a sacred historical space are also potentially being overtaken. The conflict at the docheong is yet another contest over how to represent collective understandings of 5.18 in Gwangju. 


\section{The Conflict}

Out of concern for the memory of 5.18 and its victims, in the years following the event, three associations (sadan beobin) developed ${ }^{40}$ : the Minju Yugongja Yujoghoe or 'Bereaved Family Association' (BFA) ${ }^{41}$; the M injuhwa Undong Busangjahoe or 'Wounded Persons Association' (WPA)42; and the Yugongja Dongjehoe or 'Detainees Association' (DTA). ${ }^{43}$ Broadly speaking, the three 5.18 associations have five main goals ${ }^{44}$ : the search for the truth behind 5.18, the punishment of the people responsible for 5.18 , to obtain compensation and/or reparation for the people affected by 5.18 , the recovery of honour for those affected by 5.18, and the memorialisation of 5.18 .

According to Kim Byeong-In, a History Professor at Jeonnam University in Gwangju, the first three goals have been accomplished through the creation of a special law $^{45}$ that allowed for the prosecution of those responsible for 5.18 ; the fourth goal, the recovery of honour, was brought about through the construction of the 5.18 National Cemetery at Mangwol-dong; and the fifth goal, memorialisation, is said to be represented through the docheong. ${ }^{46}$ However, with the new plans to build the ACC, the

\footnotetext{
${ }^{40}$ The English translations of the association names were made by Na Kahn Chae, 2008.

${ }^{41}$ Established on the $31^{\text {st }}$ of May 1980 (Lewis, 2002: 112). Family members or descendants of those who died between the $18^{\text {th }}$ and $28^{\text {th }}$ of May 1980, are eligible for membership (Na Kahn-Chae, 2008: 712).

${ }^{42}$ Established on the $13^{\text {th }}$ of June 1982 (Lewis, 2002: 126). Membership is limited to one representative from the immediate family of a person who was wounded or died during treatment received as a result of 5.18 (Na Kahn-Chae, 2008: 718).

${ }^{43}$ No official establishment date. In September 1980, gatherings amongst family members began in relation to trials for those imprisoned as a result of 5.18. Over time these meetings became official ( $\mathrm{Na}$ Kahn-Chae, 2008: 722). Those detained during 5.18, and their family members, are eligible for membership (Na Kahn-Chae, 2008: 721).

${ }^{44}$ According to Kim Byeong-In, Pers. Comm. 25/05/09.

${ }^{45}$ 'Special Act on the May 18 Democratisation Movement,' first passed on the $21^{\text {st }}$ of December 1995 , with various amendments made since. This act prescribed prosecution rights against those who committed criminal conduct around 5.18, provided guidelines for the payment and honorable treatment of those affected by 5.18, and provided guidelines for how the government could promote commemorative projects (May 18 Memorial Foundation, A Complete Collection of the Korea Laws and Regulations Concerning the M ay 18 Democratic Uprising, 2007).

${ }^{46}$ Pers. Comm. 25/05/09.
} 
5.18 associations have expressed concerns over whether the ACC can appropriately represent the memory of 5.18 (See Figures 4 and 5 on pages 48 and 49 respectively for images of the docheong and the planned ACC).

On the $24^{\text {th }}$ of June 2008 , the 5.18 DTA initiated a protest over the need to demolish the byeolgwan. The major argument made by protestors was that demolishing the byeolgwan will reduce the symbolism of the site and diminish memories of 5.18 and the family members who died there. By the $17^{\text {th }}$ of February 2009, the DTA had been persuaded to give up their protest. However, at this time the other two 5.18 associations, the BFA and WPA, had already moved in, stating that they would not leave until plans were changed so that the byeolgwan would be preserved. Thus began a stalemate.

From the information I gathered, there are two main reasons (openly spoken of) why the government was reluctant to change plans for the ACC despite the protest: increased cost and a matter of principle, as the plans had been agreed on by all parties involved previously. According to Mr. Ryu, a representative of the HCAC project who requested confidentiality, the committee would have had to fundamentally change the architectural design of the complex in order to preserve the building. ${ }^{47}$ Furthermore, changing the plans to conform to the demands of protesters would have cost around 20 billion won ${ }^{48}$ and delayed construction up to a year. Mr. Ryu also claims that the plans for the ACC had been decided upon in 2005, and that the winning design was shown throughout the city and then went through a series of open and democratic approval processes. Most importantly, he asserts that the 5.18 associations agreed that the plans could go ahead. Mr. Ryu claims that the presidents of the 5.18 associations attended a meeting three years before the protests started, in which the demolition of the byeolgwan was discussed. I later obtained a copy of the evidence Mr. Ryu had talked

\footnotetext{
${ }^{47}$ Pers. Comm. 24/04/09.

${ }^{48}$ Approximately NZ\$25 million in 2010.
} 
about, a Ministry of Culture, Sport and Tourism document that shows that the presidents of all three 5.18 associations attended a meeting on the $18^{\text {th }}$ of June 2005 , in which plans for the ACC - which showed that the byeolgwan would not be preserved were discussed. As one source who asked to remain confidential reasonably posits, it is hard to believe that the Ministry of Culture would make documents like these up.

However, Gang Gu-Yeong, the WPA Director of Policy and Planning (Jeongchaek Gihoek Gukjang), stated (Pers. Comm. 20/05/09) that the bereaved families and wounded persons had not been told about the demolition of the byeolgwan and that the plans had been made without them. Gang also denied that changing the ACC plans would be as time-consuming and expensive as Mr. Ryu had made out. The WPA obtained a professional estimate, which, according to Gang, claims that the costs and delays would be significantly less than suggested by the government.

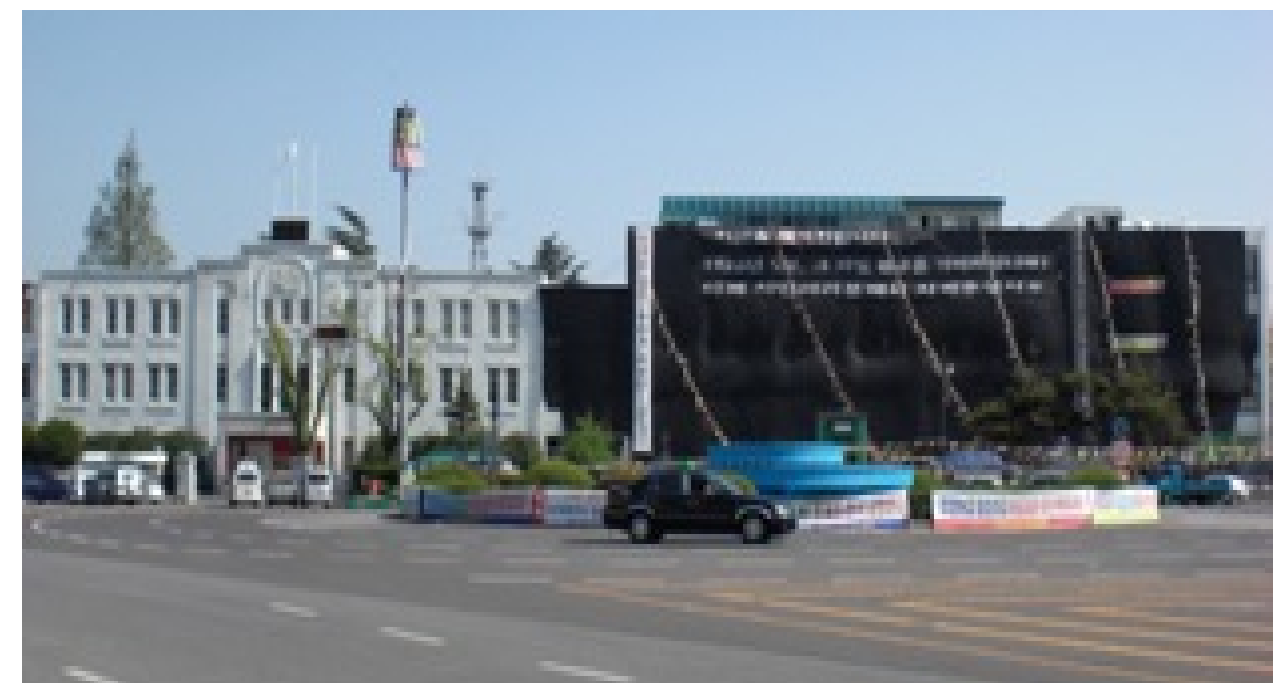

Figure 4: The docheong (left) and the byeolgwan (right, covered in protest banners). In the foreground is 5.18 Democratic Plaza. Gwangju (Photo: Thomas Vink, 17/04/09). 


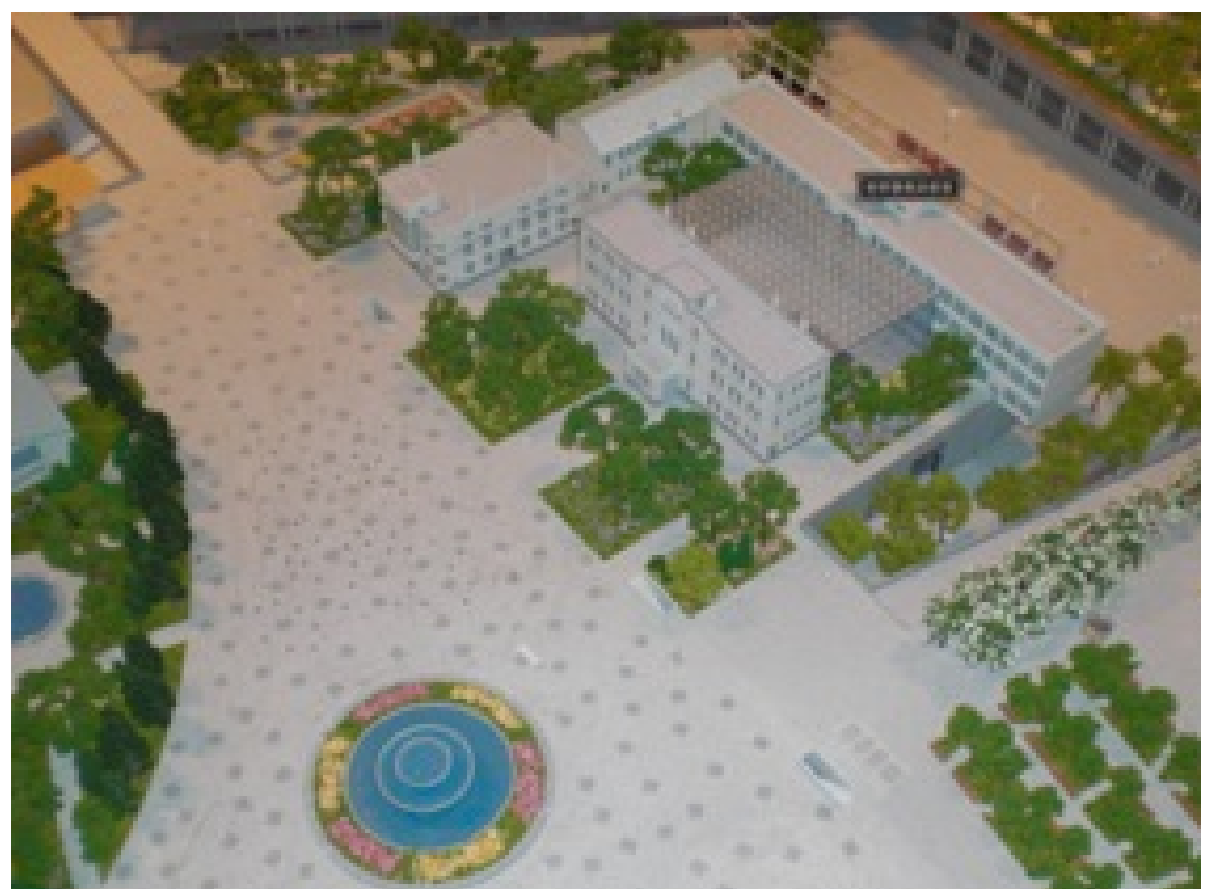

Figure 5: Model of the completed Asian Cultural Center, with the byeolgwan removed. HCAC Information Centre. Gwangju (Photo: Thomas Vink, 19/05/09).

As the conflict grew, more and more academics became involved in the issue. In mid-April 2009, 19 professors at Jeonnam University signed a petition to save the byeolgwan. Nonetheless, Mr. Ryu (Pers. Comm. 24/04/09) claims that, as with the 5.18 associations, a number of these professors had stated in 1995 that it was not important to keep the byeolgwan in future developments in the docheong area. Mr. Ryu saw the added interest in the ACC issue on their part as an appropriation of the memory of 5.18, and claimed that both academia and the 5.18 associations were utilising the issue to attack government policy in general. The conflict over the ACC became a struggle for hegemony as the 5.18 associations hold quite a lot of power. However, Mr. Ryu claimed that there is evidence that the relationships between and within the 5.18 groups are not good and that they are working under 'impure' motives. 


\section{Impurity and Fatigue}

Mr. Bae, an organisational representative in Gwangju who asked for confidentiality, asserts (Pers. Comm. 21/05/09) that the 5.18 associations are not 'pure,' by which he means that many in the associations are motivated by a desire for profit and material gains. Mr. Bae also claims that the 5.18 groups are never satisfied and always looking to make the most of new situations surrounding 5.18. As an example he cited the case of Sangmudae, a former prison, which held detained citizens during 5.18. In 2007, the government wanted to build an education center there, but the DTA demonstrated and prevented it, arguing that their association should have a greater say in how the center was built and operated. When the $5.18 \mathrm{M}$ emorial Foundation building opened in 2001, two busloads of people from various 5.18 associations came and demanded that the profits made from the vending machines at the site go to their associations (Mr. Bae, Pers. Comm. 21/05/09). Mr. Bae believes that the conflicts will keep continuing, even after the complex is built, because the associations have political heft and "are hungry for money all the time." Likewise, Father Na Seung-Gu, a priest at Sinwol-dong Cathedral in Seoul and a member of the Catholic Priests Association for Justice (CPAJ), states (Pers. Comm. 02/06/09) that money is the most important issue with the docheong, and Kim Byeong-In similarly claims (Pers. Comm. 25/04/09) that the 5.18 associations focus on getting repayments from the government.

In 2002, Linda Lewis argued that by the late 1990s most Gwangju citizens believed that the 5.18 associations had benefited sufficiently from the government and that further demands were seen as self-serving and greedy; what separates the various 5.18 associations from each other (including other organisations like the May 18 Memorial Foundation), is self-interest. Yet, the 5.18 associations appear to have grown in status, achieving greater power, in recent years. Mr. Bae alleges (Pers. Comm. $21 / 05 / 09$ ) that if these groups already had a similar level of influence back in 1997, when issues surrounding the 5.18 National Cemetery were being debated, the situation may have turned out differently. However, according to Lewis (2002b) and Yea (2002), 
the key activists behind the construction of the new cemetery were bereaved family members who believed that the old cemetery, small and hidden away from sight, did not show appropriate honour to their dead family members. Thus, the construction of the monumental new 5.18 National Cemetery was a success for the BFA, as it recognised the 5.18 dead as national heroes and ironically, according to Lewis (2002b: 122), precluded any further demands. If the BFA already achieved their demands in 1997, and if, as Lewis argues, the public sympathy for the 5.18 associations had run its course, then questions need to be asked here: If public sympathy is over, where is their power coming from? What is the motivation for the continued demands from these associations?

The growing influence of the 5.18 associations clearly follows a few key developments within Korean society. As Korea has democratised, some memories of past events that were suppressed from general knowledge at the time have become mainstreamed and commodified. 5.18, as an event and as a movement, has become generally accepted as an important part of Korea's past, rather than the mere incident it was presented to be by government-controlled media at the time. M oreover, from 1998 to the end of 2007, South Korea had two relatively progressive presidents, Kim Dae-Jung and Roh Moo-Hyun, who fostered an improved relationship between civil society and the government. Kim Dae-Jung was the first elected President to have strong support from the student-protest generation of the 1980s (the ' 386 generation' 49 ). Even more so, the election of liberal-minded Roh M oo-Hyun - a former human rights lawyer - in 2002 was seen as a triumph for the 386 generation, and for the first time Korea had a "leftist government" (Lankov, 2008). Roh's administration became the youngest in Korean history with many of the 386 generation also represented on his staff (Lee, 2003). The democratic ideals that were espoused so strongly during demonstrations in the 1980s finally became part of mainstream politics and, during Kim's and Roh's presidencies, it

\footnotetext{
${ }^{49}$ The "386 generation" (sam-pal-yuk sedae) was first termed in the 1990s and referred to those in their 30 s (hence the ' 3 ') who were starting to come into positions of power within Korean society, who had attended University in the 1980s (hence the ' 8 ') and were born in the 1960s (hence the ' 6 ').
} 
became politically correct to pay attention to events related to commemorating the minjuhwa undong. The recent progressions in Korean politics and society have given groups like the 5.18 associations in Gwangju, credibility and power that they did not have even as recently as 1997, when 5.18 National Cemetery was constructed.

Many now feel, however, that the 5.18 associations are using their new power for gains not necessarily related to their five professed goals. ${ }^{50} \mathrm{Kim}$ Byeong-In (Pers. Comm. 27/05/09) states that the relationships between and within the associations are strained, and Mr. Seo, a university professor in Gwangju who asked for confidentiality, concurs, adding (Pers. Comm. 17/04/09) that the "activists are having problems in their internal leadership." The DTA is perhaps the best example of these problems. They started the protests at the docheong, and "dragged" the other two 5.18 associations into it (M r. Bae, Pers. Comm. 21/05/09). When the government offered them the rights to manage the docheong within the ACC and to make a profit from it, the DTA became satisfied enough to leave.

Gang Gu-Yeong, though, believes that, to the 5.18 associations, the meaning of the byeolgwan is greater than money; indeed, it overwhelms money. Gang claims (Pers. Comm. 20/05/09) that there are eight key places within the docheong area related to the symbolic representation of 5.18, including the byeolgwan. Whereas the docheong itself was where key decisions were made by Gwangju citizens during 5.18, the byeolgwan was where they lived and fought. Gang maintains that Koreans need to remember this history, to remember the people who were arrested and killed there. He believes that thought should be given to the value of the byeolgwan and the symbolism that will be lost with it.

A good metaphor to represent Gang's claims is the idea of "historical layers," a thought that Kim Byeong-In, a history professor at Jeonnam University in Gwangju, mentioned when I interviewed him on the $25^{\text {th }}$ of May 2009. According to Kim there are three symbols represented through the docheong and its surrounding buildings. One is anti-authoritarianism: the docheong is a symbol of democracy and the fight against ${ }^{50}$ See p. 46. 
authority. Another symbol is community: the companionship and collective identity built amongst Gwangju citizens during 5.18. Finally, the docheong is a symbol of those who died in Gwangju during 5.18. At the time of the uprising the docheong became a site of resistance. Following 5.18, and up until 1983, no memorials for 5.18 were allowed and not until after democratisation in 1987 did memorial ceremonies become official events. Thus, from 1980 to 1987, the docheong was an outlawed space. In more recent years, the docheong has, however, primarily represented a memorial space. Now, with the construction of the ACC, the 'Gwangju spirit' is being kept alive through new ways of memorialising and commemorating (Kim Byeong-In, Pers. Comm. 25/05/09).

To Kim, the changing image of the docheong over time, and the three symbolic meanings it now embodies, represent its historical layers. While the docheong is always seen as a key symbol - the most pervasive symbol of 5.18 - to some, demolishing the byeolgwan, too, is seen as a form of reconfiguring the symbolism of the site and thus detracting from the area's historical layers. Sheila Jager and Kim Ji-Yul argue (2007) that the Korean War museum in Seoul places the Korean War within a larger narrative that marginalises the event's actual brutality. I believe the 5.18 associations too, are genuinely concerned that the ACC will act in the same way. Thus, 'monumentalising' 5.18 by getting rid of real sites of memory, like the byeolgwan, and replacing them with alternate but more sterile memorialising institutions like the ACC could sanitise the memory of what actually occurred during 5.18 or even cause it to be forgotten (cf. Funder, 2003: 276; Huyssen, 1996: 199; M usil, 1986: 320).

Despite the claims of the 5.18 associations being backed up by arguments in the literature, a question still needs to be asked of whether they are actually damaging the memory of 5.18 through their continued appropriation of the event. For example, I believe that the constant interference of the 5.18 associations in memorialising activities and developments has at least partly contributed to 5.18 fatigue in Gwangju and throughout the country. A number of the people I interviewed (Park Hae-Gwang, Lee Seong-Hun, M r. Ryu, Mr. Seo, M r. Bae) as well as academics like Linda Lewis (2002a: 
168) have mentioned a weariness or fatigue toward 5.18 felt by many Gwangju citizens and, thus, a growing will to de-politicise, or potentially remove, the influence of 5.18 in Gwangju. Getting rid of the byeolgwan, and diminishing the role of the docheong, is, in their eyes, a step along the road to moving beyond 5.18.

Regionalism has also contributed to the growing fatigue related to 5.18. Although HCAC is the biggest government-funded cultural project in Korean history, few outside Gwangju know about it, let alone the conflict surrounding the construction of the ACC. Jung Hae-Gu, a Political Science professor at Seongkonghoe University in Seoul, went so far as to assert (Pers. Comm. 13/05/09) that almost nobody in Seoul knows anything about it and that it is an issue purely of interest in Gwangju, while Mr. Ryu, exhibiting considerable frustration, told me (Pers. Comm. 24/04/09) the "rest of the country don't care...don't give a damn." Despite recent efforts to change the way Gwangju is depicted, the lack of interest in the ACC outside of the city suggests that some of the old stereotypes regarding Gwangju as a dissident and marginal place remain. Gwangju is the sixth most populous ${ }^{51}$ city in Korea and yet, amongst some Gwangju citizens, feelings of neglect remain, giving some individuals, I believe, even more reason to be weary of the continued appropriation of 5.18.

The combination of conflict and fatigue over the commemoration of 5.18 in Gwangju, and the general apathy throughout the rest of the country, means that coming to an agreement has been a process that swings between vitriolic disputes and studied silence and, therefore, a process lacking in progression towards a settlement: "immobilism [sic] pervades over Gwangju" (Mr. Seo, Pers. Comm. 17/04/09). Kim Byeong-In claims (Pers. Comm. 25/05/09) that money and time are not important, for if the ACC is built, it will be a lasting institution with enormous potential to invigorate the economy. Whether or not the byeolgwan itself is demolished, ultimately, is not the most important issue. More important is the way given understandings of 5.18 are

${ }^{51} 1.42$ million people in 2007 (Gwangju Metropolitan City website). Behind Seoul, Busan, Daegu, Incheon and Daejeon. 
represented (Park Hae-Gwang, Pers. Comm. 27/05/09), and the symbolism of the building itself, the principles involved in deciding whether it will be preserved, and who has a say in determining such issues.

\section{Symbolism: What's In a Name?}

Great importance rests in the words that name a place or an event. Korea is currently emphasising the creation of 'Hubs' and 'Meccas' in conjunction with the increasing prominence of 'culture industries' locally. The link between culture and naming has particular significance for building a specific cultural identity for a given site. Thus Gwangju, for example, is being referred to as the 'Hub City of Culture' and a 'Mecca of Democracy and Human Rights.' Naming is also an important indicator of the issues involved in the construction of the ACC.

In the days and months following 5.18, the government denounced the uprising as a rebellion or a political conspiracy led by then dissident, Kim Dae-Jung, and regulated the press to prevent it from mentioning the truth about what happened in Gwangju (Chung Sangyong, Rhyu Simin, et al, 2003). Many activists, in Korea and globally, offered alternate readings, and the event became widely known as the Gwangju Uprising or Massacre. However, it was not until years later, following the achievement of democracy in the country, that 5.18 became officially recognised by the government. More recently, official interpretations have removed the name of the city itself and refer to 5.18 as the '5.18 Democratisation Movement.' These interpretations do rather "drain the blood from the event" (Lewis, 2002: 82). However, this naming recognises 5.18 as a mass political action rather than a mere incident and it also implies more nationalistic relevance, rather than the regional or local focus the "Gwangju..." implies. The national focus is also evident within sites of memory in Gwangju: 5.18 National Cemetery, 5.18 Liberty Park and 5.18 Memorial Park, for example. A common point within these names is the reference to 5.18 , to the Gwangju Uprising, but without the Gwangju focus. Regional division hindered the immediate recognition of the truth behind 5.18, with the event reduced to a regional issue by the government (Jung, 2003: 
420). Thus, the new naming of the event, with its nationalising implications, suggests an attempt to overcome the issue of regionalism in Korea, and the historical marginalisation of the Jeolla region.

While the names of the new developments related to 5.18 memory are all "bloodless," to quote Lewis again, at least they clearly evoke the memory of 5.18. However, where is 5.18 or May 18 in the names associated with the ACC and HCAC project? The name, Asia M unhwa Jeondang (literally, Asia Cultural Hall), is already up on road signs and has been given to the closest subway stop, giving the impression that the docheong is already history, and potentially (cf. Funder, 2003, 2009), on its way to being forgotten.

\section{Contradictions and M isunderstandings: The Bigger Picture}

Contradictions and disagreements pervaded the discussions I had regarding the construction of the ACC. Much of the conflict has been about one group disproving the other and vice versa. In fact each side has produced books to back up their competing arguments. ${ }^{52}$ Some claim (Gang Gu Yeong, Pers. Comm. 20/05/09; Kim Byeong-In, Pers. Comm. 25/05/09) that consensus conveyed that the docheong and its surrounding buildings were always to be preserved. Others (Mr. Ryu, Pers. Comm. 24/04/09; Mr. Bae, Pers. Comm. 21/05/09) believe that as early as 1995 the consensus was that the byeolgwan, and a number of other buildings in the area, could be demolished. Park HaeGwang, an assistant professor of Cultural Sociology at Jeonnam University, believes that the ACC plans introduced when Roh Moo-Hyun became president, did not make it explicit that the byeolgwan would be torn down. The general population of Gwangju has

\footnotetext{
52 In November 2008, the Ministry of Culture and Tourism released 'Asia Munhwa Jeondangeuro Saeropgetaeo Naneun Gu) Docheong Byeolgwan Chujingyeonggwa Bogoseo' (Report for the Asia Cultural Center on the ongoing progress with bringing forth evidence on the Provincial Hall annex building). Then, in April 2009, the WPA and BFA jointly published '5.18 Minjuhwa Undong Sajeokji Yet Jeonnam Docheong Byeolgwan Cheolgeo Gyeoljeong Gwajeongui Jaengjeomgwa Jinsil' (Bringing the truth and disputing the decision-making process regarding the demolition of the Jeonnam Provincial Hall annex building and the achievements of the 5.18 democracy movement). (Note: my translations).
} 
been, for the most part, left out of discussions (Park Hae-Gwang, Pers. Comm. 27/05/09).

The general consensus within Gwangju is that the ACC should be built and that it will benefit the city. Nonetheless, Park Hae-Gwang claims (Pers. Comm. 27/05/09) that most people do not know about the proper plans and simply view the docheong as a symbol. However, a wealth of information is available about what the ACC entails. I got the impression that most people were unaware that a HCAC information centre is located across the road from the docheong on Geumnamno. Disseminating HCAC information more transparently would resolve many issues.

The plans for the ACC were made by artists [architects], who wanted to create an aesthetically pleasing structure: "enlightenment in this old city" (Park Hae-Gwang, Pers. Comm. 27/05/09). Park believes, however, that an artistic emphasis is not necessarily a good way to represent a given understanding of the past. Other groups in Gwangju, including the 5.18 associations, and many general citizens, are also of the opinion that the ACC cannot properly represent 5.18 , because its design ignores the docheong's symbolism, its historical layers. However, the bigger story behind the construction of the ACC is worth noting. While the majority of the area surrounding the docheong has been demolished and cleared, the intention was always that the main building of the docheong be left as a memorial space because of its symbolism (Kim Byeong-In, Pers. Comm. 25/05/09). According to a HCAC DVD (2008), the ACC is designed to remember the spirit of 5.18 and the meaning behind Gwangju's history. One only need look at comments made by architect Kyu Sung-Woo, who designed the ACC plans, to see that he indeed understood the meaning and symbolism inherent in this historic area:

"the overarching concept behind my design was the memory of the May 18 Democratic Uprising. Since the very site, to begin with, is associated with the great historical event, I first and foremost thought of ways to conjure up such memories in the mind of visitors... had to grapple with ways to preserve and 
revive the dear memories of the site where the May 18 Democratic Uprising took place." ${ }^{53}$

The docheong, and other historical sites for that matter, are imbued with 'layers of history,' symbols that hold varying and often contested levels of meaning. The comments above indicate that the designers behind the ACC did at least consider symbolic and representative issues related to 5.18. However, while the docheong and the byeolgwan do offer a clear symbol of the past, and help in remembering 5.18, bigger issues are at stake in representing 5.18 than the buildings that symbolise it. The docheong and byeolgwan, as they stand, do not offer much more than symbols of 5.18, even if that symbolism is affecting and important. Conversely, by providing a space for people to learn about and debate the past, the ACC has the potential to do a better job of representing multiple interpretations of 5.18, and the event's importance to many Gwangju citizens, than the docheong. An unanswered question now, given the state of conflict, is whether the ACC will be able to bring about this desired result.

\section{Conclusion}

The city of Gwangju has a history of marginalisation and is associated with resistance and dissent, most notably because of 5.18. To Gwangju's citizens, 5.18 (both the memories of it and the event itself), was essential to building a sense of collective identity in the city. More recently, however, as the potential national and international importance of 5.18 was recognised, collective memories of the event have been appropriated, creating contestation and conflict over which narratives of 5.18 are given more importance. In this chapter, I have discussed the recent conflict over the construction of an Asian Cultural Center in Gwangju. The protests made by 5.18 associations against the destruction of the byeolgwan, a building with important symbolic resonance, are representative of a wider fear that the new emphasis on the

\footnotetext{
${ }^{53}$ Kyu Sung-Woo is an architect of Korean descent, who lives and works from offices in Cambridge, Massachusetts, in the United States. He was previously responsible for the Olympic Village at the 1988 Seoul Olympic Games (M inistry of Culture and Tourism, HCAC Website)
} 
city as an Asian hub of culture, democracy and human rights, will marginalise the meaning that 5.18 holds to local citizens.

Many of the images of Gwangju as a resistant and marginalised place remain. The importance that 5.18 holds to the city is seen by many as a key reason behind the persistence of these images. Thus, an increasing number of Gwangju citizens have a desire to remold the city's image. Yet, while maintaining the relevance of 5.18 in Gwangju is clearly not desirable to everybody, for others, maintaining a sense of the historical layers that buildings like the docheong and the byeolgwan represent, is essential to sustaining their sense of place and identity. Ultimately, the conflict at the docheong illustrates that the process by which some memories of the past are emphasised over others in Korea, especially memories related to 5.18 , continues to resonate with contention.

This chapter has shown that contestation over the privileging of particular collective memories is ongoing in Gwangju, and that the past is very much relevant within this long-marginalised city. However, to individuals in Seoul, memories of the past hold different connotations than they do to the citizens of Gwangju. In the next chapter, I discuss the conflict over the emphasis on new understandings of the past at another key site of memory in Korea, Myeongdong Cathedral in Seoul, and show why studying the cathedral helps to uncover different, but still important, concerns within wider Korean society. 


\section{Chapter Three - Case Study Two: Myeongdong Cathedral in Seoul}

I bustle through the barriers and up the stairs of Myeongdong subway station and burst through into the bright lights and busy streets of one of the largest fashion districts in the world. That one of Korea's most important historical sites (and a cathedral at that) is located amidst a sprawl of consumerism - short skirts, ice cream waffles, iced coffees, business suits, camera-toting tourists, banks, and rows and rows of clothing stores - strikes me as somehow distinctly Korean. I walk through the densely populated streets, listening to the clatter of high heels and the ear-splitting yells of colourful 'human billboards' (people wearing signs that promote nearby merchandise) and evading stalls sizzling with fried food. Mopeds race by, dodging me on the way to make their next delivery. I try to glimpse the M yeongdong Cathedral spires through this glass and concrete jungle but sighting the building is almost impossible. Eventually, I make my way past some road works and lift my eyes to see the sun-drenched bricks of the first cathedral built in Korea. At the foot of the path leading up a small hill to the cathedral I pass a temporary building, where people can sign up to donate their organs when they die. ${ }^{54}$ Then the obligatory newspaper stand, instant coffee machines and Ajumma (middle-aged woman) peddling jewellery.

I walk up to the cathedral, picturesque, silhouetted against the hazy blue afternoon sky. A service has just finished and people are meandering down the hill, opening their umbrellas or pulling down visors to block the sun, preparing themselves as they head back into Seoul's busy streets. I turn my head and follow their gazes to the snapshot of globalisation below; Korea Securities Corp, Royal Hotel, Paris Baguette, Holly's Coffee, Starbucks, the YM CA, various banks and restaurants, and a norae-bang (karaoke room) line the street. Myeongdong Cathedral still offers a trip to the past in a city of constant change. Stepping inside the oaken doors and into the cool air from the mugginess of outside is like stepping into another world. The silence is eerie after the

${ }^{54} \mathrm{~A}$ practice - 'one body, one spirit' - made popular by the late Cardinal Kim Sou-Hwan, who died on the $16^{\text {th }}$ of February 2009 and donated his corneas to posterity. 
constant hum of the streets. I find it hard to imagine the history - both tragic and uplifting - surrounding this place of asylum. Perhaps it is understandable, then, that many today can no longer relate to this site that once served as an unparalleled safehaven for protest in Korea.

M yeongdong Cathedral (See Figure 6 on page 62) represents the headquarters of the Catholic Church for the Archdiocese of Seoul. In the 1970s and 1980s, the cathedral became increasingly involved in Korea's fledgling steps toward democracy, developing into one of the most important sites of protest against authoritarianism and human rights violations in the country. This chapter documents the changing identity of M yeongdong Cathedral over the years, focusing on how the history of the cathedral's involvement with Korea's minjuhwa undong is now being represented. First, I give background on how the cathedral came to be associated with the minjuhwa undong and socio-political demonstrations in Korea. The discussion then moves to shifting depictions of the cathedral with the coming of democracy in Korea, and changing opinions regarding the involvement of the Catholic Church in Korean socio-political issues. Individuals whom I interviewed during my field research in Korea generally expressed two contrasting views: firstly, that Korea, politically and socially, is in a better situation than ever, and secondly, that Korean democracy is actually deteriorating in recent years. I consider, therefore, the way in which changing opinions over the state of Korean politics and society have affected the role of the Catholic Church and how the Church's changing position is related to an increasing disconnection, in official circles, between religion and socio-political concerns. Finally, I discuss a potentially growing apathy throughout wider Korean society towards history, and to social and political issues in the present. The situation at M yeongdong Cathedral, where Church officials now focus on religion and culture over democracy and human rights, is symbolic of a contrast in Korean society between this growing apathy and a continuing culture of protest, as growing numbers question the country's democracy. 


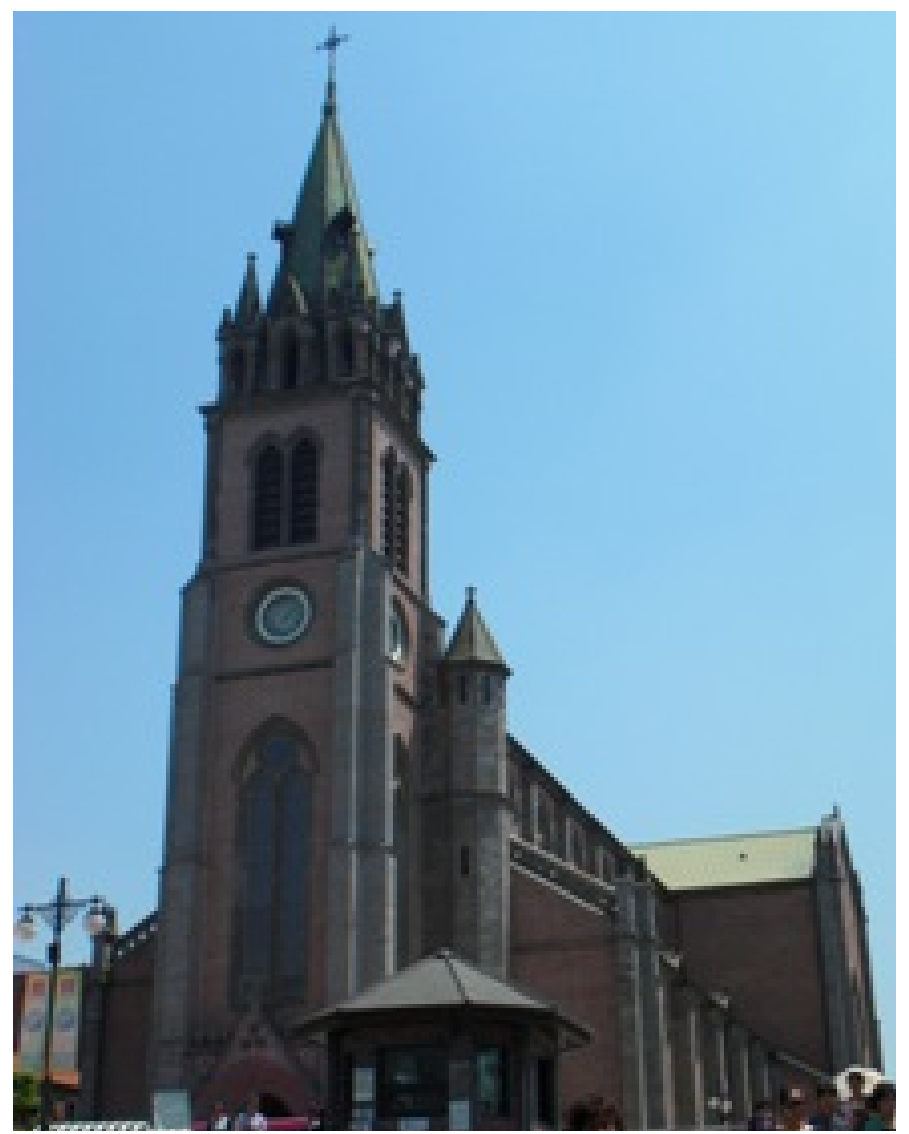

Figure 6: Myeongdong Cathedral, Seoul (Photo: Thomas Vink, 07/ 05/ 09).

\section{Changing Identities: Painting a Picture of Myeongdong Cathedral}

Built in 1898 for the first Catholic parish in Korea, ${ }^{55}$ M yeongdong Cathedral has survived relatively unscathed through a tumultuous period of Korean history: from Japanese imperialism in the first half of the $20^{\text {th }}$ Century, through the Korean War and then the decades of authoritarianism that followed. After its initial construction, the cathedral dominated the skyline. Now, following Korea's development boom, M yeongdong Cathedral is surrounded, the skyline dominated behind, by Seoul tower; and in front, by the warrens of shops, hotels and restaurants of Myeongdong, ${ }^{56}$ and the

\footnotetext{
${ }^{55}$ On the site of the first Catholic gathering in Korea, which occurred in 1785 (Inshil Choe Yoon, 2007: 365).

${ }^{56}$ Myeongdong ranks as the world's 11th-most expensive shopping district in terms of rental rates, according to a report by the New York-based consulting firm Cushman \& Wakefield (Kim Hyung-Eun, 2009).
} 
towering office buildings and teaming traffic of Chungmuro and Euljiro. While the Seoul skyline grew around it, Myeongdong Cathedral remained largely untouched and now represents an important historical site and tourist spot. However, the cathedral is most well known for being a site of pro-democracy gatherings during the 1970s and 1980s, and its continued appropriation as a 'site of resistance' since then.

Christianity has been widely embraced by Korea and when Protestants and Catholics are combined ${ }^{57}$ can now claim more adherents than any other religion in the country. ${ }^{58} 59$ The distinct Korean appropriation of Christianity is representative of the fact that it has often been seen as a symbol of three phenomena which seldom coincide: modernity, compassion and social justice (Lankov, 2007: 194). In Korea, Christian Churches have frequently been associated with Western knowledge and education, and because Korea was never colonised or occupied by a Christian nation, Christianity does not held the same associations with an oppressor as it does for some other Asian countries. In fact, given Japan's occupation of Korea, where Shintoism was often pushed on to the Korean population, Christianity offered distinctly anti-colonial connotations.

In the post-Korean War period Protestantism expanded its emphasis on social outreach $^{60}$; thus, offering support to South Koreans by bringing a sense of community

\footnotetext{
${ }^{57}$ Koreans are inclined to draw a distinction between these two denominations of Christianity: "In terms of their theology, church organisation, and experience, Korean Catholics and Protestants do not normally see themselves as belonging to the same tradition or even the same religion" (Clark, 2002: 188).

58 This statement only holds if we discount ancestor worship in Confucianism. As James Grayson comments (2002: 234), long after its loss of effective political influence, "Confucian thought still dominates the thinking of the majority of the Korean people and it exercises a degree of influence on the folk religion, Buddhism and Christianity."

${ }^{59}$ In Asia, South Korea is third only to East Timor and the Philippines in terms of the proportion of the population that is Christian and if only Protestant denominations are taken into account then Korea has the highest proportion in Asia. In 2003, the South Korean government, based on a partial census, estimated that 54 percent of Korean citizens had a religious affiliation ( 25.3 percent Buddhist, 19.8 percent Protestant, 7.4 percent Catholic) (Baker, 2007: 3). This is up slightly on official data from the 1995 census (23.2 percent Buddhist, 19.7 percent Protestant and 6.6 percent Catholic) (for full summary of 1995 Korea census religious data see Grayson, 2002, p. 249).

${ }^{60}$ Projects with labourers and prostitutes, and education, for example.
} 
and equality (Grayson, 2002: 164). As a result of the new emphasis, membership in the Protestant Church doubled from 3 percent of the total Korean population in the late 1950s to 6 percent in the late 1960s (Grayson, 2002: 164). The adoption of evangelical methods (p. 165), ${ }^{61}$ the "Koreanisation" of the clergy, and the increased urbanisation of the Church also helped the rapid development of both the Protestant and the Catholic Churches in the post-war period (Grayson, 2002: 234).

While Protestantism was the dominant Christian denomination in the post-war period, from the 1970s through the 1980s, the Catholic Church grew in prominence as one of the few institutions that criticised the military dictatorships. A major reason the Catholic Church became more involved than the Protestant Church in issues surrounding human rights and democracy is that Korean Catholicism has traditionally been more representative of lower social classes and had fewer ties to the government. ${ }^{62}$ As James Grayson (2002: 175) explains,

"more so than Protestants, Catholics have been noticeably involved in social movements concerned with the welfare of the industrial worker in Korea's rapidly changing society which is undoubtedly a reflection of the roots of the church in the poorer sector of society."

What's more, among Catholics a "ghetto mentality" also persisted until the late 1970s. This mentality was established through years of persecution experienced by followers of Catholicism going back to the Joseon period (Grayson, 2002: 171). ${ }^{63}$ In contrast to the Catholic Church's association with the poor, from the 1950s onwards, the Protestant Church emphasised 'Church Growth' (gyohwe seongjang) and, thus, became associated

${ }^{61}$ Charismatic ministers being the most notable example.

${ }^{62}$ With prominent Catholics such as politician, Kim Dae-Jung and poet Kim Ji-ha (famous for his satirical attacks on the Park government) voicing such strong criticism, Catholicism also became identified with the opposition (Clark, 2002: 196).

${ }^{63}$ From the early 1800 s up until the 1870 s, followers of Catholicism were severely persecuted. This included the "Great Persecution" of 1866-1871, where some 8000 believers were executed (the most severe persecution in the entire 500 year history of the Joseon dynasty) (Grayson, 2002: 146). 
with wealthier sections of Korean society (Grayson, 2002: 164). Denominational fragmentation within Protestantism has also impeded a united Protestant response to social concerns. ${ }^{64}$

The Catholic Church's involvement in the minjuhwa undong was initiated in the mid-1960s when the 'Second Vatican Council' (1962-1965) pursued an ecumenical emphasis within the Catholic Church (Grayson, 2002: 234). As a result of the Vatican's new emphasis, progressive movements arose in many Catholicised parts of the world, including South Korea. Liberation theology is a movement, predominantly within the Roman Catholic Church, that attempts to unite theology with sociopolitical concerns; known in Korean as minjung sinhak (literally, theology for the people or for the masses), it has had a strong influence on Korean priests. With its aim of overcoming exploitation and injustice, liberation theology is also strongly associated with class struggle and informed by Marxism (Webster, 2009). In Korea, the political involvement of the Catholic Church "began as a contest between issues of national security/economic development on the one hand, and democracy and human rights on the other" (Chang $\&$ Kim, 2007: 347). By turning activism in to a religious act, however, minjung sinhak provided Korean Catholic activists with a theological justification for political protest (Chang \& Kim, 2007).

Myeongdong Cathedral began to play a significant role in Korean social and political life from the 1970s. In 1974, a well-known activist priest, Father Ji Hak-Sun, along with more than 200 young people, was arrested at Myeongdong Cathedral during a drive by Park Chung-Hee to extirpate social movements around the country. Ji HakSun was the first Catholic priest to be arrested in Korea, ${ }^{65}$ and his arrest acted as a catalyst for the establishment of the Catholic Priests Association for Justice (Jeongeui

\footnotetext{
${ }^{64}$ In the mid-1990s the official number of Protestant "denominations" was 96, while the Catholic Church, officially, continued to have one (Clark, 2002: 202).

${ }^{65}$ Not to discount the long history of persecution experienced by Catholics (cf. Grayson, 2002).
} 
Guhyeon Sajedan) (CPAJ). ${ }^{66}$ The families of those arrested also began to hold large gatherings at Myeongdong Cathedral to pray for the release of their loved ones. From 1974, the gatherings gained momentum and, in the process, Myeongdong Cathedral became ingrained in citizens' minds as a 'site of resistance.' Constant interactions between the Catholic Church and the general public built a sense of trust amongst the Korean population (Yeong Gyeong-Hi, Pers. Comm. 13/05/09). Myeongdong Cathedral became an 'umbrella' under which those fighting for human rights and democracy in Korea made a stand against the authoritarian regimes of Park Chung-Hee and, later, Chun Doo-Hwan.

In 1976, 11 prominent Christians - priests, university professors and politicians with progressive leanings gathered at Myeongdong Cathedral (Lee Mun-Yeong, Pers. Comm. 16/05/09), ${ }^{67}$ and issued a signed statement demanding that Park Chung-Hee stand down. ${ }^{68}$ The event is now recognised as an important step in Korea's democracy movement and, as a result, Myeongdong Cathedral has been permanently identified with minjung Christianity (Clark, 1995).

Myeongdong Cathedral's status as a symbol of democracy was confirmed in 1987. By this time, it had become a natural progression for demonstrations to end up at the cathedral (Yeong Gyeong-Hi, Pers. Comm. 13/05/09). On the $10^{\text {th }}$ of June 1987, following the torture and homicide of student, Park Jong-Cheol, by police, more than one million demonstrators marched towards Myeongdong protesting against the authoritarian government. Hundreds gathered on the M yeongdong Cathedral grounds seeking shelter from riot police. Cardinal Kim Sou-Hwan was at the forefront of

\footnotetext{
${ }^{66}$ Which became known through a statement issued at Myeongdong Cathedral in 1974 (CPAJ Website, 2009).

${ }^{67}$ The gathering included Kim Dae Jung, former President (from 1960-1962) Yoon Bo-Seon, and Fathers Ham Seok-Hoon and Ham Se-Eung (now the President of the Korea Democracy Foundation).

${ }^{68}$ The "Declaration of Democratic National Salvation" (CPAJ website, "History'). This statement had four declarations, demanding the restoration of the democratic constitution, the release of Ji Hwak-Sun and other "fighters for democracy," to guarantee freedom of speech and a minimum living standard (see Inshil Choe Yoon, 2007, p. 374 for a full copy of the statement).
} 
negotiations with the government and in the negotiations Kim made a now famous speech:

"If the police come into the church, they will see me. Once they knock me down, they will see other priests and nuns. Only when they knock them down too, [will they] find the students" (In Kim Sung-Hee \& Sung-Ho Baik, 2009).

After almost eight years of strict and abusive military rule under Chun Doo-Hwan, the demonstrations of 1987 affected a change. Under the weight of citizen unrest and discontent, Chun Doo-Hwan's authoritarian regime finally announced concessions to the demands of civil society groups and the opposition party, including the adoption of a direct presidential election system. Chun Doo-Hwan stood down as president and South Korea held its first ever 'democratic' elections.

\section{Following Democracy: Changes Afoot}

The intersection at the bottom of the path leading up to the cathedral is an invisible barrier that signifies the beginning of Church-owned land and police forces can not - due to an implicit understanding - cross it. Protesters use this advantage to demonstrate. Because police are also not able to touch priests - out of issues of respect - during the democracy protests of the 1970s and 1980s, priests would extend the area, pushing the protests further into the streets and increasing their impact (Yeong GyeongHi, Pers. Comm. 13/05/09).

Until 1987, protests at Myeongdong Cathedral were common and progressive priests vocal. After 1987, and the coming of democracy, however, Myeongdong Cathedral experienced another identity change and became the place for labour, migrant, and farmer unions to have strikes. Police forces broke the long-held understanding not to cross the invisible barrier for the first time in June 1995 when they came on to Myeongdong Cathedral grounds to arrest telecommunication unionists. 
Then, in 2000, after "a messy demonstration by telecommunication unionists who beat female churchgoers, vandalised church property and left behind piles of trash during six days of rallies" (Lee, 2002), the Myeongdong Cathedral Council of Worshippers and Office Workers (Pyeongsindo Samu Hyeopuihoe) issued a declaration banning people from using M yeongdong Cathedral as a protest site without prior approval.

Renovations on the cathedral were carried out between 2004 and $2008 .{ }^{69}$ The renovations cost approximately 10 billion won, ${ }^{70}$ with seventy percent coming from the government and the rest collected from church members (Yang Hyeon-Hong, Pers. Comm. 16/05/09). Myeongdong Cathedral Council has begun work on the grounds, installing European-style lighting to make the cathedral more prominent at night. According to Yang Hyeon-Hong, the vice-president (buhwejang) of the Myeongdong Cathedral Council, the shift in emphasis has arisen because the cathedral is a 'Korean treasure. ${ }^{11}$ Myeongdong Cathedral has also been holding more cultural festivals. For example in 2009, during May, the sacred month of Santa M aria, cultural and religious events (concerts, performances and presentations) were held almost daily.

Increasing investment in the cultural and religious side of Myeongdong Cathedral is indicative of an underlying attempt to depoliticise the site and distance its more radical history. This desire has arisen in part because, as the next section will highlight, many church officials claim that the social and political climate in South Korea is better than ever

\footnotetext{
${ }^{69}$ For these renovations clay was taken from Jeoldusan (which literally means the 'hill of beheadings'). During the "Great Persecution" from 1866-1871, Jeoldusan was an execution site for native Koreans who had converted to Catholicism (Grayson, 2002: 175). So, almost literally, the blood and sweat of the people who died for the Catholic Church is now in the foundations of Myeongdong Cathedral (Yang Hyeon-Hong, Pers. Comm. 16/05/09).

${ }^{70}$ Approximately NZ\$12 million in 2010.

${ }^{71}$ Pers. Comm. 16/05/09.
} 


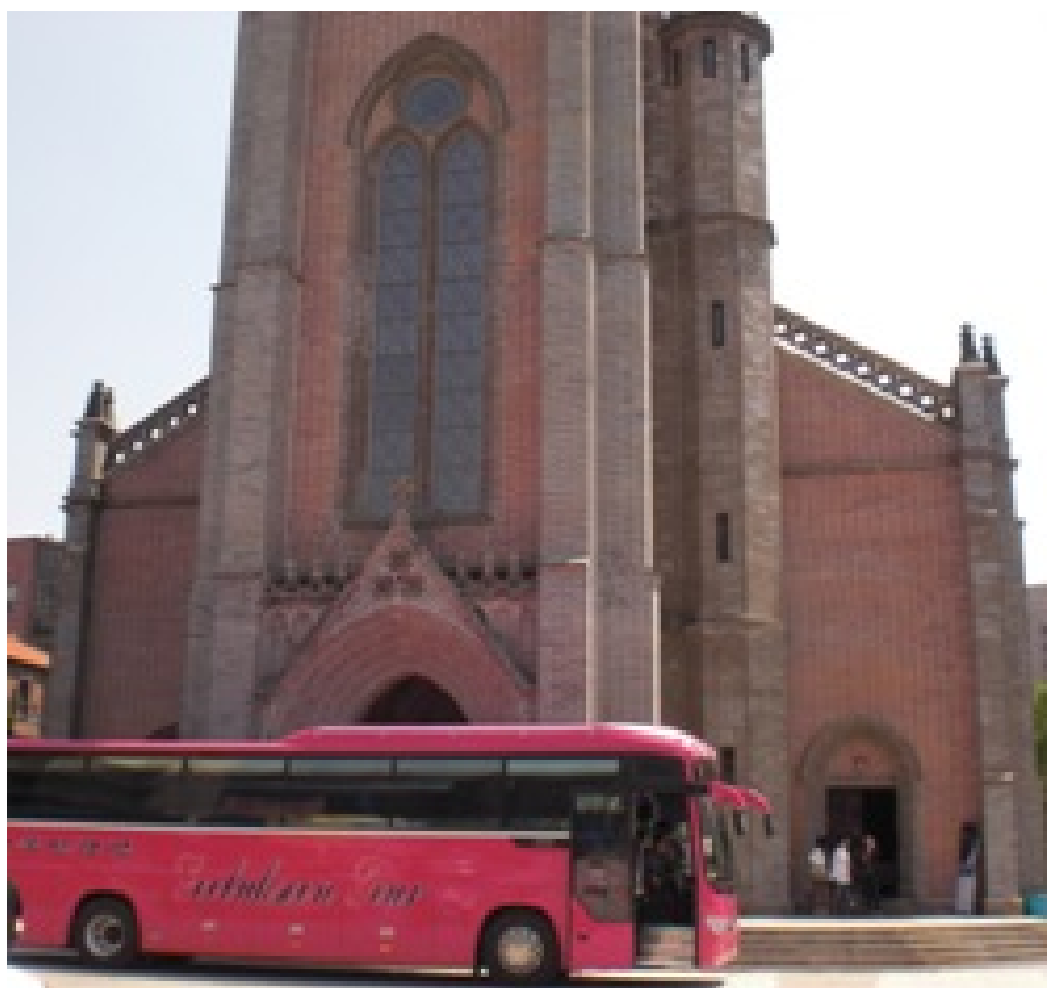

Figure 7: Tour bus outside Myeongdong Cathedral, Seoul (Photo: Thomas Vink, 07/05/ 09).

\section{"The Best Time We've Ever Had"}

I found it difficult to find officials to talk to within the Catholic Church. For example, when I visited the Myeongdong Cathedral Council Offices (samugwan), the Church secretary told me that there are no people to talk to about the protest-related aspects of the cathedral's past. After my second unsuccessful visit to the samugwan, my friend and I sat down outside to discuss where to go next. Out came a man who had been sitting and methodically licking stamps in the background during our conversations with officials inside. He was a volunteer at Myeongdong and told my friend and me that the officials in the samugwan would not provide us with any information; priests move every three years and, thus, none currently present would have been around in the 1980s. However, he went on, priests sometimes come back to work in an administrative capacity at the archdiocese offices (gyogucheong), the administrative headquarters for 
the Catholic Church in Seoul. I approached officials at the gyogucheong, but again, I got the answer that there was no one to talk to, and that I should try the samugwan once more.

As I left the gyogucheong, feeling discouraged by the lack of "people to talk to," my friend, trying to comfort me, made a point of telling me that I should not take the unwillingness of officials to talk personally. Rather, what I was encountering was an important reflection of a larger trend in Korean society: there is no talk about 5.18, human rights and democracy anymore because officials are trying to depoliticise the Catholic Church. The most important information I was able to glean about official Catholic Church opinion was that there was nothing they could tell me; there were no people (officially) to talk to.

The impression I was given that Catholic Church officials would rather not talk about, or make references to, the minjuhwa undong any more was highlighted further in other conversations and interviews I had. Mr. Bae, an organisational representative in Gwangju who asked for confidentiality, told me (Pers. Comm. 21/05/09) that on tours he used to organise, which included Myeongdong Cathedral, church officials never spoke about the more radical aspects of the cathedral's past. I received a similar story from one of the assistants in a quaint bookshop across the courtyard from the cathedral. She told me that, when compared to the situation she experienced when working in the shop in the 1970s and 1980s, Korea's democracy is doing well now and, therefore, the Catholic Church does not like to talk about the harder times of the past. Furthermore, in her eyes, there was no need to protect protesters anymore because the protesters are just fighting for themselves now. During the 1970s and 1980s (the 'era of upheaval' as she put it), protesters needed help and the Catholic Church needed to intervene, but now the situation is different. Yang Hyeon-Hong made a similar point when he told me (Pers. Comm. 15/05/09) that, unlike today, in the 1980s people had no power and needed to fight for justice. In his view, the Catholic Church should not be involved in politics for a few labour workers. Yang considers the Korea Confederation of 
Trade Unions (KCTU) (Jeon-guk M inju Nodong Johap Cheonyeonmaeng) 'impure' and iikjipdan (people who pursue things for their own benefit), thus, their protests are no longer for a good cause. He went so far as to say that South Korea is now more democratic than ever and that right now is the best time Korea has ever had. Thus, the Catholic Church is totally against any involvement in political issues and M yeongdong Cathedral is trying to emphasise its role as a religious institution. As two elderly women I talked to before one evening service at the cathedral asked me, "isn't Korea beautiful now? Everyone says it is beautiful."

\section{"The Deterioration of Democracy"}

The view that South Korea is a democratic country now, and that the Catholic Church should no longer be involved in protests, is now common. However, it contrasts with another widely held view, that democracy in South Korea has actually been deteriorating since the election of the latest President, Lee M yung-Bak. ${ }^{72}$

On the second of May 2009, Buddha's Birthday, a series of demonstrations occurred throughout Seoul. The timing was important given that the day before, the first of May, Labour Day, was also a holiday that has associations with demonstrations in Korea and worldwide. Most importantly, however, the second of May was also the anniversary of the so-called 'candlelight protests' of 2008. ${ }^{73}$ Participants were primarily protesting against the increasingly authoritarian way in which the government was dealing with civil society and public gatherings. In front of City Hall a group singing folk songs were arrested, while others held up signs denouncing Lee Myung-Bak and the police, such as 'Myung Bak twejin. Gyeongchal haeche' (Myung-Bak resign. Dismantle the Police Force) (see Figure 8 below). The images that stayed with me are of the riot

\footnotetext{
${ }^{72}$ Who was inaugurated in February 2008.

${ }^{73}$ Where citizens had protested the resumption of US beef imports due to fears of mad cow disease. The 2008 protests turned into a mass questioning of Lee Myung-Bak and his government. The gatherings peaked on the $10^{\text {th }}$ of June 2008 (the anniversary of the demonstrations in 1987 (6.10) that led to Korea's first democratic elections), where up to one million people filled central Seoul, while tens of thousands of others participated in one or other of the 117 different candlelight protests held around the country (Hankyoreh, 11 June 2008).
} 
police: dozens of buses blocking roads and thousands of grunting 'robots' bearing fiberglass shields and batons. In a remarkably short time the police cleared out the whole plaza and blocked off further entrance. In the dark of the night it was easy to imagine how situations like the protests on the second of May could turn into stereotypical and ideological conflicts. On the internet many arguments developed in the following days, discussing whether the protesters were legitimately standing up against a violent crackdown by police or whether protesters were distorting facts to promote their own agendas.

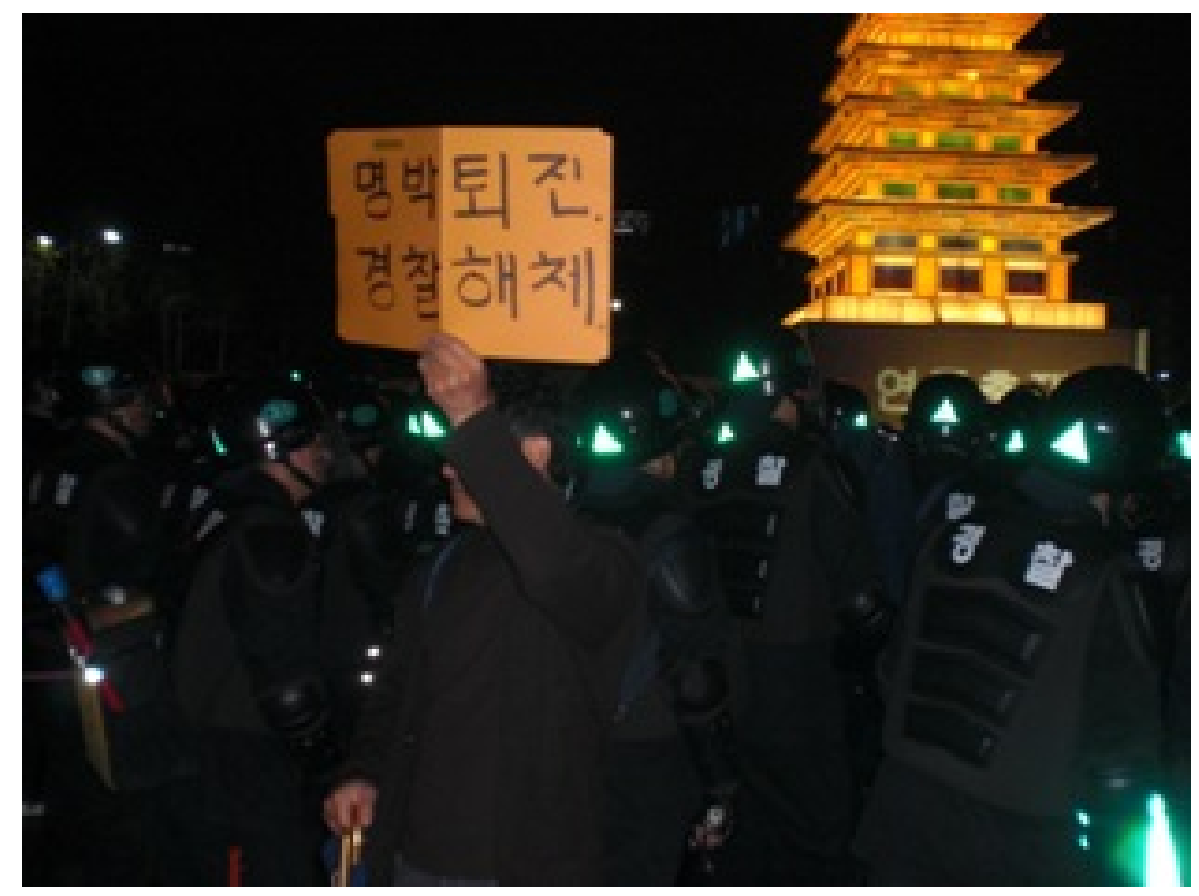

Figure 8: A man holds up a sign asking for the resignation of President Lee Myung Bak and for the police to dismantle. City Hall plaza, Seoul (Photo: Thomas Vink, 02/05/ 09). 
That evening 124 people were arrested and, in the following days and weeks, discussions regarding democracy in Korea grew more frequent. As well as discussions in the media and on the internet, many individuals I interviewed talked of the 'deterioration of democracy' occurring in Korea. Kim Jin-Hoe, a middle-aged M yeongdong Cathedral church-goer, states (Pers. Comm. 22/05/09) that Korea was a democratic country, but that the Lee M yung-Bak government now shows similarities to the government of the Park Chung-Hee-period. Lee Dae-Hun, a professor at Seongkonghoe University in Seoul, echoed Kim's statement when he claimed (Pers. Comm. 17/05/09) that police brutality was much worse than even a year before. Father Na Seung-Gu, a priest at Sinwol-dong Cathedral in Seoul and a member of the CPAJ, claims (Pers. Comm. 02/05/09) democracy in Korea is deteriorating. In his view, the core of Korean society is in decline since Lee Myung-Bak took office, with many civil society gatherings now considered illegal. Lee was elected in a landslide victory, but within months of his inauguration his popularity had fallen below twenty percent. At the same time, the candlelight demonstrations occurred, thus, creating a level of paranoia within the Lee Myung-Bak government. Now, President Lee does not want to risk demonstrations on the scale of the candlelight demonstrations happening again, so the military cracks down on any sign of protests (Father Na Seung-Gu, Pers. Comm. 02/05/09). George Katsiaficas, a visiting professor at Jeonnam University in Gwangju, also agrees with the claims that democracy is deteriorating in Korea. Katsiaficas (2009) compares President Lee M yung-Bak to Chun Doo Hwan and Park Chung-Hee, and claims that with the streamlining and empowerment of the police force, a discontinuation of permits for large demonstrations, and a "bulldozing" of liberal policies, Lee Myung-Bak has taken a "stranglehold" on South Korea's democracy.

While democracy itself is a complex term and means different things to different people, the comments regarding its 'deterioration' give a fair indication of a high level of concern within Korean society, and the continued fractiousness of Korean politics. Within the wider arguments over the state of democracy in Korea and the merits of the 
current government, are conflicts amongst individuals within the Catholic Church, and thus, conflicts over how to use important sites imbued with religious and political meaning, like M yeongdong Cathedral.

\section{The Conflicting Role of the Catholic Church in Social and Political Movements in South Korea}

Conservative Korean Christians have often lambasted minjung theologists for engaging in activities outside the obvious jurisdiction of the Catholic Church (Chang $\&$ Kim, 2007: 350). Such criticism is related to an ongoing struggle for many Christians in reconciling faith with political and social reality (Clark, 1995). The current relationship between the Catholic Church and the CPAJ, in which a separation is increasingly emphasised, exemplifies the conflict between faith and political/social involvement. The official position of the Catholic Church is that the CPAJ is not a formal organisation. Officials refuse to recognise the CPAJ and treat it as though it does not exist (Father $\mathrm{Na}$ Seung-Gu, Pers. Comm. 02/06/09). In the past, identifying the views of the CPAJ with those of the Catholic Church was common and the separation between the two factions was minor.$^{74}$ Catholic Church officials are now doing everything they can to make this separation clear and to emphasise that the CPAJ is not part of the Church itself. Yang Hyeon-Hong admits that many priests remain involved in political movements (like the CPAJ), but claims (Pers. Comm. 15/05/09) that this involvement is unnecessary and unrelated to the outlook of the Catholic Church. For Kim Jin-Hoe (Pers. Comm. 22/05/09), a large difference exists between the demonstrations now and those during the years of military dictatorship, not just because of the changing political and social context in Korea, but also an altered stance by the Vatican, who no longer want priests involved in social movements, but instead, to focus on God and faith. To comply with Vatican requests, the Catholic Church gave an order in September 2008 to send CPAJ

\footnotetext{
${ }^{74}$ In fact, of the roughly 900 priests in Korea in the 1970's and 1980's, approximately 500 of them participated in the CPAJ (CPAJ website, 2009).
} 
priests away from Seoul to other regions, where priests have more difficulty making a political impact (Father Na Seung-Gu, Pers. Comm. 02/06/09).

Despite such attempts to limit the socio-political role of Catholic priests, members of the CPAJ continue to wield a notable influence within Korea. For example, in 2008, the CPAJ had significant involvement in the candlelight protests. When the government banned non-religious gatherings out of fear that they might become riots, approximately 300 members of the CPAJ became involved in the protests, in order that demonstrations could fall into the category of 'religious gathering' and, thus, helped to keep the vigil going (Katsiaficas, Pers. Comm. 27/05/09). The fallout from the CPAJ's involvement in the candlelight demonstrations has become ambiguous because of the Catholic Church's stance, denying that any of their priests were involved. The continued political and social involvement of Catholic priests within the CPAJ, conflicts with the Catholic Church's current desire to separate religion from political and social concerns.

The CPAJ persist with the view that Myeongdong Cathedral is a 'site of resistance,' and 'borrowed' it in May 2009 for a memorial service in honour of Roh M ooHyun, the former president who had committed suicide a few days before. Given the emotional nature of the service, the Catholic Church were under great pressure to say yes and conceded the use of the cathedral (Father Na Seung-Gu, Pers. Comm. 02/06/09). Approximately 50 priests, and 2500 people overall, attended Roh's service, with a number of priests using the event to voice concerns about the state of Korean politics. For example, Philip Kim Byeong-san, a retired priest currently involved as an adviser to the CPAJ, compared the death of Roh to those of Koreans who had sacrificed their life for democracy and stated, "this [Lee Myung-Bak] government has been destroying the political and social achievements of the past 10 years and erasing them from our memory" (Union of Catholic Asian news, 2009). 
The CPAJ also use general church services for protest. Although, after sunset any public gathering is illegal, ${ }^{75}$ church services are exempt from this law. Members of the CPAJ have held late night church services, which created further tension between themselves and the Catholic Church, who oppose the late night services (Father $\mathrm{Na}$ Seung-Gu, Pers. Comm. 02/06/09). In January 2009, six people died in conflicts between protestors and police at a building in the Seoul district of Yongsan, where citizens were forced to move out of their homes for a redevelopment project. Debate over the level of police violence in the following months was widespread, ${ }^{76}$ and a Catholic memorial service for the victims was held, at the site in Yongsan where the conflict occurred, every night (except Thursday when a Protestant service was held) throughout 2009. ${ }^{77}$ Hong Se-Hwa goes so far as to state (2009), "Yongsan is a self-portrait of our [Korea's] distorted society, the front lines on which we [Koreans] must fight those who oppose democracy and human rights." The 'Yongsan tragedy' also has connections to M yeongdong Cathedral, but not with the meaning that the daily services might suggest. After the event, demonstrators went to the cathedral to protest. Yang Hyeon-Hong (Pers. Comm. 15/05/09) believes that, in this situation as well, the demonstrators, who were not those dislocated in the development project, were people protesting for their own benefit (what he again termed an i-ikjipdan) and looking to extort money from the government using Yongsan as an excuse. Father Na Seung-Gu also claims (Pers. Comm. 02/06/09) that the priest (a member of the CPAJ) who ran the Yongsan services was taking advantage of them to voice his own political views.

\footnotetext{
${ }^{75}$ According to article 10 of the 'Act on Assembly and Demonstration,' no one is allowed to hold any public assembly or demonstration before sunrise and after sunset unless they obtain permission from a nearby police station (Ney, 2009). Many people therefore gather between May and July when the sunset is relatively late.

${ }^{76}$ This debate continues into 2010. See the Hankyoreh's discussion of the ongoing struggle of bereaved family members (31/12/09) and Matthew Lamers articles in the Korea Herald about the wider impacts of redevelopment projects in Seoul (19/01/10 and 20/01/10), for example.

${ }^{77}$ On the $30^{\text {th }}$ of December 2009, announcements were made that an agreement on a government apology and compensation had been reached. A funeral was held for the victims on the $9^{\text {th }}$ of January 2010. However, there are still groups pushing for further investigations into the facts behind the deaths that occurred (Hankyoreh, 31/12/09).
} 
The dispute between the CPAJ and Catholic Church officials highlights the complicated debate over the state of Korean politics and society, and the role that the Catholic Church has to play in this debate. As the headquarters for the Catholic Church, and as a key symbol of democracy and resistance, Myeongdong Cathedral occupies a key site in these debates. Many of those I spoke to point to the changing leadership (or rather the loss of leadership) at Myeongdong Cathedral as essential to the changing image of the Catholic Church and of the cathedral itself.

\section{Kim Sou-Hwan: The "Conscience of Korea" 78}

Cardinal Kim Sou-Hwan, the first archbishop in South Korea, died on the $14^{\text {th }}$ of February 2009, less than three weeks before I arrived in the country. Thus, feelings about him and his legacy were still palpably visible. He is remembered with a great deal of fondness and emotion; one of the first images I remember seeing in Korea was his visage smiling down on me as I walked up the path to visit M yeongdong Cathedral (see Figure 9 on page 78).

A number of people I talked to ${ }^{79}$ claimed that the real cause of conflict within the Catholic Church in Korea is a lack of leadership, and that the leadership problem began when Kim Sou-Hwan retired in 1998. Kim lived in the cathedral while serving as the archbishop of Seoul from 1968 to 1998 (Kim Hyun-Eun, 2009). In this period he performed a vital role as the key spokesperson for the Catholic Church and its participation in the fight for human rights and democracy in Korea. In 1998, leadership roles started changing within the Catholic Church and the current cardinal, Nicholas Cheong Jin-Suk, does not hold Kim Sou-Hwan's ideals with the same reverence (Lee Mun-Yeong, Pers. Comm. 16/05/09). To Cardinal Cheong, M yeongdong Cathedral does

\footnotetext{
$\overline{{ }^{78}}$ Kwan Mee Yoo, 17/02/2009.

${ }^{79}$ Lee Mun-Yeong (Pers. Comm. 16/05/09), Father Na Seung-Gu (Pers. Comm. 02/06/09), Lee Dae-Hun (Pers. Comm. 17/05/09).
} 
not represent human rights and democracy, and Cheong's decision-making reflects this altered image by emphasising the cathedral as a religious institution (Father $\mathrm{Na}$ SeungGu, Pers. Comm. 02/06/09).

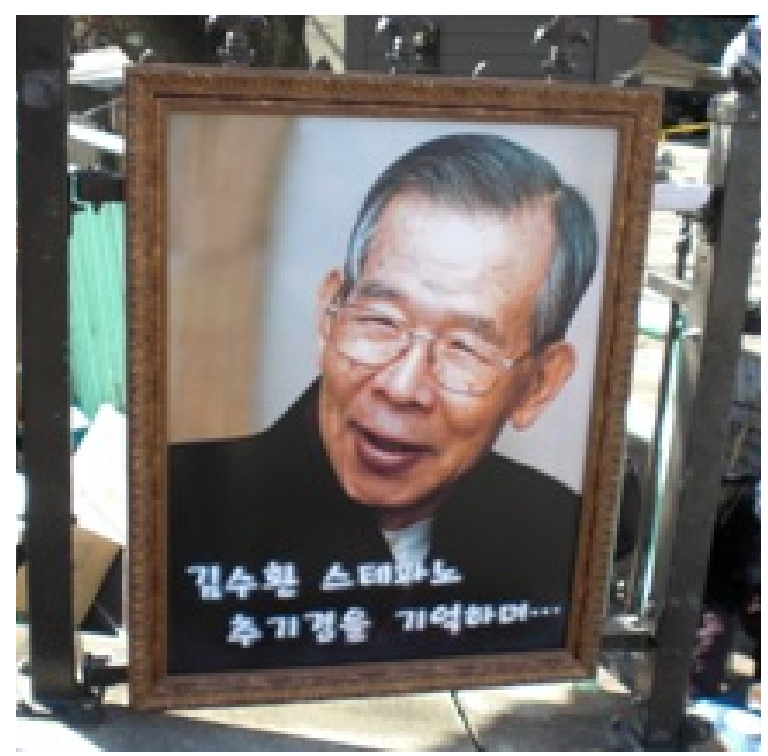

Figure 9: Portrait of Cardinal Kim Sou-Hwan. ${ }^{80}$ Myeongdong Cathedral, Seoul (Photo: Thomas Vink, 06/ 03/ 09).

A number of individuals claim that Cardinal Kim was actually more important as a symbol of democracy in South Korea than the Catholic Church itself ${ }^{81}$ and, thus, much has been lost with his death. When he passed away, over 400,000 people came to $M$ yeongdong Cathedral to pay their respects. Members among the younger generation of church-goers whom I spoke to often told me they had no idea about the extent that the Catholic Church had been involved in Korea's democracy movement until Kim, and his story, was mentioned in the media. The death of Cardinal Kim acted as a reminder of

\footnotetext{
${ }^{80}$ The caption roughly translates as: Kim Sou-hwan Stefano we will remember you...

${ }^{81}$ Yang Hyeon-Hong (Pers. Comm. 15/05/09) for example, believes Kim Sou-Hwan was the centre of the democratic movement and Kim Jin-Hoe affirms (Pers. Comm. 22/05/09) that Kim, as a person - as an image - is one of the key symbols of democracy in Korea.
} 
Korea's minjuhwa undong and of M yeongdong Cathedral's role in its eventual success. ${ }^{82}$ The Catholic Church is even growing faster since he passed away, to the extent that Lee Dae-Hun contends (Pers. Comm. 17/05/09) that Kim Sou-Hwan is being appropriated by the Catholic Church. In Lee's view, the funeral was "commercialised," with Kim's position on democracy issues pushed into the background. Therefore, while the funeral - where hundreds of thousands of people waited in line for hours to pay their respects highlighted the wide level of respect held for Kim, it also showed that perhaps a lot of respect was lost with him and that the Catholic Church is 'selling out' to attract more members (Lee Dae-Hun, Pers. Comm. 17/05/09). The claim that the Catholic Church appropriated Kim's funeral relates to a wider argument that corruption is now more evident within the Catholic Church and that the values of social justice and human rights, so strongly enforced by the Catholic Church in the past, are now ignored too often.

\section{Impurity and Corruption}

The Protestant Church in Korea is often compared to a huge business. Donald Clark even argues (1995) that the Church in Korea is an authoritarian structure in itself. M any Protestant churches have grown rich and Clark (2002: 202) claims that the biggest churches actually resemble empires, with business enterprises and a strong influence in areas outside the bounds of religion. With allegedly secret budgets and leaders who exert great personal power, many Protestant churches are also suspected of corruption (Clark, 2002). Now Lee M un-Yeong believes (Pers. Comm. 16/05/09) there is corruption even within the Catholic Church, and that rather than thinking about the prevailing of justice, Korean Christians are talking about how they can bring wealth back in to their own homes. Although involvement in political movements contributed to the growth of the Catholic Church, Father Na Seung-Gu claims (Pers. Comm. 02/06/09) the Church was also corrupted by its involvement. Father Na's claim is supported by Clark, who states

\footnotetext{
${ }^{82}$ Yang Hyeon-Hong even claims (Pers. Comm. 15/05/09) that right now people recognise Myeongdong Cathedral as a site of democracy and protest more than ever.
} 
(2002: 202) that, ironically, it is middle-class prosperity and democracy, and the corruption this has caused, that now poses the biggest threats to the future of South Korea's Protestant community. Thus, if Father $\mathrm{Na}$ and Lee Mun-Yeong are correct and corruption is growing within the Catholic Church, then the Catholic community could now be experiencing a similar threat.

Following the elections of 1987, divisions became more prominent within the Catholic Church and many arguments developed between priests (Yang Gyeong-Hui, Pers. Comm. 13/05/09). Over the last two decades, official opinion within the Catholic Church has evolved. Church officials view labour strikes and unification protests as radical, selfish, and impure, and increasingly, have distanced themselves from the more radical factions of the Church's past. This new direction is understandable at Myeongdong Cathedral, where many officials are frustrated by the continued appropriation of the site to protest issues increasingly seen as irrelevant to the Catholic Church, and sometimes even to wider society. However, the shifting focus appears to be based on more than a mere intolerance of "impure labour unionists."

In the past, many poorer people went to church. However, priests and nuns now meet and interact with wealthier segments of society, who are increasing their impact on decisions within the Catholic Church (Father Na Seung-Gu, Pers. Comm. 02/06/09). Lee Dae-Hun agrees and makes further claims (Pers. Comm. 17/05/09) that Catholic Church leadership has regressed because they are no longer concerned with issues raised by poorer sections of society, and Catholic Church officials are now proconservative and "openly antagonistic to pro-democracy groups."

M yeongdong Cathedral has also come to enjoy a great deal of respect from the government. Among Catholic officials, promoting less radical perceptions of Myeongdong Cathedral could be a way of making peace with the government and building on this respect. The recent renovations at the cathedral demonstrate that the state has become more involved with the affairs of the cathedral, and the Catholic Church in general, than in the past. The government has policies to control renovations 
of historic sites, so much negotiation was required before the Myeongdong Cathedral renovations were allowed to proceed. That the renovations were approved, however, is a potential sign of government respect for the Catholic Church, and acknowledgement of Myeongdong Cathedral's significance in Korea's history (Yang Hyeon-Hong, Pers. Comm. 15/05/09).

The move by Catholic Church officials away from social concerns towards building relationships with the government and wealthier segments of society has contributed to the shifting image of Myeongdong Cathedral, and is also emblematic of changes within wider Korean society. Some Koreans now appear more apathetic towards events of the past, and to social and political issues in the present, as selfinterest has taken prominence in Korea's now neoliberal, growth-driven economy.

\section{Apathy}

In the past, the Youth Association at M yeongdong Cathedral played a large role in the political mobilisation of students. M any people came to the Association for help, and it became a symbolic leader, "like trade union headquarters," says Lee Dae-Hun, a professor at Seongkonghoe University in Seoul (Pers. Comm. 17/05/09). Lee talked animatedly of the students who pioneered the cultural movement in the 1980s and about his involvement at Myeongdong Cathedral, particularly with open theatre, which he saw as a way to convey political criticism under the guise of Christian themes. Lee himself taught theatre and traditional music there, despite not being religious at the time, and was attracted to Catholic openness to these activities. You could, he says, "do and speak, and produce anything on that compound [M yeongdong Cathedral]."

The role that the Youth Association played in the 1980s, indicates the importance of Myeongdong Cathedral as a 'site of resistance.' It was not merely an asylum, but provided space for citizens to discuss, and learn about, wider national and global concerns. Although universities are often regarded as the centre of the Korean democracy movement, Myeongdong Cathedral offered "a very free space...even in university you have be careful" (Lee Dae-Hun, Pers. Comm. 17/05/09). 
Claims that many Koreans, particularly the younger generation, are apathetic towards their history and the current political situation in Korea (both in terms of applications of democracy in the South and unification with the North) have become more widespread. For example, when Lee Myung-Bak was elected, Koreans overwhelmingly declared that they were interested in economic growth and higher salaries rather then social concerns (Hardin, 2008: 119). ${ }^{83}$ The increasing apathy towards history in Korea is an illustration of the arguments made in wider literature that history is "speeding up" and that in the globalised and fast-changing world of today, only aspects of the past can hold individual meaning. ${ }^{84}$ In my personal experiences, I also came across a potentially growing apathy towards social concerns. For example, I asked one friend's opinion on how the minjuhwa undong is being represented today. His reply, that he had too much happening in his own life to think about rather than worry about history, is not atypical. Of the younger Koreans I spoke to, knowledge related to 5.18, the minjuhwa undong, and Myeongdong Cathedral's relation to these events was limited, and what knowledge they did have usually came not from school or parents, but priests, or popular culture and movies. One young woman told me the recent movie, 'May 18' (Hwaryohanhyuga), which dramatises happenings in Gwangju, opened her mind up to Korea's past and motivated her to learn more. Like others I spoke to, she had not even noticed that the previous week had been the anniversary of the Gwangju Uprising.

During my interview with Yang Hyeon-Hong (Pers. Comm. 16/05/09), he even expressed concern for me, and my thesis, believing I would not find enough people who

\footnotetext{
${ }^{83}$ In the same poll, only three percent of the Koreans asked, said that North Korea was an important concern (Hardin, 2008: 119). Kang Hyun-Kyung, in the lead up to the 2007 presidential elections also stated (2007), for example, "a growing number of younger voters have begun to show a conservative political orientation and are interested in Lee M yung-bak as he has so far been portrayed as a candidate who can create the most jobs" and Al Jazeera (2007) that, "unlike previous elections dominated by issues such as security policy with rival North Korea or relations with the US, this year voters were focused on economic matters." Kim Jin-Hoe stipulated (Pers. Comm. 22/05/09) that if Korea's democracy is deteriorating, it is not just because of the government, but also because of apathy amongst younger generations and a growing focus on individualism within Korean society.

${ }^{84}$ cf. Huyssen, 2000; Klein, 2000; Kundera, 1979, 1984; Nora, 1989, 2002; Todorov, 2001.
} 
knew about the topic and gestured toward the young people sitting nearby. It has been so long now since 5.18 , he said, that not many people can name the year in which it occurred. The latest generation of Koreans has grown up in an environment removed from the harsh authoritarianism of the past and, therefore, events like 5.18 are much more distant and hard to comprehend. Some churchgoers I met talked of the cathedral as a religious site. Others acknowledged the role of the Catholic Church, and of Myeongdong Cathedral, in Korea's minjuhwa undong but claimed that this role was exaggerated. Increasingly, younger generations of Koreans grow up without an awareness of the role Myeongdong Cathedral played as a political site, and its importance in achieving democracy in Korea. Thus, it appears the shifting image of M yeongdong Cathedral is not just because of the new emphasis privileged by Catholic Church officials, but also because of a wider lack of awareness or empathy towards the past in Korean society at large.

\section{Conclusion}

This chapter began by documenting the historical rise of $M$ yeongdong Cathedral to a 'site of resistance' and key symbol of democracy in Korea. Now the identity of the cathedral is going through another identity change, as Catholic Church officials promote the religious and cultural aspects of the cathedral over its radical and dissident past. The new image of M yeongdong Cathedral is representative of an increasing disconnection, made by the Catholic Church, between religion and socio-political concerns. Church officials argue that Korean society is in a better position than ever and that those who continue to demonstrate are looking to make their own personal gains. In contrast, many other individuals, such as members of the CPAJ, claim that democracy in Korea has been deteriorating in recent years. This contestation over the involvement of the Catholic Church in socio-political concerns is represented through Myeongdong Cathedral, as the headquarters for the Korean Catholic Church, and as a key symbol of democracy. Underlying the conflict within the Catholic Church is a wider issue in Korean society: a potentially growing apathy amongst Korean citizens towards history and social 
and political issues in the present. However, the persistence of Korea's protest culture, most clearly seen in the candlelight demonstrations of 2008, illustrates that large numbers of Koreans are still concerned about social and political matters. Clearly, many individuals in Korea still need a space to come together communally. Despite the emphasis by Catholic Church officials away from Myeongdong Cathedral's dissident past, the site continues to incite contention and to be invested with political meaning. Thus, if officials allow it, Myeongdong Cathedral can still provide that space, where collective understandings of both the past and the present are debated and understood into the future. 


\section{Chapter Four - The docheong and Myeongdong Cathedral: Comparison}

The three of us walk into the byeolgwan and form a rough triangle, hunching over on plastic pull-out chairs in the middle of a parched and dusty hallway that looks as though it could collapse around us at any moment. A friend of mine, who has come along to translate, is next to me and a bright-eyed Gang Gu-Yeong ${ }^{85}$ stands against the opposite wall. It is the $20^{\text {th }}$ of $\mathrm{May}$, two days after the anniversary of 5.18 , and the city, like every year in May, has become focused on memory. The 5.18 National Cemetery, relatively empty throughout the previous months, suddenly becomes the site of dozens of school trips, memorial ceremonies and visits from human rights organisations. As we go through a round of obligatory name-card exchanges, head bows and thank-yous, another relaxed looking middle-aged man brings in three steaming paper cups of the sweet instant coffee that I have come to know so well. Others I had talked to in previous days, spoke of the 5.18 associations as unaccommodating, yet, within the byeolgwan the atmosphere is communal and convivial, and Gang's warmth is genuine.

We end the discussion with a promise to meet again. Then, driving away through the wide, angular streets of Gwangju, I ask my friend to give me a quick run-through of the conversation (which we would go over and translate in depth later). As contradictions related to facts and figures have come through, I consider the other views that those in favour of demolishing the byeolgwan had taken up; views that painted the situation caused by protests as a time-consuming and expensive exercise in self-interest and corruption. Suddenly, the conversation takes a surprising turn, and my friend undergoes a brief transformation. He animatedly explains how important (very!) it is to keep the building and to remember what happened there. Most of the citizens in Gwangju do not realise the full implications of demolishing the byeolgwan and building a new cultural complex in its place, he tells me, they do not realise what will be lost. I am dropped off at home, left alone to ruminate on this outburst of emotion and feeling.

${ }^{85}$ The Director of Policy and Planning in the 5.18 Wounded Persons Association (WPA). 
As part of a week-long period to commemorate the $29^{\text {th }}$ anniversary of 5.18 (5.18 minjung hangjaeng 29 ju nyeon ginyeom), an exhibition is also on display in the former docheong next door. While some displays do not leave much to the imagination - a shovel sticking out of the dead earth - others are more poignant. One powerful image is a painting of a baby, sleeping peacefully in a cocoon of toys, blankets and plants, floating on a river of candles in a landscape of darkness. The suggestion is that the candles represent those who perished during 5.18, fighting against the 'darkness' of dictatorial rule and brought about the peace that the baby now blissfully enjoys. The painting also suggests Korean youth of today, who enjoy peace and material gains, but ignore the long river of hardship that led to these gains.

Another friend, who acted as translator for many of the interviews I carried out in Seoul, converted from Protestantism to Catholicism ${ }^{86}$ as a result of these interviews. The stories of social engagement and past events that priests, Catholic Church officials and general church-goers told us heightened her impression of religion and the kind of outreach it can have in Korea. At other times, friends would tell me things like, "the people in Gwangju, they fought for us, what we have now is because of them," with such sincerity that for a second I would forget the quizzical looks that most youth gave me when I asked them about o-il-pal (5.18) or the minjuhwa undong. These moments of passion contradicted the more general impression I was given that many young people in Korea do not know about, or do not care about, 5.18 or the minjuhwa undong.

The emotional outpouring I unexpectedly received from my friend in Gwangju is an example of a difference that exists between Seoul and Gwangju. The memory of Korea's minjuhwa undong holds different meaning to the people of Gwangju, a city so long associated with struggle and neglect. Taking the sense of difference between Seoul and Gwangju - between M yeongdong Cathedral and the docheong - as a starting point, this chapter works to elicit the wider meaning of my research. I begin by elaborating on the generational and regional divergences that exist between Gwangju and Seoul, and

${ }^{86}$ Which, given the distinction that Koreans hold between the two (cf. Clark, 2002: 188) is essentially the same as changing religion. 
the impact these divergences have on the issues at the docheong and Myeongdong Cathedral. I go on to compare the shifting understandings of Myeongdong Cathedral and the docheong as new images of the sites are emphasised over those of the past. The altered emphasis at each site is informed by multiple readings of place and space that have created contestation over whose reading of the past should be given importance. Finally, I argue that the past can only maintain its relevance through ongoing contestations. Therefore, the conflict over whose representations of the past are privileged at the docheong and M yeongdong Cathedral still has the potential to have a positive impact - despite widespread fears of the opposite - upon wider Korean society and add contemporary relevance to the meaning of the past.

\section{Generational and Regional Discrepancies}

$M$ any scholars claim that there is a large generational gap in Korea. For example, Sheila Jager argues (2003: xiv) that unlike many "modern nations where the contests between various groups have been drawn along ethnic, religious, or linguistic lines, in Korea these contests have been drawn, broadly speaking, between the generations." Generational conflict in Korea is understandable given the speed with which the country has developed and the vastly different environment that generations born since the 1980s have grown up in. The so-called 'new generation' (sinsedae) of Koreans, for example, grew up in a prosperous economic environment, with democracy and easy access to technology, and are increasingly conservative or "indifferent to politics" (Park Sun-Young, 2007). They contrast with the previous, political and liberal-minded 386 generation, who were the first Koreans to grow up relatively free of poverty, and became politically active as students during the 1980s. Despite the disparities between generations in Korea, in the context of my research, discrepancies between regions appear more important than generational gaps in contestations over the meaning of the minjuhwa undong. Gwangju's history of neglect, its counter-hegemonic status, and its ties to resistance have caused the city to build a local identity around which citizens - 
and generations - can coalesce more readily than elsewhere in the country (cf. Lewis 2002b; Yea, 1999, 2002, 2003).

When I chose my two case study sites, variety and difference were important factors. Leaving Seoul for the first time and witnessing the diversity in Korea had a major impact on me and was, therefore, a difference that I wanted to represent in my research. Gwangju struck me as different straight away, not just because of the cleaner air, the lower skyline and the thinner lines of traffic, but also the people. Other regional centres in Korea are known for characteristics like their cultural and historical artifacts (such as Gyeongju), their ports and access to surrounding islands (Busan and Incheon), or their natural environments (such as Seokcho and Jeju Island). In contrast, Gwangju is best known for a violent uprising, an association that the city's citizens have also inherited. Accordingly, as well as the memory of 5.18 forming a key feature of the city, many of Gwangju's citizens have also incorporated 5.18 as an important event in constructing their identities. Friedrich Nietzsche (1969: 61) argues that only that which still hurts remains in the memory. I believe the ongoing importance of buildings like the byeolgwan to Gwangju citizens, is partly because, to them, 5.18 does still 'hurt.' The ongoing resonance of 5.18 in Gwangju illustrates the unique connection that citizens there have to the event. In Gwangju, I got the sense that the city's history is felt at a personal level, whereas, to many in Seoul, 5.18 is a more abstract historical event. This sense of meaning is reflected in how I have interpreted the issues at each of my case study sites.

The regional and national connotations of the minjuhwa undong, especially in relation to Gwangju and 5.18, are important in understanding recent contestations over how the past is remembered in Korea. The state's appropriation of 5.18, through structures like the 5.18 National Cemetery, was an attempt to create a singular, national narrative of the event (cf. Yea, 2002). Now, 5.18 is being promoted as an event of global and universal importance, with Gwangju at the centre, as a 'mecca' of democracy and human rights. However, many in Gwangju still present personal histories that are 
"counter-hegemonic" and "offer a site of resistance" to the imposition of national and universal interpretations of 5.18 (Lewis, 2002: 153). Therefore, the ongoing conflict over whose narrative of 5.18 to emphasise is a sign of fundamental local Gwangju differences in perspective about 5.18 and the meaning it holds for various individuals and groups: "after more than twenty years, Gwangju continues, inscribed on the minds and bodies of its victims" (Lewis and Byun, 2003: 63). The contestation at the docheong over the meaning of 5.18 is representative of these ongoing differences in perspective. Like the historical positioning of 5.18 as a Jeolla concern, the conflict over the HCAC project is largely thought of as a Gwangju problem, with Gwangju still widely recognised as a city of resistance. However, the emphasis on 5.18 as above all a local incident means Gwangju citizens have built a communal sense of history from which they derive a strong sense of identity. Even members of younger generations, who have grown up in an environment quite removed from the upheavals of the 1980s, feel connected to 5.18; for them, the history of the city remains important and relevant.

The situation at Myeongdong Cathedral in Seoul is different. The lack of concern over shifting meaning of the cathedral is representative of a growing apathy towards history in Korean society at large. M embers of the younger generation, in particular, are increasingly disconnected from the past in a climate that focuses on economic growth and material gain. Even amongst weekly church-goers at Myeongdong Cathedral, the role that the cathedral played in the minjuhwa undong was widely unknown or unimportant. While large-scale demonstrations in Seoul do still recall 5.18 and 6.10, the 'new generation' of Koreans in Seoul are generally more detached from the past than their counterparts in Gwangju. The regional discrepancies over the meaning of the minjuhwa undong are important. They help to understand the various, often conflicting, reactions that arise when different representations of the past are privileged at M yeongdong Cathedral and the docheong, as the next section highlights. 


\section{Shifting Representations}

Myeongdong Cathedral in Seoul and the docheong in Gwangju are two of the sites with the most symbolic resonance for remembering Korea's minjuhwa undong. They were both sites of resistance, where citizens gathered to demonstrate against the state, and they occupy spaces in the two major cities of protest in contemporary Korean history. In the changing political and economic climate of Korea, with its neoliberal, growth-driven focus, self-interest has overtaken social issues as a key concern for many Korean citizens. Therefore, associating with resistance does not hold the same liberating connotations as it did in the 1970s and 1980s. Jeong Su-M an, then chairman of the 5.18 Bereaved Family Association (BFA), clearly expresses the move away from resistance in his opening address at the 1997 memorial ceremony at 5.18 National Cemetery in Gwangju:

"Now, as an unhappy era has been brought to a close and history is victorious, 5.18 is approaching a second stage, changing to a spirit of universal humanity. Accordingly, the underlying tone of the commemoration events must be stripped of the so-called antigovernment struggle style of the past" (In Lewis, 2002: 152).

Newly sanctioned understandings of the past signal a move beyond the political and resistant images of previous decades. The docheong is now in the process of being (re)presented as the central site in the 'Hub City of Asian Culture,' while Myeongdong Cathedral is presented as the centre of Korean Catholicism and as a national cultural treasure.

When I arrived in Gwangju the situation surrounding the demolition of the byeolgwan had reached a stalemate, with none of the groups involved backing down on their demands. HCAC officials have two main reasons for not altering their plans to demolish the byeolgwan. One is that officials believe they had been open about their

plans for the ACC and that all groups involved had previously agreed that keeping the byeolgwan was not important. The second reason is that the ACC may lessen the 
importance that memorialising 5.18 has in Gwangju. Many individuals in Gwangju are weary of 5.18 and its continued appropriation by the 5.18 associations, and believe that Gwangju's economy cannot be sustained through the memorialisation of 5.18 alone. However, lessening the significance of 5.18 in representations of Gwangju - and thus lessening Gwangju's ties to resistance and anti-government attitudes - could also create a social environment less critical of the government. Therefore, relegating 5.18 to history could be seen as a political strategy to ease pressure on President Lee MyungBak (Jung Hae-Gu, Pers. Comm. 13/05/09).

In contrast, however, a number of significant motives for protecting the byeolgwan also exist. One is a genuine concern that, if removed, the building will take memories of 5.18 with it, and that the museum-like ACC built in its place could consign 5.18 to the past. A kitsch effect would also operate here (cf. Kundera, 1984, p. 278; Funder, 2003). The ACC may sanitise interpretations of 5.18 , downplaying aspects of the event, from which many citizens take personal meaning, in order to promote an image that conforms to HCAC aims. ${ }^{87}$

Another motive is that some groups and individuals can make personal gains if the byeolgwan remains. For example, officials, such as Mr. Ryu (Pers. Comm. 24/04/09) and Mr. Bae (Pers. Comm. 25/05/09), claim that the 5.18 associations are impure and corrupt. They suggest that rather than protecting 5.18 and its memory, some within the 5.18 associations are looking to profit out of memorialising the tragedy. The public, too, is not sympathetic towards the 5.18 associations, who have achieved their professed goals. However, they continue to protest at sites related to the memory of 5.18, like the byeolgwan and, thus, their motives appear outdated. For over a decade, the docheong area has been out of use and fallen into disrepair (See Figures 10 and 11 on page 92). Only now, with potential re-development ahead, have the buildings been 're-inscripted' with meaning (cf. Yea, 2002: 1571), implying that appropriation of 5.18 could be

\footnotetext{
${ }^{87}$ Many of the images regarding 5.18 already conform to touristic ideals, with brochures and pamphlets promoting a theme park experience when visiting the 5.18 Liberation Park or touring important 5.18 sites on the bus.
} 
occurring. My own experiences strongly suggest that, while the 5.18 associations are generally well-meaning, at least some members have a vested interest in the byeolgwan.

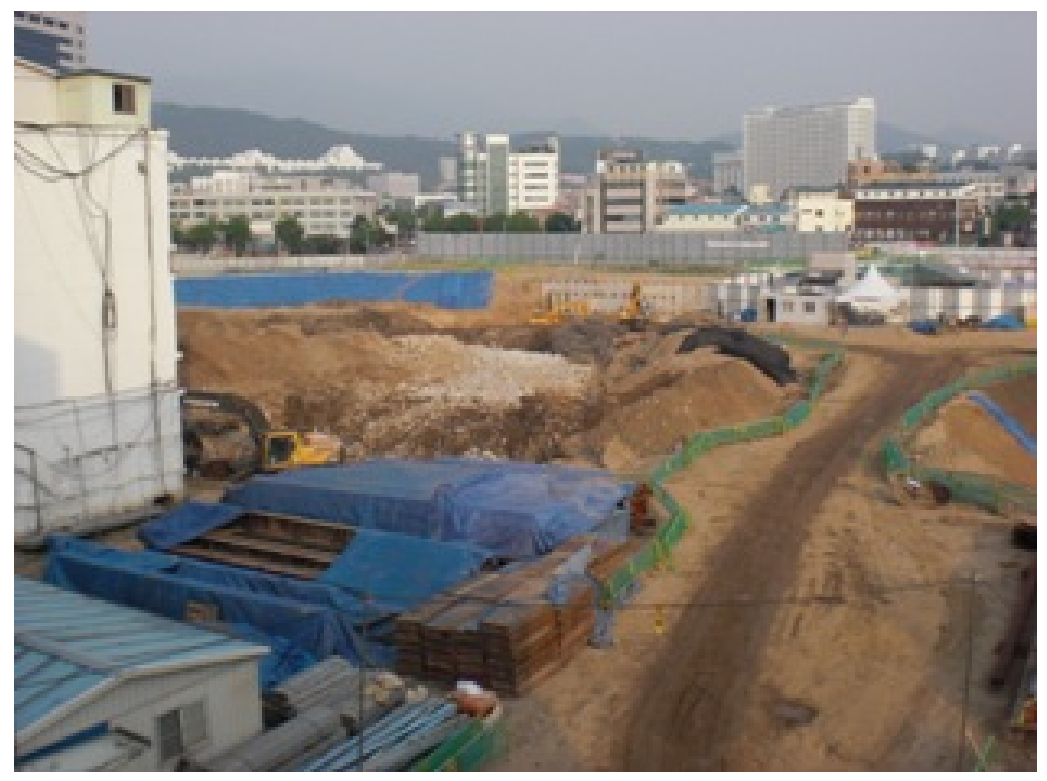

Figure 10: ACC construction site (view from the byeolgwan). Gwangju (Photo: Thomas Vink, 30/05/09).

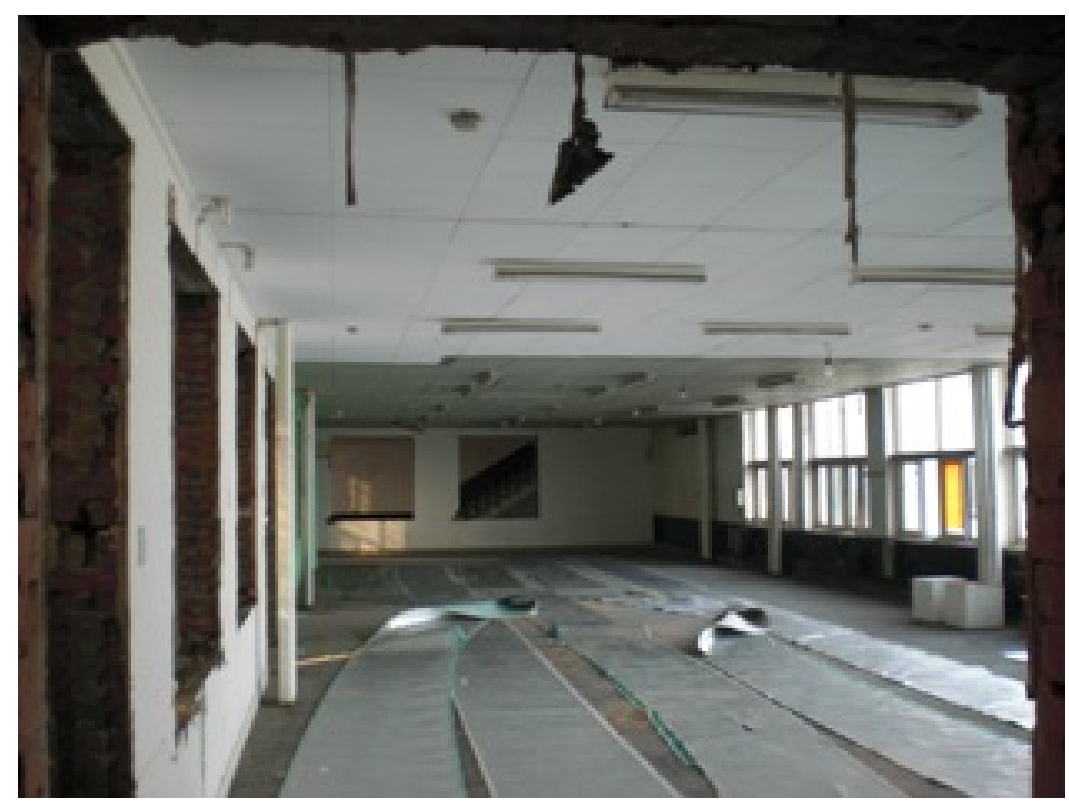

Figure 11: Inside the byeolgwan. Gwangju (Photo: Thomas Vink, 30/05/09). 
Given the lack of sympathy towards the 5.18 associations, tropes of impurity arose often in my discussions in Gwangju. Demonstrators in Seoul, such as the KCTU, continue to appropriate Myeongdong Cathedral's reputation as a safehaven for their own protests, despite the establishment of democracy in Korea. Therefore, the charges of impurity and corruption at the docheong hold distinct similarities to the situation at M yeongdong Cathedral, where Catholic Church members like Kim Jin-Hoe (Pers. Comm. 22/05/09) and Yang Hyeon-Hong (Pers. Comm. 16/05/09) claim that those who continue to use the cathedral as a safehaven to protest are impure and members of an i-ikjibdan. Catholic Church officials are also weary of re-interpretations of the past that continue to associate M yeongdong Cathedral with resistance. Therefore, officials dismiss the claims of demonstrators, asserting that protesters are merely using the cathedral's reputation as a justification for personal gain. At the same time, the Catholic Church has motives for disassociating from the past, for as it has developed increasingly close ties with the government it has seemingly been co-opted. The recent renovations at the cathedral, which were 70 percent funded by the state, give an indication of these growing ties, and appear as a reason behind the turn towards less radical understandings of Myeongdong Cathedral and its once distinctly anti-government connotations.

The docheong and Myeongdong Cathedral, as important 'sites of memory,' are and always have been variously interpreted by a diverse range of individuals and groups. The contestation that arises from these different understandings, however, generates a space in which to explore wider social issues and, thus, is a positive sign that alternate interpretations may be voiced. The real concern will arise when contestations end and such sites are represented by single narratives, and risk becoming 'invisible monuments' (cf. Musil, 1986: 322). 


\section{Interpreting Place and Space}

Both the docheong and Myeongdong Cathedral are typical 'sites of memory' in the way their meaning is constantly recycled and re-inscribed. The literature on sites of memory argues that the very substance of a memorial is political (cf. Richter, 1999: 109) and that sites of memory not only represent political conflict, but are spaces of contention in and of themselves (cf. Yea, 2002: 1571). Given their history, the docheong and Myeongdong Cathedral are also inherently political and contentious. Furthermore, M yeongdong Cathedral and the docheong are liminal places, reforming their identities, as collective understandings of the meanings they imbue shift. Both sites are caught inbetween the past images that they became known for, and representations that promote new uses for the sites in the future.

Because the docheong is not yet appropriated with 'hub city' inclinations, it represents an in-between space, much like the city of Gwangju itself. The conflict between Gwangju's ties to its radical, neglected and violent past and its aspirations to become a future-oriented, global city of culture are encapsulated in the docheong, a relic of the past that is intended as a catalyst for future aims. The key issue is a concern that the ACC does not pay heed to the various interpretations of place and identity represented through the docheong, and more generally through sites of memory in Gwangju. More specifically, the 5.18 associations claim personal and regional meaning from the buildings that represent 5.18, but these personal and regional assertions conflict with the goals of the HCAC project.

Myeongdong Cathedral, conversely, maintains its primary use as a place of worship. Nonetheless, contestation over its symbolic connotations abound. Entering the M yeongdong Cathedral grounds is like crossing a border. The invisible barrier that keeps the police out also maintains a separation from the growth-driven, individual, consumeristic society represented by M yeongdong's shopping and business district (See Figure 12 on page 95). While the cathedral no longer offers a sanctuary in the same way as the past, I got a sense from the people I spoke to that the cathedral does still represent aspects of a more emotional, socially- and politically-driven past. Therefore, 
M yeongdong Cathedral is also, in a sense, caught between worlds. The history of the cathedral, which associates Catholicism with the minjung and the site with resistance against the state, is now at odds with the Catholic Church's promotion of the cathedral's religious and cultural aspects.

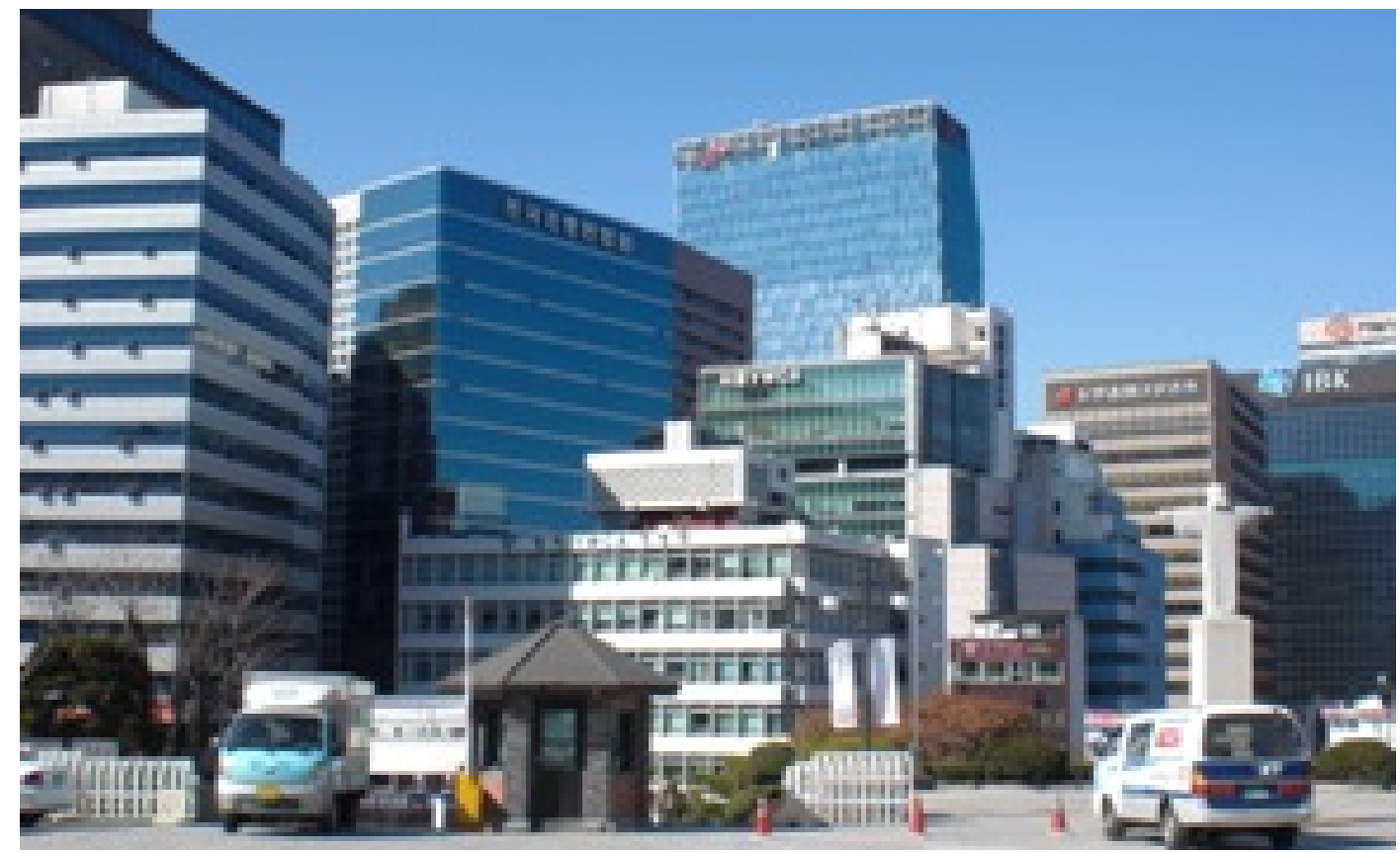

Figure 12: Looking across the road from Myeongdong Cathedral, Seoul (Photo: Thomas Vink, 06/03/09).

Two primary interpretations of Myeongdong Cathedral exist: that it is an important historical and religious site, or that it is a site of ongoing resistance towards authoritarian social and political institutions. Father Na Seung-Gu jokingly suggested (Pers. Comm. 02/06/09) making a copy of M yeongdong Cathedral, so that one can be for religion and the other for protests. In the past, the two stances were intimately connected via minjung theology, but now the connection is growing weak. The cathedral has traditionally symbolised both Catholicism and democracy in Korea. However, the increasing separation of these two symbolic meanings has created an identity conflict for those (such as members of the CPAJ) who wish the two to be connected and to 
reconcile faith with political and social reality (cf. Clark, 1995). Without official support, priests no longer have the same justification to stand up for their social and political concerns as in the past.

Similarly, the conflict over the construction of the ACC in Gwangju, illustrates a number of competing interpretations, this time over 5.18. The event itself, as well as the marginalisation of Gwangju in the following years, built a collective sense of identity within the city - a 'Gwangju spirit' - and many local citizens still hold a personal attachment to 5.18. Local understandings of 5.18 conflict with another narrative, which gained prominence in the 1990s: that 5.18 is nationally important as a key event in the achievement of democracy in Korea. The lessons learned, and achievements made, as a result of 5.18 are now being promoted as of international importance. Like the identity concerns at M yeongdong Cathedral, the changing meaning of 5.18 has created a conflict of identity within Gwangju, as local readings of the event diverge with recently privileged national and international interpretations.

Sites of memory have an inherent capacity for transformation, thus, despite conflict over what images of past should be privileged, each site still has the potential, through ongoing appropriation, to act as an inclusive space where competing interpretations can all be represented.

M yeongdong Cathedral can represent both Catholicism and democracy or social justice, at least in a symbolic sense, because of the use of space at the site. As the head cathedral for the Korean Catholic Church and as a highly recognised and often visited site, the cathedral does still stand out within the city sprawl that has taken over the Myeongdong neighbourhood. An understanding of the space the cathedral occupies highlights the potential to move beyond the dichotomous - centre of Catholicism versus centre of democracy and human rights - image that has developed. The interior of the cathedral does not have a history of association with democracy; the interior has always maintained its religious emphasis, as a place to hold services and events. Images related to the minjuhwa undong at Myeongdong are, instead, typically of the cathedral grounds, 
where protests were held and demonstrators camped (See Figure 14 below). The unspoken barrier of asylum began as soon as one entered the cathedral precinct and not merely the building itself. In this sense, therefore, Father $\mathrm{Na}$ 's suggestion to have two cathedrals is not entirely a joke. Ongoing renovations to the grounds may allow the cathedral to address these increasingly divergent functions and to exist as both a centre of Catholicism and as a centre of democracy, resistance and social justice.

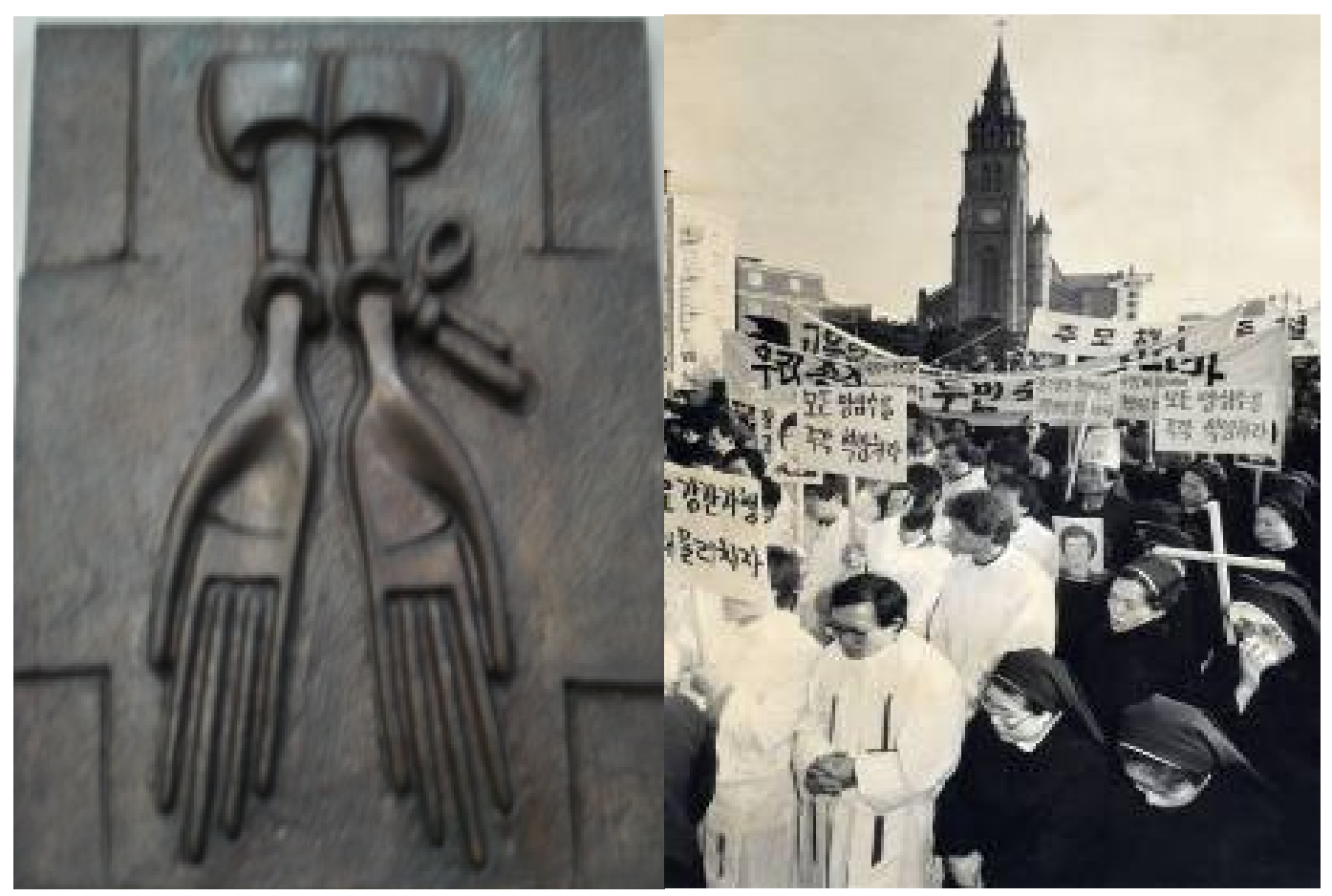

Figure 13 (left): One of the 'stations of the cross' inside Myeongdong Cathedral. Seoul (Photo: Thomas Vink, 07/ 05/ 09).

Figure 14 (right): Memorial service and prayer meeting held for Park Jong-Cheol. Myeongdong Cathedral. 02/ 07/ 1987 (Catholic Priests' Association for Justice website, 2009).

In addition to the use of space at the site, Myeongdong Cathedral also holds importance beyond its symbolism. In the 1980s, education was one of the key factors behind the development of the cathedral's safehaven reputation (cf. Lee Dae-Hun, Pers. 
Comm. 17/05/09). By continuing to educate the public, the cathedral can act as a "real environment of memory," where memory is passed down through the generations and maintains its personal connections (cf. Nora, 1989: 7). M yeongdong Cathedral not only represents an important symbol of the past, but still has the potential, if allowed, to be a juncture for political discussion - a space that actively attempts to create understanding of Korea's history (cf. Portelli, 1991: 52) - and an aide to the democratic values that numerous people in Korea are questioning. Many church-goers mentioned the late cardinal, Kim Sou-Hwan, and even movies like 5.18 (Hwaryohanhyuga), as their key informants regarding Korea's contemporary history. Myeongdong Cathedral can continue to be an important site of memory by performing a similar role to that of Kim Sou-Hwan and acting as a catalyst to understandings of Korea's recent past and the past's relevance to the present and future.

Likewise, the ACC can, potentially, represent local collective understandings of 5.18 and provide a space to debate the meaning that 5.18, and the city of Gwangju, holds in a national and international context. While the docheong and byeolgwan are real symbols of the past, to those without personal connections to 5.18 , the buildings are mere monuments to the event. Not in the 'disneyfied' (cf. Funder, 2003; Kundera, 1984; Richter, 1999) sense that has the 5.18 associations concerned about the ACC, but rather as 'invisible' (cf. Musil, 1986: 320) places that are imbued with meaning but do not necessarily spur remembering (cf. Bell, 2003: 73). As the docheong site stands now, the scope for renewing the meaning of 5.18 is limited, an issue that I believe has contributed to the growing fatigue towards memorialising 5.18 in Gwangju.

The ACC has the potential to create the space needed to renew the meaning of 5.18. However, issues remain. Despite the appropriation of 5.18 as of national and international importance, very few outside of Gwangju know anything about the HCAC project, let alone the conflict over the byeolgwan, which suggests that conflict over whose interpretations of 5.18 are privileged, is still largely a local Gwangju issue. Though the HCAC project was initially approved as an act of contrition for past neglect (Hoffmann, 2000), Gwangju and the Jeolla region remain separate from the rest of the 
country. While the marginalised image of Gwangju and 5.18 perseveres - in a project that is meant to hold important national connotations - a question remains over whether the HCAC project can represent multiple understandings of the docheong site, and of Gwangju itself.

\section{Conclusion: "The past is never dead; it's not even past" 8}

The emphasis on new representations of the past at the docheong in Gwangju and Myeongdong Cathedral in Seoul has created conflict and contention. Maintaining the past in the present is not a universal desire, a point clearly illustrated by these case study sites: the emphasis on new images at the docheong and M yeongdong Cathedral is distinctly future-oriented. Nevertheless, the re-interpretation of historical events can also maintain the relevance of the past events in the present. Jung Hae-Gu (Pers. Comm. 13/05/09) believes that the events of Korea's recent past contain lessons that are relevant to the present political and social situation in Korea. Thus, to Jung, the contestation over and appropriation of memory in Korea is a sign that the past will not be forgotten, and that events like 5.18 do still resonate with many Korean citizens.

In the wider literature on studies related to remembering the past, a question is often asked of whether it is more important to 'remember' or 'forget' when building collective identity? ${ }^{89}$ For Korea, in the 1960s and 1970s, forgetting helped the country move forward and create a successful nation..$^{90}$ In recent decades, the emphasis has shifted to remembering with marginalised groups able to reclaim their own collective understandings of history. Korea's protest culture has helped to maintain the relevance of the past for today's society. However, the two case studies explored here illustrate

\footnotetext{
${ }^{88}$ Faulkner, William. (1951). Requiem for a Nun.

${ }^{89}$ cf. Funder, 2003: 52; Huyssen, 2000; Nietzsche, 1969; Nora, 1989, 2002; Ricoeur, 1999.

${ }^{90}$ Yun Ch'oe and Mark Morris (2010) claim that forgetfulness of the extremity of past events may have actually helped Koreans to move without fear into the future and build their modern nation and Cho Han Hae-Joang asks (2000: 67) "Have South Koreans been walking so quickly and mindlessly in order to forget the terrible experiences that they have had to go through?"
} 
that the conflict between violent aspects of history and the sanitised cultural future that many officials are emphasising is growing. The question of memory explored throughout the literature cannot be answered in the Korean context either; the merits of remembering or forgetting the past are still in debate.

The city of Gwangju symbolises Korea's domestic subaltern. Although long without a voice, citizens were able to reclaim their identities by promoting their own local narrative of the past. Now this 'Gwangju spirit' is being conveyed in terms of democracy and human rights in Asia. Gwangju sees itself as a role model for other cities in Asia, providing a locale to build and strengthen international relationships. However, the memory of Gwangju's resistant past represents a core part of many citizens' identities and Gwangju's potential new role risks de-legitimising the meaning that 5.18 holds to them. At the docheong, the construction of the ACC has the potential to consign local memories of, and connections to, 5.18 to the past by emphasising the uprising's wider national and international connotations. However, the contestation over memory at the docheong has also created new debates over the meaning of the site, rather than letting the docheong become an "invisible" space (cf. Musil, 1986: 322). The ACC, by giving groups in Gwangju a chance to debate the meaning of 5.18, also has the potential to construct a more visible and meaningful narrative of memory for the city and the country.

The contention over the renewed emphasis on Myeongdong Cathedral's religious and cultural aspects is not so much at the site itself, but rather a wider conflict regarding social concerns in Korea. The reframing of Myeongdong Cathedral's meaning away from its symbolism as a site of resistance is representative of a growing apathy within the Catholic Church, as well as some parts of the Korean population, about both past struggles against authoritarianism, and to present social and political issues, as economic growth and individual concern has taken prominence. However, at the same time, many citizens continue to gather and protest (See Figure 15 on page 101). South 
Korea has often been touted as a role model for development because of its rapid shift from poverty to economic and technological powerhouse in a matter of decades. But the rapid shift came on the back of harsh authoritarianism and human rights abuses that the populace fought against for years. In the current political and social climate an increasing number of people are referencing this past in relation to what they term Korea's deteriorating democracy. Continuing restlessness in Korean society and the ongoing involvement of religious figures in political movements is a clear sign that sites like Myeongdong Cathedral, despite the growing apathy in some sections of Korean society, still hold great relevance today.

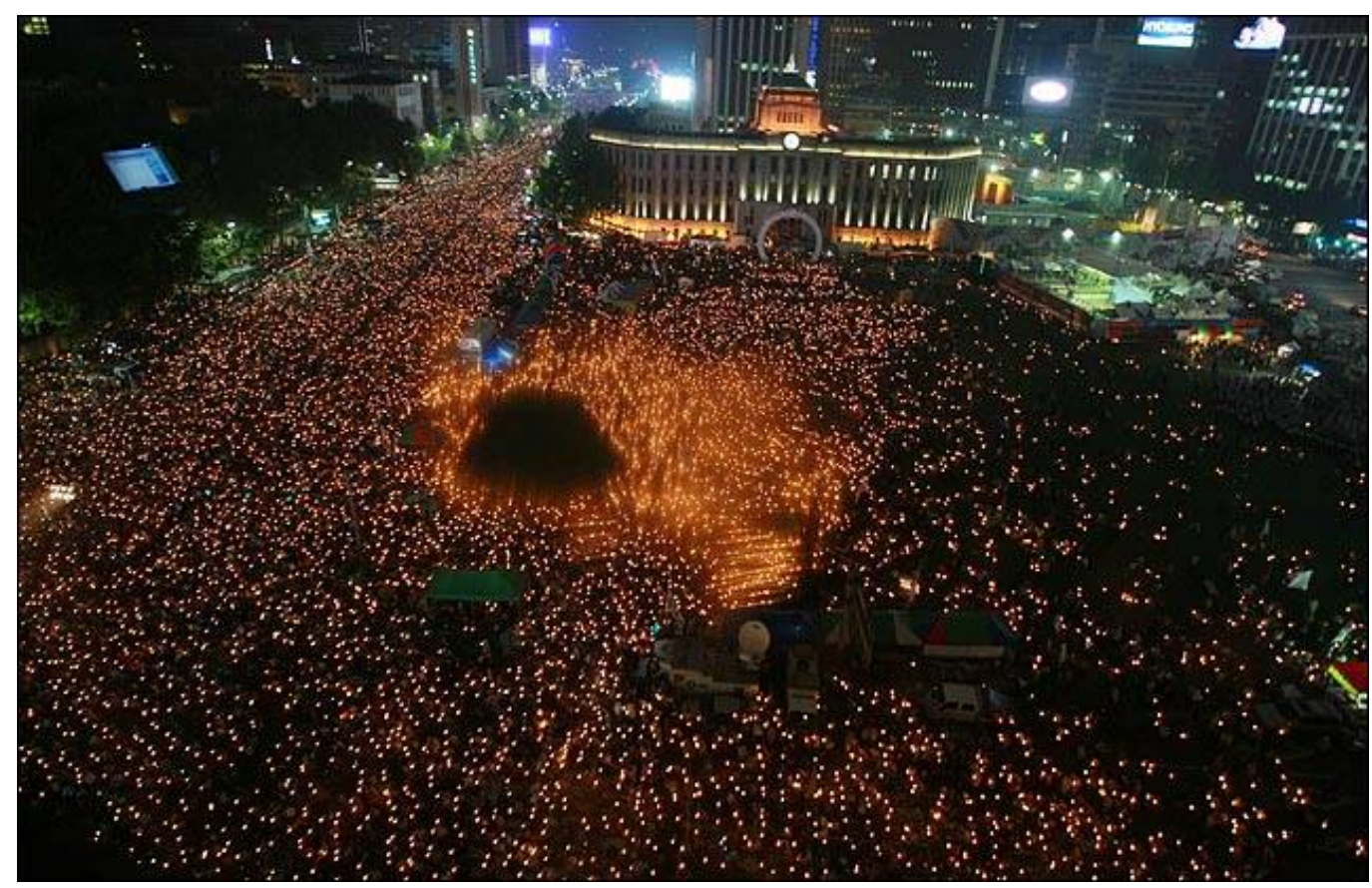

Figure 15: The so-called 'candlelight demonstrations.' Seoul. 10/06/ 08 (S.H. Yoo. In R. Hauben, 2009).

The privileging of particular representations of the past not only helps to build collective understandings of memory and of identity, but, by acting as a form of legitimisation, can also marginalise individuals and groups whose interpretations of the past may differ. Many in Korea now use history as a justification for demonstration and 
protest, relating abuses and injustices in the past to those of today. With so many different interpretations of history - so many ways of justifying its appropriation deciding whose representations of the past are privileged in Korea, as everywhere, becomes necessarily a contentious and political process. However, having the chance to make that decision - the chance to debate the various meanings that the past entails is a positive sign that democratic values are established in Korea. Sites of memory, like the docheong and Myeongdong Cathedral, may be inherently contentious and political places, but that contention at least indicates there is space within Korean society to discuss ongoing concerns and to move into the future knowing that various groups, even marginalised groups, have a space to convey their voice. Thus, the fact that sites of memory in Korea are so contentious and political is not a problem. Rather, problems arise with non-contested spaces. When the past is no longer contested and when important historical sites present a fixed meaning, or convey a singular narrative of the past; that is when representations of the past become silent and 'invisible,' and particular past events, firmly set in history. 


\section{Chapter Five - Epilogue: Back to the Future}

"Man - Just remember that the things you put into your head are there forever, he said. You might want to think about that.

Boy - You forget some things don't you?

Man - Yes. You forget what you want to remember and you remember what you want to forget."

Cormac M cCarthy The Road (2006: 12).

"There is a secret bond between slowness and memory, between speed and forgetting... a person who wants to forget a disagreeable incident he has just lived through starts unconsciously to speed up his pace, as if he were trying to distance himself from a thing still too close to him in time"

Milan Kundera Slowness (1995: 39).

The air is charged and electric, with bouts of thunder gaining in frequency as I wait patiently outside the former docheong of South Jeolla in Gwangju. It is the $26^{\text {th }}$ of May, which means the summer monsoon season is just around the corner. For now, though, I just have to deal with a dull pattering on the temporary tents above my head as I stand in line behind those paying their respects to the late Roh Moo-Hyun. The memorial image fastened to the docheong wall depicts a smiling Roh pulling his grandson through the countryside on a bicycle. Above the image are the words Uri Daetongryeong (Our President). Roh Moo-Hyun was born and raised in Gimhae, in South Gyeongsang province in the southeast of Korea. Rather surprisingly, however, in this country where antagonisms between regions often have functioned as a great concrete wall in the middle of the political and social landscape, the citizens of Gwangju revere him as one of their own. As president, Roh took an interest in their often neglected region, and the votes he received from Jeolla residents went a long way to helping him win the 2002 presidential election.

As I approach the memorial altar - as the people in front of me form a group and bow as one - a volunteer to my left breaks down and starts weeping. A sense of guilt swells in the pit of my stomach that I am there more to see this aspect of Korean culture rather than necessarily pay my respects. Despite my ulterior motives, however, and the 
fact that I have no connections to this man, the ceremony was one of the most moving experiences I had in Korea.

Three days later, I woke up with the first rays of the sun to catch an early bus up to Seoul to witness the main funeral. Images and discussions of Roh filled the television screen for the entirety of the three hour drive. Meanwhile, as I scanned the Korean countryside out of my window, vehicles and groups lined the sides of the road or camped on the hillsides waiting to get their view of the hearse driving the length of the country with Roh's body. I couldn't shake the feeling that it would overtake us at any moment, almost as if we were racing him to his own funeral.

Central Seoul itself is packed to the brim. I often reflect, on how the image of the man could change so drastically. Roh Moo-Hyun died a broken man. When his presidency ended in 2008 , he left the office dogged by accusations of incompetence and the reality that under his leadership the general mood of the public had shifted from progressive leanings back to conservatism. Then, after facing bribery charges, which broke his formerly clean image, he was widely derided. In May 2009, Roh jumped to his death off a cliff near his home, leaving a typed message on his computer screen stating that his life had now become a burden on others.

But, as I waded through the 500,000 people lining Sejongno - a well-known and busy street in downtown Seoul - and crammed into City Hall Plaza, it was clear that Roh's supporters had been given rein to express their emotions publicly again. Many of those gathered were dressed in his campaign colour, yellow, some lifted standards to the air, and a woman wailed next to my ear as the funeral cortege passed by. Standing in front of City Hall, my arms burning on the radiant heat of the people jammed next to me and my clothing wet with sweat not all my own, the crowd joined in as performers on the stage started singing. As voices swelled around me to the lines of Achim Iseul (Morning Dew) - a famous Korean song widely known as an anthem used at mass gatherings - the emotion was palpable. Roh was loved once more. 


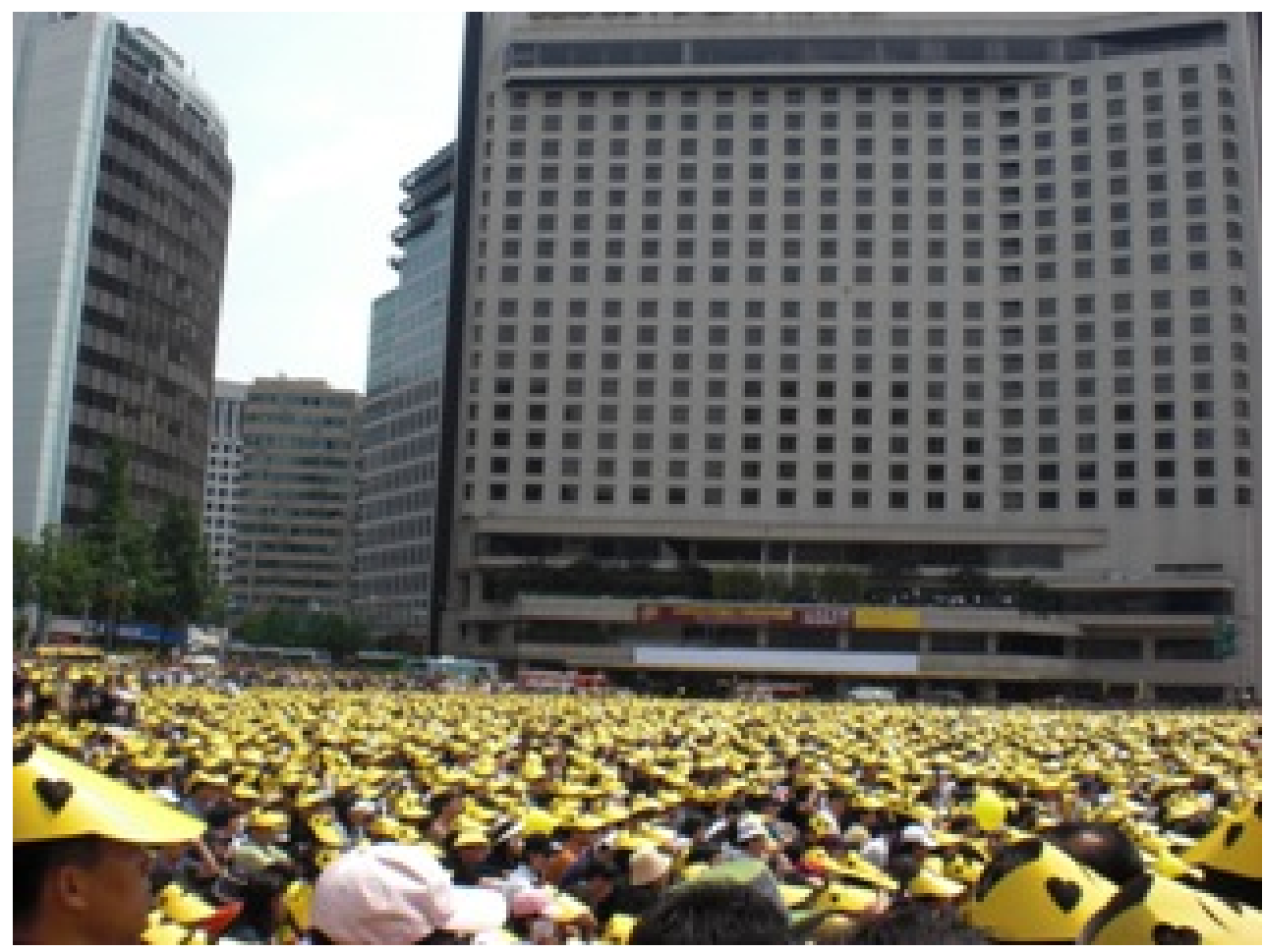

Figure 16: People gathered in front of City Hall for Roh Moo-Hyun's funeral. Seoul. Photo: Thomas Vink, 29/05/ 09.

The reports in the days and weeks following Roh Moo-Hyun's suicide generally set aside his faults in order to preserve the memory of the former president. In fact, Roh's suicide became a vehicle for anti-Lee M yung-Bak propaganda, with some going so far as to blame President Lee, through general policies and pressure on Roh via prosecution that appeared politically motivated, for Roh's death. A memorial service for Roh at M yeongdong Cathedral was appropriated by the CPAJ in order to voice concerns about the state of Korean politics. Others predicted that because of the emotion involved and its timing at the beginning of the "summer [protest] season," the anniversary of Roh's death would be an important day in the future for anti-government protests.

October 2009 marked the $30^{\text {th }}$ anniversary of former president Park Chung-Hee's death. While the truth regarding the human rights abuses and harsh authoritarianism of 
his regime is becoming more widely known every year, many Korean citizens now recall Park with a sense of nostalgia. As Korea's democratic presidents have failed to achieve the level of economic growth set by the dictatorial leader, the collective memories of Park Chung-Hee have shifted to create a more accommodating image of the former President. ${ }^{91}$ Like the nostalgia for Roh Moo-Hyun, as circumstances change, good memories can come to override the negative: "In the sunset of dissolution, everything is illuminated by the aura of nostalgia, even the guillotine" (Milan Kundera: 1984: 4). In the 1990s, as Korean democracy became established, and former presidents Chun DooHwan and Roh Tae-Woo were put on trial for their roles in 5.18, the costs of Korea's rapid development gained more attention. Nevertheless, in more recent years a question is commonly asked of whether economic growth could have been achieved with a more open and democratic system. Park's leadership was dictatorial, however, it also resulted in relatively even social and economic growth throughout Korean society and brought almost the whole population out of poverty in a matter of decades, a unique achievement. The drive to develop in the 1970s has been described as a straight line to which all else must bend: "If planners wanted to build a straight road and there was a tree in the way...they moved the tree." (Oppenheim, Robert, 2008: 48). But, that dogmatic approach enabled Korea to, essentially, "make something out of nothing," and impressed a strong-minded work ethic upon the Korean people that remains today (Kang Hyun-kyung, 2009). ${ }^{92}$

Under the rule of Chun Doo-Hwan, Korea's economic growth remained strong, yet there is no sign of any such reverence for Chun. Park Chung-Hee was widely acknowledged as a modest and honest person, who was working for the good of the

\footnotetext{
${ }^{91}$ Michael Breen goes so far as to claim (2004: 255) that "Koreans are haunted by the ghost of Park Chung-Hee" and Seungsook Moon (2009) states that Park has achieved a "phantasmagoric afterlife" as images have shifted from "an antinational, fascist dictator to that of a superhuman hero and national savior."

${ }^{92}$ Choi Yearn-hong (2009), too, claims that Park was a "necessary evil for the nation" and Seungsook Moon states (2009) that "the nostalgic memories glorifying Park justify his authoritarian rule as the inevitable condition for the achievement of rapid industrialisation in a "less-developed" country like Korea."
} 
nation rather than for selfish ends. ${ }^{93}$ By the time Chun came into power, however, a new generation of middle-class Koreans, who had grown up relatively free from poverty, were becoming politically active and saw democracy, not only as a possibility, but as a necessity. Furthermore, Chun was never able to eliminate the stigma attached to him as a result of the brutality of 5.18: "The ghosts of murdered protestors haunted Chun DooHwan" (Breen, 2004: 216).

The changing images of Roh M oo-Hyun and Park Chung-Hee are representative of a nostalgic view of the past, where "the absent/gone is valued as somehow better, simpler, less fragmented, more comprehensible, than its existent alternative in the present" (Hirsch \& Spitzer, 2003: 82). As millions of Koreans lost their jobs in the 1997 financial crisis, the costs of Park's regime, again, fell under the veneer of the economic growth and wealth generation he had brought, and calls for a Park Chung-Hee-like savior intensified. Nevertheless, while Park's motives may have been genuine, the costs of his regime were still surprising and horrific. Thus, the nostalgic image of Park has consequences. Yun Ch'oe and M ark Morris speculate (2010), for example, that speaking of historical events with a sense of nostalgia is like "ignoring pains that have not yet faded from the minds and the hearts of the Korean people, from all generations who lived through these events. Their impact is still very much at the core of Korean society."

As the images of significant figures, like Park Chung-Hee and Roh Moo-Hyun, have changed following their deaths, so to have the memories of Korea's minjuhwa undong after the movement ended. The achievement of democracy in Korea was built on decades of dissent and a movement that came to incorporate a large proportion of Korean society. Following the successful demonstrations of 1987, and most notably, with the advent of procedural democracy in the 1990s, the minjuhwa undong had finally achieved its primary goal. Why, then, given that Korea has been a democratic country

\footnotetext{
${ }^{93}$ For example, Kim Choongnam claims (2007) that Park was committed to doing what was possible (economic development) to improve the nation, rather than what was desirable (democratic development). Park was apparently disinterested in personal luxuries and wealth and did not accept bribes; an image that Seungsook Moon (2009) terms "a thrifty, modest and incorruptible life (Jeongnyeom Gyeolbaekhan Saenghwal)."
} 
for over 20 years now, do the streets still continue to convulse at times with mass demonstrations?

\author{
The iron shackles are broken, \\ In the aloneness of freedom, \\ I long for your order of oppression. \\ I shall have no dreams; \\ I will not stop this business of \\ Bearing pain with dreams. \\ I will live from day to day without feeling \\ This life I cannot bear. \\ Kim Ji-ha, 'The Aloneness of Freedom' (In Robinson, 2005: 25).
}

Kim Ji-ha, a famous Korean poet, widely known for his satirical criticism of the Park Chung Hee government, ${ }^{94}$ writes above of the dissolution felt by many Koreans since the achievement of democracy. Around the minjuhwa undong large numbers of Koreans formed a collective sense of identity and purpose. The loss of the "order of oppression" that came with the achievement of democracy, though, "has created an identity crisis" (Linda Lewis, 2000: 184). With the rise and fall of the minjung movement, and now with a growing emphasis on multi-culturalism in Korea, more voices are represented than ever before. A great contrast is evident within Korean society as a greater number of citizens seek to move beyond the past while many others still appropriate past events and reputations to demonstrate against present concerns.

Furthermore, the political terrain in Korea remains fractious. The ten-year period of progressive politics under Kim Dae-Jung and Roh Moo-Hyun was seen as a sign that the social ideals fought after for so long were finally coming to fruition. Yet, many within Korea's new generation hold a conservative mind-set and are more concerned by unemployment and competition for jobs and university entrance than the ideological issues that were the focus of the 386 generation (Park Sun-Young, 2007). Immediately following the term of President Roh (seen as the ultimate success of the liberal-minded 386 generation) the conservative Lee Myung-Bak was elected and the Korean populace overwhelmingly declared their interest in economic growth and higher salaries.

${ }^{94}$ In 1976 he was sentenced to life imprisonment because of this, but was later pardoned. 
In 2005, under Roh's presidency, the Korean Truth and Reconciliation Commission was formed to uncover the truth behind past events and help the country reconcile with the past. Dr. Kim Sung-Soo, the head of the International Cooperation Team at the Commission and one of their key translators, was one of my first contacts in Korea, and he was a great help to me during my stay there. In the final weeks of writing my thesis I received emails from Kim discussing concerns within the Commission. President Lee Myung-Bak made it clear that the Commission's mandate will not be renewed when it expires at the end of March 2010. In December 2009, a new Commission president, Lee Young-Jo, an academic known for his past association with the New Right Union, was selected with government backing (McDonald, 2010). Lee Young-Jo has banned the distribution of a new report by the Commission regarding their historical findings on the grounds that it has "translation errors." Kim Sung-Soo believes this ban is an attempt to get rid of a perceived left-wing bias within the Commission. Now that the Commission's term is running out, Kim is concerned about work that is yet to be done, and that the conservative administration will override much of the work already completed and the recommendations the Commission has made.

In Gwangju, while the conflict at the docheong is essentially over, the future of the byeolgwan, and of whose narratives of 5.18 are emphasised more generally in the city, remains uncertain. In the days before I left Gwangju in late M ay 2009, I was told of a new plan suggested by the 5.18 associations, that the government could incorporate the byeolgwan as an entrance to the ACC complex (Park and Katsiaficas, Pers. Comm. $27 / 05 / 09$ ). I saw this as a sign that the conflict at the docheong was finally coming to a resolution. By August 2009, the 5.18 associations had given up their protests and entrusted the "Commission of Civil Organisations" (Simin Daechaek Wiwonhoe), a group of labor organisations and labor party activists, to negotiate with the government (Park Hae-Gwang, Pers. Comm. 12/08/09). By February 2010, as I finish this thesis, the future of the byeolgwan, though, remains unclear. The M inistry of Culture and Tourism agreed, 
in principle, to preserve as much of the building as possible. However, the byeolgwan is in such disrepair that part of it may have to be demolished anyway to keep its integrity. The opening of the ACC has now been delayed until 2014, two years behind schedule (M r. Ryu, Pers. Comm. 16/02/09).

At M yeongdong Cathedral, renovations to emphasise the site as a historical treasure have now been completed, and the situation remains the same: the Catholic Church continue to emphasise the religious and cultural aspects of the cathedral. Perhaps, though, there are other sites ready to take up the role that $M$ yeongdong Cathedral, at the behest of officials in the Catholic Church, is leaving behind. Buddhist Koreans are showing an increasing ambivalence towards the government, as Protestant president, Lee M yung-Bak, shows apparent disrespect and discrimination towards the Buddhist faith (Do Je-hae, 2010). A number of monks, for example, played a vocal and visible role in the candlelight protests of 2008 , and on the $16^{\text {th }}$ of June 2009 , the Hankyoreh reported that "some 1400 Buddhist monks have joined the declaration movement [for the 'restoration' of democracy in South Korea]." Six of the leaders that took part in the 2008 candlelight protests later sought refuge in Jogye Temple, in central Seoul (Kim Rahn, 2008). Like M yeongdong Cathedral, Jogye Temple offers a rare sanctuary in the middle of Seoul, in that, as a religious site, police can not enter the grounds. Apparently, some individuals in Korea still see a need for a 'sanctuary' or a 'site of resistance,' whether Myeongdong Cathedral continues to provide it or not.

As I finish this chapter I realise that I first arrived in Korea to begin my fieldwork almost a year ago to the day. In that year memories of the past have continued to resonate across Korean society. Roh M oo-Hyun's suicide came in between the deaths of two of the most important figures in the history of Korea's democracy movement: former Cardinal, Kim Sou-Hwan, in February, and former President, Kim Dae-Jung, in August. What's more, with the full effects of the global financial crisis still unclear and the current president, Lee Myung-Bak, continuing to fall short of his election promises to improve South Korea's economy, nostalgia for another deceased former President, 
Park Chung-Hee, and the rapid economic growth he brought remains strong.

Despite the evidence of growing apathy amongst sections of Korean society towards the nation's troubled past and towards present socio-political concerns, the candlelight demonstrations of 2008, and the apparent 'deterioration of democracy' occurring since Lee took over the presidency, highlight that political concerns can still bring people out to protest in Korea en masse. The issues at the Truth and Reconciliation Commission, too, still ongoing as I print off this thesis, are a clear sign of the ongoing contestation over interpretations of memory in Korea; the politics of collective remembering are still controversial and relevant. Indeed, remembering or forgetting a particular aspect of the past is at the core of, not only collective understandings of Korean identity, but of given representations of identity throughout the world. The past is never dead, rather, its meaning is forever shifting; Korea, and the ongoing contention over how its past is represented and remembered, is emblematic of this change. 


\section{Appendices}




\section{Appendix One: VUW Ethics Committee Approval Memorandum}

TF WHARE WĀNANGA O TE ÜPOKO O TE IKA A MĀL

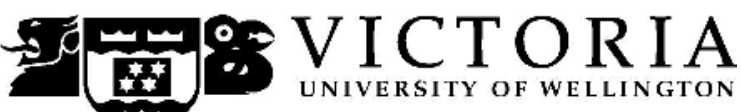
MEMORANDUM
Phone $\quad 0-4-4635676$
Fax $\quad 0-4-4635209$
Email Allison.kirkman@uw.ac.nz

\begin{tabular}{|c|c|}
\hline TO & Thomas Vink \\
\hline COPY TO & Dr Stephen Epstein, Supervisor \\
\hline FROM & Dr Allison Kirkman, Convener, Human Ethics Committee \\
\hline DATE & December 21, 2008 \\
\hline PAGES & 1 \\
\hline
\end{tabular}

\begin{tabular}{l|l}
\hline SUBJECT & $\begin{array}{l}\text { Ethics Approval: No 16244, The politics of memory: represent- } \\
\text { ations of place and identity through sites of memory in South } \\
\text { Korea. }\end{array}$ \\
\hline
\end{tabular}

Thank you for your application for ethical approval, which has now been considered by the Standing Committee of the Human Ethics Committee.

Your application has been approved from the above date and this approval continues until 28 February 2010. If your data collection is not completed by this date you should apply to the Human Ethics Committee for an extension to this approval.

Best wishes with the research.

Allison Kirkman

Convener 


\section{Appendix Two: Participant Information Sheet and Consent Form for 'Organisational Representatives'}

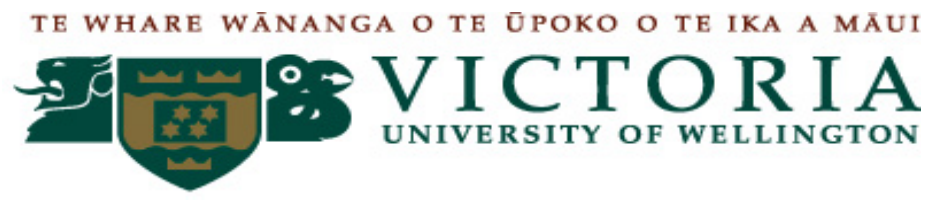

\section{Participant Information Sheet for Research on Representations of Pro-Democracy Movements in South Korea in the 1980s}

1980 년대 민주화 운동의 representations 조사연구를 위한 참여 설명서
Researcher: Thomas Vink - School of Geography, Environment and Earth Sciences, Victoria University of Wellington, New Zealand
조사연구원: 토마스 빙크 - 뉴질랜드 웰링튼 빅토리아 대학교, 지리, 지구 환경 대학 논문 주제 : 한국에서 “현장의 기억”을 통한 공간 및 정체성의 형태

I am a Masters student in Development Studies at Victoria University of Wellington, New Zealand. As part of this degree I am undertaking research that will lead to a thesis. This research looks at how a number of different sites of memory in South Korea related to pro-democracy movements, and their suppression, in the 1980s, are currently being represented and reinterpreted. It is intended that this research will contribute to further understanding about how South Korea's past is affecting its future and bring insights to how important events can be interpreted to meet different ends. The university requires that ethics approval be obtained for research involving human participants.

저는 뉴질랜드 웰링튼 빅토리아 대학교에서 발전학을 공부하고 있는 대학원생입니다. 이 학위 과정의 한 부분으로 저는 논문을 위한 조사연구를 실시하고 있습니다. 이 조사연 구는 1980 년대의 한국의 민주화 운동들과 관련된 다수의 “기억의 장소들" 이 현재 어떻 게 제시되며 재해석되고 있는지에 주목하고 있습니다. 이 연구조사는 과거의 역사가 어 떻게 한국의 미래에 영향을 끼치고 있는지에 대해 좀 더 심도 있게 이해할 수 있도록 도 와주며 또한, 중요 사건들이 다른 시야에서 어떻게 재해석될 수 있는지에 대한 통찰력을 가져오는 데에 그 목적을 두고 있습니다. 저희 대학교는 조사에 관련된 모든 참여 대상자 들로부터 윤리도덕적 승인을 받는 것을 원칙으로 요구합니다.

I am carrying out interviews with people who have visited these sites to find out why they visit and what meaning the site(s) hold for them. I am also interviewing people who have done research related to the suppression of pro-democracy movements in 1980s South Korea and how the memory of this suppression is represented. 
저는 이러한 장소들을 방문한 적이 있는 사람들을 대상으로 그들의 방문 목적과 그 방문 이 그들에게 가지는 의미에 대해 인터뷰를 시행하고 있습니다. 저는 또한 1980 년대 한국 의 민주화 운동 억압과 관련된 조사 연구를 주도했던 이들을 상대로도 인터뷰를 하고 있 습니다.

Some of the interview questions deal with sensitive issues and you may decline to answer any question without having to give reasons. Should you feel the need to postpone or end the interview you may do so without question at any stage. Likewise if, for any reason, you decide after the completion of the interview that you do not want any of the information given to be used, let me know and I will destroy it or return it to you.

몇 가지 인터뷰 질문들은 민감한 사회 문제들을 다루고 있으며 본인이 원치 않을 시에는 이유를 불문하고 대답을 거절하실 수 있습니다. 또한, 원하실 때에는 언제든지 인터뷰를 연기하거나 중단하실 수 있습니다. 마찬가지로, 인터뷰를 마치신 후에라도 인터뷰 내용 이 쓰여지기를 원치 않으신다고 결정하시게 될 경우, 제게 연락을 주신다면 그 내용을 폐 기 처분하거나 본인에게 돌려드리겠습니다.

The interview will take approximately ... minutes and will be one-off, unless we agree at the time that a follow up interview would be beneficial.

인터뷰에 소요되는 시간은 대략 -_- 분입니다. 인터뷰는 한 번만 시행되지만, 때에 따라 필요 시에는 서로의 동의 하에 추가로 더 시행될 수도 있습니다.

Interview responses will provide specific insights that will be combined with my observational and literature research to form the basis of my thesis. This interview will follow a semistructured format and will be tape recorded unless otherwise requested. You may request that any information you provide, including interview notes and tape recordings, will be kept confidential. If this is the case personal pseudonyms will be used for all identifiable information. You may choose the pseudonyms. You may also request to see my interview notes at the completion of the interview. No other person beside my supervisor, Dr Stephen Epstein, and myself will see the interview notes or hear the tape recordings. Notes will be destroyed, and tape recordings wiped, two years following the completion of my thesis. Interview transcripts will also be destroyed unless you request that they be returned to you.

인터뷰에서 응답에 주신 내용들은 현장 조사와 기타 자료 수집과 더불어 제 논문을 위한 구체적인 근거 자료로 제시될 것입니다. 이 인터뷰는 반(牛)구성의 형식을 따르며 따로 거부 의사를 밝히지 않는 이상, 인터뷰 내용은 녹음이 되는 것을 원칙으로 합니다. 기재 되거나 테이프에 녹음된 인터뷰 내용을 포함하여 제공하신 어떤 정보도 요청에 따라 익 명으로 쓰여질 수 있습니다. 이에 해당하는 경우, 부득이하게 이름을 기재해야 할 필요가 있을 시에는 인터뷰 응시자의 필명이 쓰임을 알려드리는 바입니다. 필명은 인터뷰에 참 여하는 본인이 정할 수도 있습니다. 또한, 원하시는 경우에는 인터뷰가 끝난 후 기재된 인터뷰 내용들을 당사자가 직접 확인하실 수도 있습니다. 저와 제 담당 교수인 스티븐 엡스틴 박사 이외의 어느 누구에게도 이 인터뷰 기록에 대한 열람이나 녹음 테이프의 청 취가 허용되지 않을 것임을 알려드리는 바입니다. 인터뷰 기록의 파기와 녹음 테이프의 
소각은 논문 완성 후 2 년 후를 기점으로 이루어집니다. 이때에 반환 요구가 없을 시에는 인터뷰 녹취록 또한 파기됨을 알리는 바입니다.

The thesis will be submitted for marking to the School of Geography, Environment and Earth Sciences and deposited in the University Library. A summary of the thesis may be presented at academic or professional conferences and it is intended that one or more articles will be submitted for publication in scholarly journals. In addition, an executive summary will be produced and be made available to all participants.

If you have any questions or would like to receive further information about my research, please contact me on my cellphone (010-2233-4232); at my home address (Ka320, Hanil Village, 275-11 Seongsan-I-Dong, M apo-gu, Seoul); or from the $3^{\text {rd }}$ of June at my postal address in New Zealand (PO Box 29052, Ngaio, Wellington 6043, New Zealand), phone (+640210642689), email (vinkthom@gmail.com). You can contact my supervisor, Dr Stephen Epstein, at the Asian Studies Institute, School of Languages and Cultures, Humanities and Social Sciences at Victoria University, P O Box 600, Wellington 6140, New Zealand, phone: +6444635703, email: Stephen.Epstein@vuw.ac.nz.

Thomas Vink

Signed:

이 논문은 심사를 위해 웰링튼 빅토리아 대학교의 지리, 지구 환경 과학대학에 제출되어 본 대학 도서관에 소장될 것입니다. 논문 요약은 학술회의나 전문 학술 대회에 제출될 수도 있으며 학술지에 이 연구 조사와 관련된 기사들이 기고될 수도 있습니다. 이와 함 께, 추후 작성될 논문 개요는 인터뷰 참가자 전원이 받아 보실 수 있음을 알려드리는 바 입니다. 본 조사연구와 관련된 문의 사항이 있으시거나 이에 대해 좀 더 자세한 정보를 얻고 싶은 경우,다음에 기재된 연락처를 통해 제게 알려주시기 바랍니다.

제 현재 한국에서의 이동전화번호는 010-2233-4243이며 주소는 서울특별시 마포구 성산 1 동 275-11 한일 빌리지 가동 320호입니다. 한국에서의 조사연구 일정이 끝나는 2009년 6 월 3 일 이후에는 다음의 뉴질랜드 연락처로 연락 주시기 바랍니다. 제 뉴질랜드 우편 주소는 PO Box 29052, Ngaio, Wellington 6043, New Zealand 이며 전화번호는 +640210642689, 그리고 이메일 주소는 vinkthom@gmail.com 입니다. 제 지도 교수인 스 티븐 엡스틴 박사는 빅토리아 대학교 인문 사회 과학대 언어 문화학과의 아시아 연구소 소속이며 그의 연락처는 P.O. Box 600, Wellington 6140, New Zealand, 전화: +6444635703, 이 메일 주소는 Stephen.Epstein@vuw.ac.nz. 입니다.

토마스 빙크

서명: 


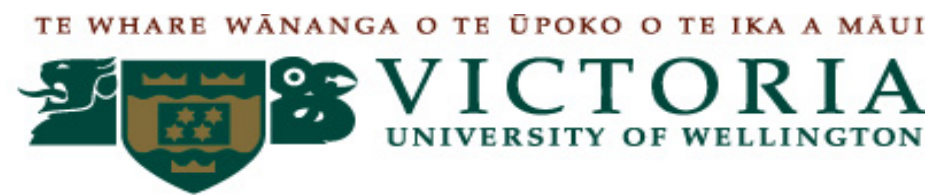

\section{Consent to Participation in Research on Representations of Pro-Democracy Movements in South Korea in the 1980s \\ 1980 년대 한국의 민주화 운동 representations 에 대한 조사연구 참여 동의서}

[Please tick the appropriate box] 해당 항목에 $\vee$ 표시하십시오.

네 아니요

"I have been given and have understood an explanation of this research project. I have had an opportunity to ask questions and have them answered to my satisfaction."

"나는 이 조사연구 프로젝트에 대한 설명을 듣고 이를 충분히 이해하였

\begin{tabular}{|l|l|}
\hline Yes & No \\
\hline
\end{tabular}
다. 나는 이 프로 젝트에 대해 질문할 기회가 주어졌으며 그 질문들에 대한 대답에 만족한다."

네 아니요

"I understand that I may withdraw myself (or any information I have provided) from this project (before data collection and analysis is complete) without having to give reasons or without penalty of any sort."

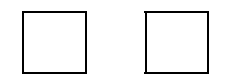

"나는 이유를 제시할 필요와 어떠한 불이익도 없이, 인터뷰 참가나 내가 제공한 정보를 취소할 수 있음을 숙지하는 바이며 이는 논문 준비 과정의 정보수집과 자료분석 단계가 완결되기 이전에 이루어져야 한다."

네 아니요

"I understand that if I withdraw from the project, any data I have provided will be destroyed."

"나는 이 프로젝트에서의 참여를 그만두게 된다면 내가 제공한 그 어떠

\begin{tabular}{|l|l|}
\hline Yes & No \\
\hline
\end{tabular}

한 자료도 폐기처분의 대상이 될 것임을 숙지한다."

"I understand that two years following the completion of the thesis the information obtained will be destroyed."

네 아니요

"나는 해당 논문이 완성된 시점으로부터 2년 후에 수집된 정보들이 폐

기처분 될 것임을 충분히 숙지하는 바이다."

\begin{tabular}{|l|l|}
\hline Yes & No \\
\hline
\end{tabular}

네 아니요 
"I understand that the information I have provided will be used only for this research project and academic articles/conference presentations arising from it, and that any further use will require my written consent."

\begin{tabular}{|l|l|}
\hline Yes & No \\
\hline
\end{tabular}

"나는 내가 제공한 정보가 이 조사연구 프로젝트 그리고 그와 관련된 학술기사나 학술대 회 발표에서만 사용됨을 숙지하는 바이며, 이에서 벗어난 다른 용도에서의 활용은 나의 동의를 요구한다."

네 아니요

"I have been given the opportunity to request that specific responses be kept confidential or not used. If I have made requests for information not to be used, I consent to the information or opinions being attributed to me using the following pseudonym,

\begin{tabular}{|l|l|}
\hline Yes & No \\
\hline
\end{tabular}

“나는 특정한 응답들에 대해서 그것들이 익명으로 쓰이거나 비공개로 될 것을 요청할 기회가 주어졌음을 인지하는 바이다. 만약 후자에 해당하는 경우, 내가 제공한 정보나 개인적 소견들이 내 본명이 아닌 필명, 의 것으로 간주될 것에 동의한다."

네 아니요

"I would like to receive an executive summary of this research when it is completed."

"나는 이 조사 연구의 논문 요약을 받아 보고 싶다."

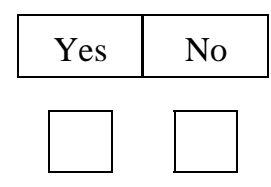

네 아니요

"I (name of participant) agree to this interview and to take part in this research" "나 (참여자 이름) 구에 참여함을 동의하는 바이다." 는!'은 이 인터뷰와 이 조사연

\begin{tabular}{|l|l|}
\hline Yes & No \\
\hline
\end{tabular}

Signed (서명):

Date (날짜): 


\section{Appendix Three: Participant Information Sheet and Consent Form for 'Site}

\section{Visitors'}

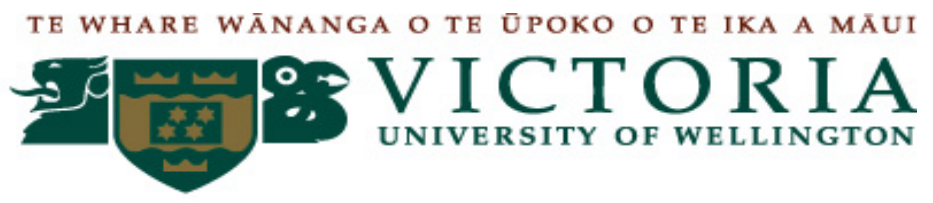

\section{0 년대 민주화 운동의 representations에 대한 조사연구를 위한 참여 설명 서 \\ Participant Information Sheet for Research on Representations of Pro-Democracy Movements in South Korea in the 1980s}

Researcher: Thomas Vink - School of Geography, Environment and Earth Sciences, Victoria University of Wellington, New Zealand

조사연구원: 토마스 빙크 - 뉴질랜드 웰링튼 빅토리아 대학교, 지리, 지구 환경 대학

논문 주제 : 한국에서 “현장의 기억”을 통한 공간 및 정체성의 형태

I am a Masters student in Development Studies at Victoria University of Wellington, New Zealand. As part of this degree I am undertaking research that will lead to a thesis. This research looks at how a number of different sites of memory in South Korea related to pro-democracy movements, and their suppression, in the 1980s, are currently being represented and reinterpreted. It is intended that this research will contribute to further understanding about how South Korea's past is affecting its future and bring insights to how important events can be interpreted to meet different ends. The university requires that ethics approval be obtained for research involving human participants.

저는 뉴질랜드 웰링튼 빅토리아 대학교에서 발전학을 공부하고 있는 대학원생입니다. 이 학위 과정의 한 부분으로 저는 논문을 위한 조사연구를 실시하고 있습니다. 이 조사연 구는 1980 년대의 한국의 민주화 운동들과 관련된 다수의 “기억의 장소들"이 현재 어떻 게 제시되며 재해석되고 있는지에 주목하고 있습니다. 이 연구조사는 과거의 역사가 어 떻게 한국의 미래에 영향을 끼치고 있는지에 대해 좀 더 심도 있게 이해할 수 있도록 도 와주며 또한, 중요 사건들이 다른 시야에서 어떻게 재해석될 수 있는지에 대한 통찰력을 가져오는 데에 그 목적을 두고 있습니다. 저희 대학교는 조사에 관련된 모든 참여 대상자 들로부터 윤리도덕적 승인을 받는 것을 원칙으로 요구합니다.

I am carrying out interviews with people who have visited these sites to find out why they visit and what meaning the site(s) hold for them. I am also interviewing people who have done research related to the suppression of pro-democracy movements in 1980 s South Korea and how the memory of this suppression is represented. 
저는 이러한 장소들을 방문한 적이 있는 사람들을 대상으로 그들의 방문 목적과 그 방문 이 그들에게 가지는 의미에 대해 인터뷰를 시행하고 있습니다. 저는 또한 1980 년대 한국 의 민주화 운동 억압과 관련된 조사 연구를 주도했던 이들을 상대로도 인터뷰를 하고 있 습니다.

Some of the interview questions deal with sensitive issues and you may decline to answer any question without having to give reasons. Should you feel the need to postpone or end the interview you may do so without question at any stage. Likewise if, for any reason, you decide after the completion of the interview that you do not want any of the information given to be used, let me know and I will destroy it or return it to you.

몇 가지 인터뷰 질문들은 민감한 사회 문제들을 다루고 있으며 본인이 원치 않을 시에는 이유를 불문하고 대답을 거절하실 수 있습니다. 또한, 원하실 때에는 언제든지 인터뷰를 연기하거나 중단하실 수 있습니다. 마찬가지로, 인터뷰를 마치신 후에라도 인터뷰 내용 이 쓰여지기를 원치 않으신다고 결정하시게 될 경우, 제게 연락을 주신다면 그 내용을 폐 기 처분하거나 본인에게 돌려드리겠습니다.

The interview will take approximately ... minutes and will be one-off, unless we agree at the time that a follow up interview would be beneficial.

인터뷰에 소요되는 시간은 대략 분입니다. 인터뷰는 한 번만 시행되지만, 때에 따라 필요 시에는 서로의 동의 하에 추가로 더 시행될 수도 있습니다.

Interview responses will provide specific insights that will be combined with my observational and literature research to form the basis of my thesis. This interview will follow an informal format and be strictly confidential. Any information you provide will not be able to be traced back to you and interview notes will be kept confidential. No other person beside my supervisor, Dr Stephen Epstein, and myself will see the interview notes. Notes will be destroyed two years following the completion of my thesis.

인터뷰에서 응답에 주신 내용들은 현장 조사와 기타 자료 수집과 더불어 제 논문을 위한 구체적인 근거 자료로 제시될 것입니다. 이 인터뷰는 비공식적 양식에 따르며 철저히 비 밀이 보장됩니다. 각 개인의 정보는 노출되지 않으며 인터뷰 기록들도

기밀로 보관됩니다. 저와 제 담당 교수인 스티븐 엡스틴 박사 이외의 어느 누구에게도 이 인터뷰 내용들에 대한 열람이 허용되지 않음을 알려드리는 바입니다. 이 기록들은 제 논 문을 끝마친 시점을 기준으로 2 년 후에 폐기 처분 될 것입니다.

The thesis will be submitted for marking to the School of Geography, Environment and Earth Sciences and deposited in the University Library. A summary of the thesis may be presented at academic or professional conferences and it is intended that one or more articles will be submitted for publication in scholarly journals. In addition, an executive summary will be produced and be made available to all participants. 
If you have any questions or would like to receive further information about my research, please contact me on my cellphone (010-2233-4232); at my home address (Ka320, Hanil Village, 275-11 Seongsan-I-Dong, M apo-gu, Seoul); or from the $3^{\text {rd }}$ of June at my postal address in New Zealand (PO Box 29052, Ngaio, Wellington 6043, New Zealand), phone (+640210642689), email (vinkthom@gmail.com). You can contact my supervisor, Dr Stephen Epstein, at the Asian Studies Institute, School of Languages and Cultures, Humanities and Social Sciences at Victoria University, P O Box 600, Wellington 6140, New Zealand, phone: +6444635703, email: Stephen.Epstein@vuw.ac.nz.

이 논문은 심사를 웰링튼 빅토리아 대학교의 지리, 지구 환경 과학대학에 제출되어 본 대 학 도서관에 소장될 것입니다. 논문 요약은 학술회의나 전문 학술 대회에 제출될 수도 있으며 학술지에 이 연구 조사와 관련된 기사들이 기고될 수도 있습니다. 이와 함께, 추 후 작성될 논문 개요는 인터뷰 참가자 전원이 받아 보실 수 있음을 알려드리는 바입니 다. 본 조사연구와 관련된 문의 사항이 있으시거나 이에 대해 좀 더 자세한 정보를 얻고 싶은 경우, 다음에 기재된 연락처를 통해 제게 알려주시기 바랍니다.

제 현재 한국에서의 이동전화번호는 010-2233-4243 이며 주소는 서울특별시 마포구 성산 1 동 275-11 한일 빌리지 가동 320호입니다. 한국에서의 조사연구 일정이 끝나는 2009년 6 월 3 일 이후에는 다음의 뉴질랜드 연락처로 연락 주시기 바랍니다. 제 뉴질랜드 우편 주소는 PO Box 29052, Ngaio, Wellington 6043, New Zealand 이며 전화번호는 +640210642689, 그리고 이메일 주소는 vinkthom@gmail.com 입니다. 제 지도 교수인 스 티븐 엡스틴 박사는 빅토리아 대학교 인문 사회 과학대의 아시아 연구소 소속이며 그의 연락처는 P.O. Box 600, Wellington 6140, New Zealand, 전화: +6444635703, 이메일 주소는 Stephen.Epstein@vuw.ac.nz. 입니다.

서명: 


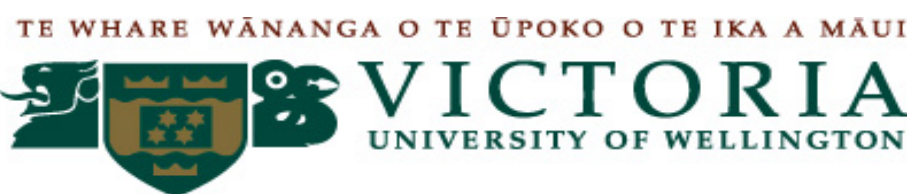

\section{Consent to Participation in Research on Representations of Pro-Democracy Movements in South Korea in the 1980s}

1980 년 대 한국의 민주화 운동 representations 에 대한 조사연구 참여 동의서

[Please tick the appropriate box] 해당 항목에 $\mathrm{V}$ 표시하십시오.

네 아니요

"I have been given and have understood an explanation of this

\begin{tabular}{|l|l|}
\hline Yes & No \\
\hline$\square$ \\
\hline
\end{tabular}
research project. I have had an opportunity to ask questions and have them answered to my satisfaction."

"나는 이 조사연구 프로젝트에 대한 설명을 듣고 이를 충분히 이해하였다.

나는 이 프로젝트에 대해 질문할 기회가 주어졌으며 그 질문들에

대한 대답에 만족한다."

네 아니요

"I understand that I may withdraw myself (or any information I have provided) from this project (before data collection and analysis is complete) without having to give reasons or without penalty of any sort."

\begin{tabular}{|l|l|}
\hline Yes & No \\
\hline
\end{tabular}

“나는 이유를 제시할 필요와 어떠한 불이익도 없이 인터뷰 참가나 내가 제공한 정보를 취소할 수 있음을 숙지하는 바이며 이는 논문 준비 과정의 정보수집과 자료분석 단계가 완결되기 이전에 이루어져야 한다."

네 아니요

"I understand that if I withdraw from the project, any data I have provided will be destroyed."

"나는 이 프로젝트에서의 참여를 그만두게 된다면 내가 제공한 그 어떠

\begin{tabular}{|l|l|}
\hline Yes & No \\
\hline
\end{tabular}

한

자료도 폐기처분의 대상이 될 것임을 숙지한다."

"I understand that two years following the completion of the thesis the information obtained will be destroyed."

네 아니요

"나는 해당 논문이 완성된 시점으로부터 2년 후에 수집된 정보들이 폐 기처분 될 것임을 충분히 숙지하는 바이다. “

\begin{tabular}{|l|l|}
\hline Yes & No \\
\hline
\end{tabular}

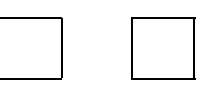

네 아니요 
"I understand that the information I have provided will be used only for this research project and academic articles/conference presentations arising from it, and that any further use will require my written consent."

\begin{tabular}{|c|c|}
\hline Yes & No \\
\hline
\end{tabular}

“나는 내가 제공한 정보가 이 조사연구 프로젝트 그리고 그와 관련된 학술기사나 학술 대회 발표에서만 사용됨을 숙지하는 바이며 이에서 벗어난 다른 용도에서의 활용은 나 의 동의를 요구한다."

네 아니요

"I understand that all responses will be strictly confidential and any information used will not be able to be attributed to me in any way."

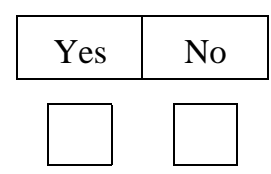

“나는 모든 인터뷰 내용들이 엄격히 비밀로 보장되며 모든 정보가 익명으로

사용될 것임을 숙지하는 바이다."

네 아니요

"I would like to receive an executive summary of this research when it is completed."

"나는 이 조사 연구의 논문 요약을 받아 보고 싶다."

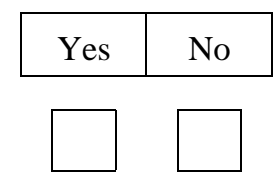

네 아니요

"I (name of participant) interview and to take part in this research" agree to this

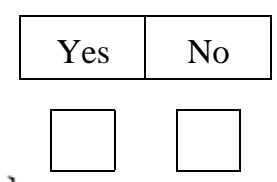

“나(참여자 이름) 는'은 이 인터뷰와 이 조사연 구에 참여함을 동의하는 바이다. “

Signed(서명): Date(날짜): 


\section{References}

\section{Literature and Websites}

Abelmann, Nancy. (1996). Echoes of the Past, Epics of Dissent: A South Korean Social M ovement. University of California Press, Berkeley.

Adams, Kathleen. M. (1997). 'Nationalising the Local and Localising the Nation: Ceremonials, Monumental Displays and National Memory-Making in Upland Sulawesi, Indonesia.' M useum Anthropology, 21(1), pp. 113-130.

Agnew, John. (1997). 'Geographies of Nationalism and Ethnic Conflict.' In J. Agnew (Ed) (1997) Political Geography: A Reader, Hodder Headline Group, London.

Al Jazeera [author unknown]. (2007). 'Lee 'wins' South Korean election.' Al Jazeera. December 19. From http://english.aljazeera.net/news/asiapacific/2007/12/2008525135142568460.html.

Anderson, Benedict. (1991). Imagined Communities: Reflections on the Origin and Spread of Nationalism ( $2^{\text {nd }}$ edition). Verso London - New York.

Baker, Don. (2003). 'Victims and Heroes: Competing Visions of May 18.' In Shin Gi-Wook $\&$ Kyung M oon Hwan (Eds) (2003). Contentious Kwangju: The M ay 18 Uprising in Korea's Past and Present. Rowman \& Littlefield Publishers Inc, United States, pp. 87-107.

Baker, D. (2007). 'Introduction.' In Robert E. Buswell (Ed) (2007). Religions of Korea In Practice. Princeton Readings in Religions. Princeton University Press, Oxford, United Kingdom, pp. 1-31.

Beech, Hannah. (2009). 'de.moc.ra.cy.' TIME. No. 1. January 12. TIME New Zealand Magazine Ltd, Auckland, pp. 32-36.

Behar, Ruth. (1996). The Vulnerable Observer: Anthropology That Breaks Your Heart. Beacon Press, M assachusetts.

Bell, Duncan S. A. (2003). 'M ythscapes: memory, mythology, and national identity.' British Journal of Sociology. 54.1. pp. 63-81. 
Bell, Duncan. S. A. (2006). 'Introduction: M emory, Trauma and World Politics.' In Duncan Bell (Ed) (2006). Memory, Trauma and World Politics: Reflections on the Relationship Between Past and Present. Palgrave Macmillan, pp. 1-32.

Bhabha, Homi K. (1990). 'DissemiNation: time, narrative, and the margins of the modern nation.' In H. Bhabha (Ed) Nation and Narration. Routledge, pp. 291-322.

Bleiker, Roland. \& Hoang Young-Ju (2006). 'Remembering and Forgetting the Korean War: From Trauma to Reconciliation.' In Duncan Bell (Ed) (2006). Memory, Trauma and World Politics: Reflections on the Relationship Between Past and Present. Palgrave Macmillan, pp. 195-212.

Bleiker, Roland. \& Hoang Young-Ju (2007). 'On the Use and Abuse of Korea's Past: An Inquiry into History Teaching and Reconciliation.' In E. A. Cole (Ed) (2007). Teaching the Violent Past: History Education and Reconciliation. Rowman \& Littlefield Publishers Inc, Plymouth, United Kingdom, pp. 249-274.

Breen, M ichael. (2004). The Koreans: who they are, what they want, where their future lies. Orion Business, Great Britain.

Bunuel, Luis. (1983). My Last Sigh. Alfred A. Knopf, New York, Translated by Abigail Israel.

Byun, Ju-na. (2000) 'Introduction.' In Ju-na Byun \& Linda S. Lewis (2000). The 1980 Kwangju Uprising After 20 Years: The Unhealed Wounds of the Victims. Dahae Publishers, Seoul, pp. 27-38.

Catholic Priests Association for Justice in Korea (CPAJ) Website (2009). From http:// www.sajedan.org/english/aboutus/aboutus02.htm.

Chang, Paul Y. \& Kim Byung-Soo (2007). 'Differential Impact of Repression on Social Movements: Christian Organisations and Liberation Theology in South Korea (1972-1979).' Sociological Inquiry. Vol. 77:3, pp. 326-355.

Charlesworth, Andrew. (1994). 'Contesting Places of Memory: The Case of Auschwitz.' Environment and Planning D: Society and Space. Vol. 12, pp. 579-593.

Cho Han, Hae-joang. (2004). 'Beyond the FIFA's World Cup: An ethnography of the 'local' in South Korea around the 2002 World Cup.' Inter-Asia Cultural Studies. Vol. 5: 1, pp. 8-25.

Choe Yoon, Inshil. (2007). 'Martyrdom and Social Activism: The Korean Practice of Catholicism.' In Robert E. Buswell (Ed) (2007). Religions of Korea In Practice. 
Princeton Readings in Religions. Princeton University Press. Oxford, United Kingdom, pp. 355-375.

Choi, Chungmoo. (1995). 'The Minjung Culture Movement and the Constitution of Popular Culture in Korea.' In Kenneth M. Wells (Ed) (1995). South Korea's M injung M ovement: The Culture and Politics of Dissidence. University of Hawai'l Press, Honolulu, pp. 105-118.

Choi, Jungwoon. (1999). The Gwangju Uprising: The Pivotal Democratic M ovement That Changed the History of Modern Korea. Homa and Selvey Books, Paramus, New Jersey. Translated by Yu Youngnan.

Choi, Yearn-hong. (2009). 'Re-Evaluation of Late President.' Korea Times. November 20, from http://www.koreatimes.co.kr/www/news/opinon/2009/12/137_55855.html.

Chung, Chulhee. (1997). 'Social M ovement Organisations and the June Uprising.' Korea Journal. Vol. 37: 1, pp. 81-97.

Chung, Hye Seung \& David Scott Diffrient (2007). 'Forgetting to Remember, Remembering to Forget: The Politics of M emory and Modernity in the Fractured Films of Lee Chang Dong and Hong Sang-Soo.' In Francis K. Gateward (Ed) (2007). Seoul Searching: Culture and Identity in Contemporary Korean Cinema. SUNY Press, pp. $115-140$.

Chung, Sangyong, Rhyu Simin, et al (2003). Memories of May 1980: A Documentary History of the Kwangju Uprising in Korea. Translated by Park Hye-Jin. Korea Democracy Foundation, Seoul.

Clark, Donald N. (1995). 'Growth and Limitations of M injung Christianity in South Korea.' In Kenneth M. Wells (Ed) (1995). South Korea's M injung Movement: The Culture and Politics of Dissidence. University of Hawai'I Press, Honolulu, pp. 87-103.

Clark, Donald N. (Ed) (1996). The Koreans: Contemporary Politics and Society (Third Edition). Westview Press, Colorado, United States.

Clark, D. N. (2002). 'Protestant Christianity and the state: Religious organisations as civil society.' In Charles K. Armstrong (Ed) (2002). Korean Society: Civil society, democracy and the state. Routledge. London, pp. 187-206.

Cole, Elizabeth A. (2007). 'Introduction: Reconciliation and History Education.' In E. A. Cole (Ed) (2007) Teaching the Violent Past: History Education and Reconciliation. Rowman \& Littlefield Publishers Inc, Plymouth, United Kingdom, pp. 1-28. 
Cumings, Bruce. (1997). Korea's Place in the Sun: A Modern History. W.W. Norton \& Company, Inc, New York.

Cumings, B. (2007a). 'The Korean War: What is it that we are remembering to forget?' Ruptured Histories: War, Memory, and the Post-Cold War in Asia. Harvard University Press, London, pp. 266-290.

Cumings, B. (2007b). 'Lesson From Gwangju Uprising.' Summary of a paper presented at the $27^{\text {th }}$ commemoration of the May 18 Gwangju Uprising, at Jeonnam National University, M ay 18. In the Korean Times. From www.koreatimes.co.kr/www/news/opinion/2008/08/198_3129.html.

Do, Je-hae. (2010) 'Monks Up in Arms Over Police Assault.' Korea Times. January 28, from http://www.koreatimes.co.kr/www/news/nation/2010/01/113_59889.html.

Frazier, Lessie Jo. (1999). "'Subverted Memories": Countermourning as Political Action in Chile.' In Mike Bal, Jonathan Crewe \& Leo Spitzer (Eds) (1999). Acts of Memory: Cultural Recall in the Present. University Press of New England, Hanover, pp. 105-119.

Funder, Anna. (2003). Stasiland: Stories from Behind the Berlin Wall. Granta Books, London.

Funder, A. (2009). 'Why Germany can't get over the Wall.' The Times. November 3, http://www.timesonline.co.uk/tol/news/politics/article6899929.ece.

Gillis, John R. (Ed) (1994). Commemorations: The Politics of National Identity. Princeton University Press, Princeton, New Jersey.

Gioni, Massimiliano. (2009). 'Gwangju Biennale 2010.' Retrieved from Gwangju Biennale Website, http://gb.or.kr/?mid=sub_eng\&mode $=02 \&$ sub $=01$.

Grayson, James Huntley. (2002). Korea - A Religious History. RoutledgeCurzon. New York.

Gwangju Metropolitan City Website. (2009). 'Dynamic City of Production.' From http://eng.gjcity.net/business/vision_production.jsp.

Hamilton, Paula. (2003). 'Sale of the Century? Memory and historical consciousness in Australia.' In K. Hodgkin and S. Radstone (Eds) (2003). Contested Paths: The Politics of Memory. Routledge, London, pp. 136-152. 
Hankyoreh [author unknown]. (2008). 'Massive Candlelight Protests Draw One Million Nationwide.' Hankyoreh. June 11, from

http://english.hani.co.kr/arti/english edition/e national/292645.html.

Hankyoreh [author unknown]. (2009). 'The Seoul Metropolitan Government and Yongsan tragedy family members reach a deal.' Hankyoreh. December 31, from http://english.hani.co.kr/arti/english edition/e national/396485.html.

Hardin, Blaine. (2008). 'Escape from a Living Hell.' Dominion Post. Wellington, December $13, \mathrm{~B} 1$.

Hauben, Ronda. (2009). 'Candlelight 2008 and Behind the Scenes in the Beef Deal.' OhmyNews. South Korea. May 6, From

http://english.ohmynews.com/ArticleView/article_view.asp?

no $=385186 \&$ rel_no $=1$.

Hub City of Asia Culture (Asia M unhwa Jungsim Dosi) (HCAC) Information Centre. Floors three and four, Cheonha building, Geumnamno 1-ga, Gwangju. Visited in May 2009.

HCAC [brochure]. (2008). 'A Flower From The Seed Called Dreams - Hub City of Asian Culture, Gwangju.' Executive Agency for Culture Cities under the Ministry of Culture and Tourism (Munhwa Gwangwangbu Asia Munhwa Jungsim Dosi Chujindan), 19F Jongno Tower, 6 Jongno 2-ga, Jongno-gu, Seoul.

HCAC [DVD]. (2008). Executive Agency for Culture Cities under the Ministry of Culture and Tourism (Munhwa Gwangwangbu Asia Munhwa Jungsim Dosi Chujindan), 19F Jongno Tower, 6 Jongno 2-ga, Jongno-gu, Seoul.

HCAC Website. Korea Ministry of Culture, Sports and Tourism. 2004-2005, from http://www.cct.go.kr/eng/.

History of 5.18 Compilation Committee of Gwangju City (Eds). (2008). History of 5.18 Democratic Uprising, Parts I \& II. M ay 18 M emorial Foundation, Gwangju.

Hirsch, Marianne \& Leo Spitzer (2003). "We Would Not Have Come Without You': Generations of Nostalgia.' In K. Hodgkin and S. Radstone (Eds) (2003). Contested Paths: The Politics of M emory. Routledge, London, pp. 79-95.

Hodgkin, Katharine and Susannah Radstone (2003a). 'Introduction: Contested Pasts.' In K. Hodgkin and S. Radstone (Eds) (2003). Contested Paths: The Politics of Memory. Routledge, London, pp. 1-22. 
Hodgkin, Katharine and Susannah Radstone (2003b). 'And Then Silence...' In K. Hodgkin and S. Radstone (Eds) (2003) Contested Paths: The Politics of Memory. Routledge, London, p. 237.

Hoffman, Frank. (2000). 'M onoculture and its Discontents - Kwangju Biennale 2000 Statistical Data Included.' Art in America. November, from http://findarticles.com/p/articles/mi_m1248/is_11_88/ai_66888245/.

Hong, Se-Hwa. (2009). 'Heading to Yongsan.' Hankyoreh. September 23, from http://english.hani.co.kr/arti/english_edition/e opinion/378222.html.

Huyssen, Andreas. (1995). Twilight Memories: Marking Time in a Culture of Amnesia. Routledge, New York.

Huyssen, A. (1996). 'M onumental Selection.' New German Critique. No. 69, Autumn, pp. 181-200.

Huyssen, A. (2000). 'PresentPasts: Media, Politics, Amnesia.' Public Culture. 12: 1, pp. 21-38.

Hwang, Min-Hyuk \& Jang Dong-Jin (2009). 'Emerging Multiculturalism in Korea: Competing Discourses of Inclusion and Exclusion.' Paper presented at the annual meeting of the ISA's $50^{\text {th }}$ Annual Convention "Exploring the Past, Anticipating the Future." New York Marriot M arquis, New York, February 15.

Jager, Sheila M iyoshi. (2003). Narratives of Nation Building in Korea: A Genealogy of Patriotism. An East Gate Book, M.E. Sharpe, New York.

Jager, S. \& Rana M itter (2007a). 'Introduction - Re-envisioning Asia, Past and Present.' In S. Jager and R. Mitter (2007). Ruptured Histories: War, Memory, and the PostCold War in Asia. Harvard University Press, London.

Jager, S. \& R. Mitter (2007b). 'Epilogue - New Global Conflict? War, Memory, and Post 9/11 Asia.' In S. Jager and R. Mitter (2007). Ruptured Histories: War, Memory, and the Post-Cold War in Asia. Harvard University Press, London, pp. 322-328.

Jager, S. \& Jiyul Kim (2007). 'The Korean War after the Cold War: Commemorating the Armistace Agreement in South Korea.' In S. Jager and R. Mitter (2007). Ruptured Histories: War, Memory, and the Post-Cold War in Asia. Harvard University Press, London, pp. 233-265.

Jeong, Hyeon-ji. (2008). 'Korea Heads to Multicultural Society.' Korea Herald. June 6, from http://www.koreaherald.co.kr/archives/result_contents.asp. 
Johnson, Nuala. (1995). 'Cast in Stone: Monuments, Geography, and Nationalism.' Environment and Planning D: Society and Space. Vol. 13, pp. 51-65.

Jung, Keun-Sik. (2000). 'The Gwangju Democratisation M ovement: It's Development and Historical Significance.' In 5.1820 주년 기념 학술연구사업 연구 소위 ['Junyeon Hagsulyeongusaeob Yeongu Soui': $20^{\text {th }}$ Anniversary Commemorative Investigation Project into 5.18 (my translation)]. Conducted by Jeonnam University 5.18 Research Institute, pp. history1-history54.

Jung, Keun-Sik. (2003). 'Essay: Kwangju Revived? Past, Present and Future.' In Chung, Sangyong, Rhyu Simin, et al (2003). Memories of May 1980: A Documentary History of the Kwangju Uprising in Korea. Korea Democracy Foundation, Seoul. Translated by Park Hye-Jin. pp. 406-430.

Kalb, Laurie Beth. (1997). 'Nation Building and Culture Display in Malaysian Museums.' M useum Anthropology. 21: 1, pp. 69-81.

Kang, Hyun-kyung. (2007). 'Paradigm Shift Underway in Presidential Campaign.' Korea Times. December 22, from http://www.koreatimes.co.kr/www/news/nation/2007/09/116_10749.html.

Kang, Hyun-kyung. (2009). 'Park Chung-Hee Admired for Making Something Out of Nothing.' Korea Times. October 25, from http://www.koreatimes.co.kr/www/news/nation/2009/10/116_54174.html.

Katsiaficas, George. (2009). 'South Korea's Rollback of Democracy.' Links: international journal of socialist renewal. From http://links.org.au/node/1108.

Kelley, Matthew. (2008). 'Gwangju Biennale 2008.' Discovering Korea. November 1, from http://discoveringkorea.com/2008/11/01/gwangju-biennale-2008/.

Klein, Kerwin Lee. (2000). 'On the Emergence of Memory in Historical Discourse.' Representations. No. 69, Special Issue: Grounds for Remembering, Winter, pp. 127-150.

Kim, Andrew Eungi. (2009). 'Global Migration and South Korea: Foreign Workers, Foreign Brides and the Making of a Multicultural Society.' Ethnic and Racial Studies. Vol. 32: 1, pp. 70-92.

Kim Choongnam. (2007). 'Leadership Style of Korean Presidents.' Korea Times. November 12, from http:// www.koreatimes.co.kr/www/news/special/2007/11/180_13602.html. 
Kim, Hyun-Eun. (2009). 'The Horned House on the Top of the Hill.' JoongAng Daily. September 28, from

http://joongangdaily.joins.com/article/view.asp?aid=2910602.

Kim, Rahn. (2008). 'President Embarrassed Over Angry Buddhists.' Korea Times. July 30, from,

http://www.koreatimes.co.kr/www/news/nation/2008/07/117_28491.html.

Kim, Sung-Hee \& Baik Sung-Ho (2009). 'The People's Cardinal: Cardinal Kim Sou-Hwan 1922-2009. JoongAng Daily. February 18, from http://joongangdaily.joins.com/article/view.asp?aid=2901164.

Kim, Youngok. (2007). 'New "Citizens" and Multiculturalism in Korea.' Women in Action. December, pp. 40-46.

Kong, Lily \& Lisa Law (2002). 'Introduction: Contested Landscapes, Asian Cities.' Urban Studies. 39: 9, pp. 1503-1512.

Kong, Lily (2002). 'In Search of Permanent Homes: Singapore's House Churches and the Politics of Space.' Urban Studies. 39: 9, pp. 1573-1586.

Korea Tourism Organisation (KTO) website. (2009). From http://english.visitkorea.or.kr/enu/index.kto.

Kundera, M ilan. (1979). The Book of Laughter and Forgetting. Translated from French by Aaron Asher. HarperPerennial, New York.

Kundera, M. (1984). The Unbearable Lightness of Being. Translated from Czech by M ichael Henry Heim. Harper \& Row Publishers, New York.

Kundera, M. (1995). Slowness. Translated from French by Linda Asher. Perennial, HarperCollins Publishers.

Kwon, Mee Yoo. (2009). 'Late Cardinal Lauded as 'Conscience of Korea'.' Korea Times. February 17, from http://koreatimes.co.kr/www/news/nation/2009/02/117_39726.html.

Lamers, Matthew. (2010). 'Evictees in the struggle of their lives.' The Korea Herald. January 19 , from http://www.koreaherald.co.kr/NEWKHSITE/data/html_dir/2010/01/19/2010011 90045.asp.

Lamers, M. (2010). 'Seoul's redevelopment dilemma.' The Korea Herald. January 20, from 
http://www.koreaherald.co.kr/NEWKHSITE/data/html_dir/2010/01/20/2010012 00042.asp.

Lankov, Andrei. (2007). The Dawn of Modern Korea: The Transformation in Life and Cityscape. EunHaeng NaM u, Mapo-Gu, Seoul.

Lankov, A. (2008). 'Fiasco of 386 Generation.' Korea Times. February 5, from http://www.koreatimes.co.kr/www/news/special/2008/04/180_18529.html.

Law, Lisa. (2002). 'Defying Disappearance: Cosmopolitan Public Spaces in Hong Kong.' Urban Studies. 39: 9, pp. 1625-1645.

Lee B. J. (2003). 'Out with the Old,' Newsweek, August 4, from http://www.newsweek.com/id/152611.

Lee Dong-M in. (2002). 'M yeongdong Cathedral Fighting Image of Protest Haven.' Korea Herald. Yonhap News Agency, M arch 22, from http://www.tomcoyner.com/myeongdong_cathedral_fighting_im.htm.

Lewis, Linda S. (1988a). 'The 'Kwangju Incident' Observed: An Anthropological Perspective on Civil Uprisings.' In Donald N. Clark (Ed) (1991). Korea Briefing. Boulder Westview Press.

Lewis, L. S. (1988b). 'City of Light/City of Outlaws: Kwangju and the Construction of an Urban Identity.' Paper presented at American Anthropological Association annual meeting, November.

Lewis, L. S. (2000). 'The Revictimisation of the Direct Victims.' In Ju-na Byun \& Linda S. Lewis (2000). The 1980 Kwangju Uprising After 20 Years: The Unhealed Wounds of the Victims. Dahae Publishers, Seoul.

Lewis, L. S. (2002a). 'Commemorating Kwangju: The 5.18 movement and civil society in the new millennium.' In Charles K. Armstrong (Ed) (2002). Korean Society: Civil society, democracy and the state. Routledge, London, pp. 165-186.

Lewis, L. S. (2002b). Laying Claim to the Memory of May: A Look Back at the 1980 Kwangju Uprising. University of Hawai'i Press.

Lewis, L. S. \& Ju-Na Byun (2003). 'From Heroic Victims to Disabled Survivors: The 5-18 Injured after Twenty Years.' In Gi-Wook Shin \& Kyung M oon Hwan (Eds) (2003). Contentious Kwangju: The May 18 Uprising in Korea's Past and Present. Rowman $\&$ Littlefield Publishers Inc, United States, pp. 53-66. 
Lim, Timothy. (2009). 'Who is Korean? Migration, Immigration, and the Challenge of Multiculturalism in Homogenous Societies.' The Asia-Pacific Journal. Vol. 30-109, July 27.

Magnun-Park, Aaron Han Joon (2005). 'Peppermint Candy: The Will Not To Forget.' In Chi-Yun Shin \& Julian Stringer (Eds). (2005). New Korean Cinema. Edinburgh University Press, pp. 159-169.

May 18 Memorial Foundation (2007). A Complete Collection of the Korea Laws and Regulations Concerning the May 18 Democratic Uprising. Hong-gil Rhee, Gwangju.

McCarthy, Cormac. (2006). The Road. Vintage International, Random House Inc, New York.

M CDonald, Hamish. (2010). 'Truth in Danger in South Korea.' Sydney Morning Herald. January 23, from http://www.smh.com.au/opinion/politics/truth-in-danger-insouth-korea-20100122-mqq5.html.

McDonald, Matthew. (2009). "Lest We forget': Invoking the Anzac myth and the memory of sacrifice in Australian military intervention.' Paper presented at International Studies Association Convention. New York, February.

M cHoul, A. and W. Grace (1993). 'Discourse.' A Foucault Primer: Discourse, Power and the Subject. Melbourne University Press, M elbourne, pp. 26-56.

M eskall, Lynn. (2006). 'Trauma Culture: Remembering and Forgetting in the New South Africa.' In Duncan Bell (Ed) (2006) Memory, Trauma and World Politics: Reflections on the Relationship Between Past and Present. Palgrave Macmillan, pp. 157-175.

M oon, Seungsook. (2009). 'The Cultural Politics of Remembering Park Chung Hee.' Asia Pacific Journal. Vol. 19-5-09, May 9.

Morris-Suzuki, Tessa. (2005). The Past Within Us: Media, Memory, History. Verso, London/ New York.

Morris-Suzuki, T. (2009). 'Remembering the Unfinished Conflict: Museums and the Contested Memory of the Korean War.' Asia - Pacific Journal. Vol. 29-04-09, July 27, from http://www.japanfocus.org/-Tessa-Morris_Suzuki/3193.

Musil, Robert (Burton Pike (Ed)). (1986). Selected Writings. Continuum, University of California. 
$\mathrm{Na}$, Kahn Chae. (2008). 'The Organisation and Activity of 5.18 Related Group.' In 5.18 History Compilation Committee of Gwangju City. (2008). History of 5.18 Democratic Uprising. May 18 M emorial Foundation, Gwangju, pp. 708-743.

Naidu, Erishnu. (2004). Empowerment through living memory: A community-centred model for memorialisation. Research report written for the Centre for the Study of Violence and Reconciliation, pp. 1-17.

Naver Korean-English Dictionary. (2009). From http://dic.naver.com/.

Ney, Jose. (2008). 'Democracy in South Korea: M ature Society versus Immature System.' Ethics in Action. 2: 4, August.

Nietzsche, Friedrich. (1969, orig. 1887). On the Genealogy of Morals. Translated by Walter Kaufmann and R. J. Hollingdale. Random House, New York, Essay II.

Nora, Pierre. (1989). 'Between Memory and History: Les Lieux de Memoire.' Representations. No. 26, Special Issue: Memory and Counter-M emory, pp. 7-24.

Nora, P. (2002). 'The Reasons for the Current Upsurge in M emory.' Transit - Europäische Revue. No. 22, from http:// www.iwm.at/index.php? option=com_content\&task=view\&id=285\&Itemid $=463$

Oberdorfer, Don. (1997). The Two Koreas: A Contemporary History. Basic Books, Indianapolis.

Oppenheim, Robert. (2008). Ky ngju Things: Assembling Place. University of Michigan Press, Ann Arbor.

Park Sun-Young. (2007). 'Shinsedae: Conservative Attitudes of a 'New Generation' in South Korea and the Impact on the Korean Presidential Election.' East West Center Insights. 2: 1, September.

Passerini, Luisa. (2003). 'Memories Between Silence and Oblivion.' In K. Hodgkin and S. Radstone (2003) Contested Paths: The Politics of Memory. Routledge, London, pp. 238-254.

Portelli, Alessandro. (1991). The Death of Luigi Trastulli and Other Stories: Form and Meaning in Oral History. State University of New York Press.

Presidential Truth Commission on Suspicious Deaths of the Republic of Korea (2004), A Hard Journey to Justice, First Term Report (10.2000-10.2002). Samin Books, Seoul. 
Ricoeur, Paul. (1999). 'M emory and Forgetting.' In Richard Kearney \& Mark Dooley (Eds) (1999). Questioning Ethics: Contemporary Debates in History. Routledge, London, pp. 5-11.

Ritcher, Linda. (1999). 'The Politics of Heritage Tourism.' In D. C Pearce \& R. L. Butler (Eds). (1999). Contemporary Issues in Tourism Development. London: Routledge, pp. 107-122.

Robinson, M. (2007). Korea's Twentieth-Century Odyssey. University of Hawai'i Press, Honolulu.

Rozentals, Darien Jane. (2008). Monumental Amnesia: Reading the Spatial Narratives Written by Contemporary Urban Landscapes. Doctor of Philosophy (PhD), University of Tazmania.

Roy, Arundhati. (1997). The God of Small Things. New York: Random House.

Saaler, Sven \& Wolfgang Schwentker (2008). 'Introduction - The Realms of Memory: Japan and Beyond.' In Sven Saaler \& Wolfgang Schwentker (Eds). (2008). The Power of M emory in M odern Japan. Global Oriental, pp. 1-14.

Schneider, Anna. (2009). 'Architectures Spectacle: Facets of the exhibition boom in South Korea and China in the context of the strategy of globalism.' Springerin. Vol. 1/09 Art on Demand, from http:// www.springerin.at/dyn/heft_text.php?textid=2167\&lang=en.

Shin, Gi-Wook. (1998). 'Nation, History and Politics: South Korea.' In Hyung II Pai \& T. Tangherlini (Eds). (1998). Nationalism and the Construction of Korean Identity. Institute of East Asian Studies, University of California, Berkeley, pp. 148-165.

Shin, Gi-Wook. (2003). 'Introduction.' In Gi-Wook Shin \& Kyung Moon Hwan (Eds) (2003). Contentious Kwangju: The May 18 Uprising in Korea's Past and Present. Rowman \& Littlefield Publishers Inc, United States, pp. xi-xxxi.

Shin, Gi-Wook. (2006). Ethnic Nationalism in Korea: Genealogy, Politics, and Legacy. Stanford University Press, Stanford, California.

Tangherlini, Timothy \& Sallie Yea (2008). 'Introduction - Constructed Places, Contested Spaces, Critical Geographies and Korea', Sitings: Critical Approaches to Korean Geography, University of Hawai'i Press, pp. 1-11.

Teather, Elizabeth K. (2000). 'High Rise Homes for the Ancestors: Cremation in Hong Kong.' Geographical Review. 89: 3, pp. 409-430. 
Teather, E. K. (2001). "Seoul's Deathscapes: Incorporating Tradition into Modern TimeSpace. Environment and Planning A. Vol. 33, pp. 1489-1506.

Todorov, Tzvetan. (2001). 'The Uses and Abuses of Memory.' Translated by Lucy Golsan. In Howard M architello (Ed) What Happens to History: The Renewal of Ethics in Contemporary Thought. London: Routledge, pp. 11-22.

Union of Catholic Asian (UCAN) news website. (2009). 'Four Religious Communities Bid Ex-President Farewell.' M ay 29, from http:// www.ucanews.com/2009/05/29/four-religions-bid-ex-presidentfarewell/.

Webster, D. D. (2009). 'Liberation Theology: Advanced Information.' Elwell Evangelical Dictionary, from http://mb-soft.com/ believe/txn/liberati.htm.

Wells, Kenneth M . (1995). 'The Cultural Construction of Korean History.' In Kenneth M. Wells (Ed) (1995). South Korea's M injung M ovement: The Culture and Politics of Dissidence. University of Hawai'l Press, Honolulu, pp. 11-38.

White, Geoffrey. M. (1997). 'Introduction: Public History and National Narrative.' M useum Anthropology. 21: 1, pp. 3-7.

Yea, Sallie. (1999). 'The Culture and Politics of Resistance in South Korea.' Futures. Vol. 31 , pp. 221-234.

Yea, S. (2000). 'M aps of Resistance and Geographies of Dissent in Cholla Region, South Korea.' Paper presented at May 18 Research Institute, Chonnam University (M ay $15-M$ ay 17) 'Democracy and Human Rights in the New M illenium - International Symposium on the $20^{\text {th }}$ Anniversary of the Kwangju Uprising.' Chonnam National University International Conference Center, Yongbang Hall, Kwangju, Korea, pp. 94-122.

Yea, S. (2002). 'Rewriting Rebellion and Mapping Memory in South Korea: The (Re)presentation of the 1980 Kwangju Uprising through Mangwol-dong Cemetery.' Urban Studies. 39: 9, 1551-1572.

Yea, S. (2003). 'Reinventing the Region: The Cultural Politics of Place in Kwangju City and South Cholla Province.' In Gi-Wook Shin \& Kyung Moon Hwan (Eds) (2003). Contentious Kwangju: The May 18 Uprising in Korea's Past and Present. Rowman \& Littlefield Publishers Inc, United States, pp. 109-131.

Yeoh, Brenda. \& Tan Bon Hui (1995). 'The Politics of space: changing discourses on Chinese burial grounds in post-war Singapore.' Journal of Historical Geography. 21: 2, pp. 184-201. 
Yun Ch'oe and Mark Morris (2002). 'South Korea's Kwangju Uprising: Fiction and Film.' The Asia-Pacific Journal. 5-4-10, February 1.

Zehfuss, Maja. (2006). 'Remembering to Forget/Forgetting to Remember.' In Duncan Bell (Ed) (2006). Memory, Trauma and World Politics: Reflections on the Relationship Between Past and Present. Palgrave Macmillan, pp. 213 - 230.

Zelinsky, Wilbur. (1994). 'Gathering Places for America's Dead: How Many, Where, and Why?' The Professional Geographer. 46: 1, pp. 29-38. 


\section{Personal Communication}

Bae, Mr. (pseudonym), an organisational representative in Gwangju who asked for confidentiality. 21/05/09.

Gang, Gu-Yeong. Director of Policy and Planning (Jeongchaek Gihoek Gukjang), 5.18 Wounded Persons Association, Gwangju. 20/05/09.

Jung, Hae-Gu. Political Science Professor, Seongkonghoe University, Seoul. 13/05/09.

Katsiaficas, George. Visiting Professor of Sociology, Jeonnam University, Gwangju. 27/05/09.

Kim Byeong-In, Professor of History, Jeonnam University, Gwangju. 25/05/09.

Kim Jin-Hoe, M yeongdong Cathedral church-goer, Seoul. 22/05/09.

Lee Dae-Hun, Francis. Graduate School of NGO studies, Seongkonghoe University, Seoul. $17 / 05 / 09$.

Lee M un-Yang, Retired, former Politics Professor, Korea University. Seoul. 16/05/09.

Lee Seong-Hun, National Human Rights Commission of Korea (NHRCK), Seoul. 17/05/09.

$\mathrm{Na}$ Seung-Gu, Father Francis. Priest at Sinwol-dong Cathedral, Seoul and member of the Catholic Priests Association for Justice (CPAJ). 02/06/09.

Park Hae-Gwang, Professor of Sociology, Jeonnam University, Gwangju. 27/05/09 and 12/08/09.

Seo, Mr. (pseudonym), a university professor in Gwangju who asked for confidentiality. $17 / 04 / 09$.

Ryu, Mr. (pseudonym), a representative of the Hub City of Asian Culture (HCAC) project who asked for confidentiality. 24/04/09 and 16/02/09.

Yang Hyeon-Hong, Vice President (buhwejang) of the Myeongdong Cathedral Council of Worshippers and Office Workers (Pyeongsindo Samu Hyeopuihoe). Seoul. 15/05/09.

Yang Gyeong-Hui, Democratic Movement Archives, Korea Democracy Foundation. Seoul, 13/05/09. 